\title{
DIESEL ENGINE ENERGY BALANCE STUDY OPERATING ON DIESEL AND BIODIESEL FUELS
}

\author{
A thesis presented to \\ the faculty of \\ the Russ College of Engineering and Technology of Ohio University \\ In partial fulfillment \\ of the requirements for degree \\ Masters of Science
}

Scott J. Wallace

June 2007 
This thesis titled

\title{
DIESEL ENGINE ENERGY BALANCE STUDY OPERATING ON DIESEL
}

AND BIODIESEL FUELS

\author{
by \\ SCOTT J. WALLACE
}

has been approved for

the Department of Mechanical Engineering

and the Russ College of Engineering and Technology by

Gregory G. Kremer

Associate Professor of Mechanical Engineering

Dennis Irwin

Dean, Russ College of Engineering and Technology 


\begin{abstract}
WALLACE, SCOTT J., M.S., June 2007, Mechanical Engineering DIESEL ENGINE ENERGY BALANCE STUDY OPERATING ON DIESEL
\end{abstract} AND BIODIESEL FUELS (149 pp.)

Director of thesis: Gregory G. Kremer

The use of alternative fuels addresses the issues of: reducing dependence on unstable petroleum supplies, reducing harmful emissions, and using renewable energy sources. This thesis focuses on a comparative energy balance on a four cylinder turbocharged diesel engine operating on diesel and biodiesel fuels. Steady-state tests were run to experimentally determine how input energy in the form of fuel was appropriated throughout the engine. The transfer of energy was measured for losses to the engine coolant and exhaust, usable power output, as well as minor and unaccounted losses. The results showed that input energy from biodiesel was distributed $37.4 \%, 31.1 \%$, and $29.6 \%$ to the major areas of coolant, exhaust, and power output, respectively. Similarly the input energy from diesel was distributed $37.5 \%, 31.4 \%$, and $29.2 \%$ to the major areas of coolant, exhaust, and power output, respectively. It was concluded from an uncertainty analysis that there was not a statistically significant difference in these results. Future improvements to obtain distinguishable results are outlined. Approved:

Gregory G. Kremer

Associate Professor of Mechanical Engineering 
Table of Contents

Page

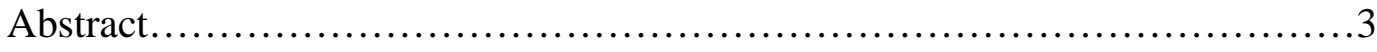

List of Tables...............................................................

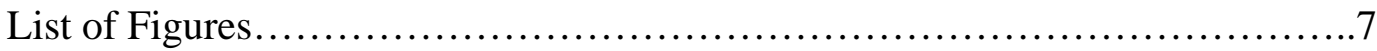

Chapter 1: Introduction...................................................10

1.1) Purpose ......................................................10

1.1A) Goals and Objectives..........................10

1.2) Context................................................... 13

1.2A) Diesel Engine Development.....................13

1.2B) Biodiesel Background............................18

1.2C) Biodiesel Benefits..............................18

1.2D) Biodiesel Production.............................20

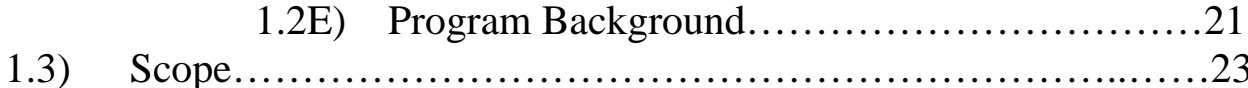

1.3A) Preparation of Laboratory and Base Test

Apparatus...............................................23

1.3B) Testing Platform Validation......................25

1.3C) Overview.......................................25

Chapter 2: Literature Review...........................................27

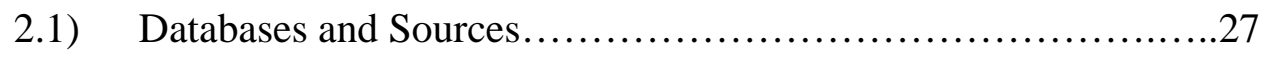

2.2) Energy Balances of Internal Combustion Engines..................28

2.2A) Alternative Fuel Energy Balance Studies and their

Results...................................................29

2.2B) Efficiency Tests with Equipment Modifications..32

2.2C) Energy Balance Theory............................34

2.2D) Measurement Techniques..........................37

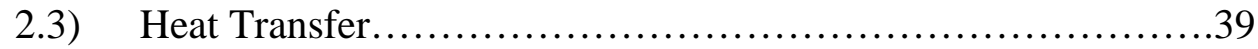

2.4) Performance of Biodiesel.....................................41

2.5) Adding to the Body of Knowledge.............................42

Chapter 3: Experimental Apparatus...............................................43

3.1) Engine Selection.........................................44

3.2) Coupling the Engine to the Dynamometer......................46

3.3) Measurement Equipment......................................48

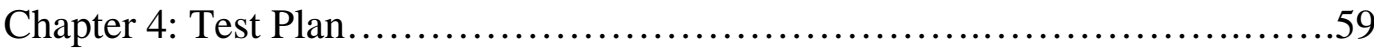

4.1) Throttle Position................................................60 
4.2) Energy Balance Calculations.................................662

4.3) Test Details................................................64

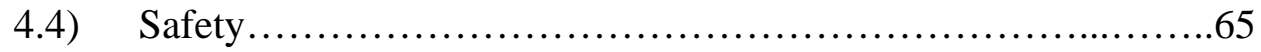

Chapter 5: Results......................................................67

5.1) Coolant and Air Temperatures.................................67

5.2) Explanation of Data Averaging.................................69

5.3) Data Analysis..............................................72

5.4) Engine Torque........................................... 74

5.5) Fuel and Exhaust Temperatures...............................76

5.6) Energy Distributions........................................77

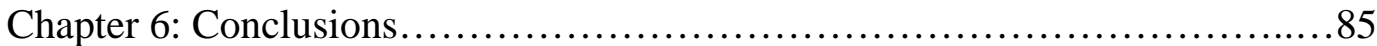

6.1) Test Condition Conclusions..................................85

6.2) Energy Distribution Conclusions.............................87

6.3) Conclusions Suggesting Improvements to the Test Procedure and Apparatus..................................................93

6.4) Achievement of Goals and Objectives..........................96

Chapter 7: Future Work...............................................100

References........................................................ 102

Appendix A: Dynamometer Information................................... 105

Appendix B: Cummins Information..................................111

Appendix C: Fuel Information............................................119

Appendix D: Hand Calculations...................................... 120

Appendix E: SOP/SER ............................................. 127 
List of Tables

Page

Table 3.1: Measurements, equipment, locations, and resolution/accuracies.......49

Table 5.1: Relative energy distribution values and uncertainties.................83

Table 5.2: Energy distribution based on input energy..........................84 
List of Figures

Page

Figure 1.1 Schematic layout of diesel and gasoline engines....................15

Figure 1.2: Cummins 5.9L diesel engine and common rail fuel system..........16

Figure 1.3: Program hierarchy........................................22

Figure 2.1: Schematic layout of the experimental set-up....................38

Figure 3.1 : Testing apparatus........................................43

Figure 3.2: Drawing of engine, stand, and radiator combination...............45

Figure 3.3: Mounting system......................................46

Figure 3.4: Machined flywheel with mounted driveshaft flange................47

Figure 3.5: Keyed and grooved shaft between couplings with caps..............48

Figure 3.6: Laboratory environment.....................................50

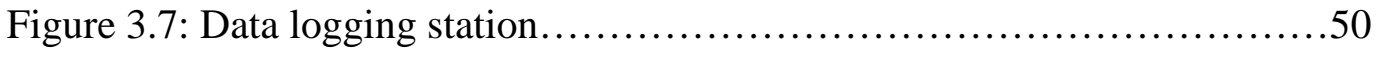

Figure 3.8: Test apparatus accessories.................................51

Figure 3.9: Test apparatus...........................................51

Figure 3.10: Measurement equipment placement..........................52

Figure 3.11: Measurement equipment placement (other side of engine)..........53

Figure 3.12: Coolant flow meter.....................................53

Figure 3.13: Coolant in thermocouple...................................54

Figure 3.14: Engine oil thermocouple..................................54

Figure 3.15: Fuel return thermocouple.................................55

Figure 3.16: Air intake thermocouple....................................55 
Figure 3.17: Coolant out thermocouple...................................56

Figure 3.18: Exhaust thermocouple and gauges...............................57

Figure 3.19: Scale readout and stopwatch.................................57

Figure 3.20: Fuel tank/digital scale.......................................58

Figure 4.1: Throttle position for No. 2 diesel fuel only.......................61

Figure 5.1: B100 temperatures (except fuel and exhaust) for 20 min. trial.........67

Figure 5.2: B100 coolant in and out temperatures 0-20 min....................69

Figure 5.3: Coolant data for B100 and diesel fuel respectively $0-20$ min...........70

Figure 5.4: Comparison of ambient air and coolant measurements for B100 0-20

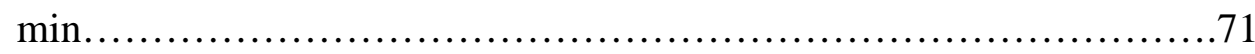

Figure 5.5: B100 engine coolant (out and in) $12-18$ min........................72

Figure 5.6: B100 torque values as a function of time $0-20 \min . . \ldots \ldots \ldots \ldots \ldots \ldots . . . \ldots 74$

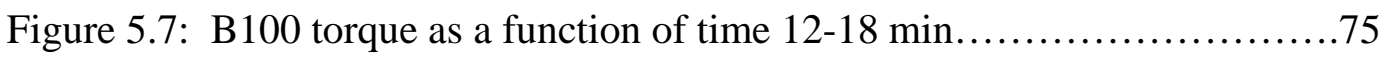

Figure 5.8: Fuel supply, fuel return, and exhaust temperatures $12-18$ min.........76

Figure 5.9: Relative energy distribution-power, coolant, exhaust, fuel, and air 12-

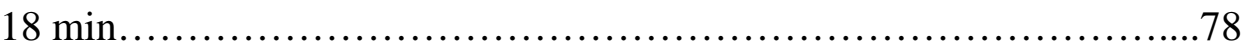

Figure 5.10: Relative energy distribution of power, coolant, and exhaust 12-18

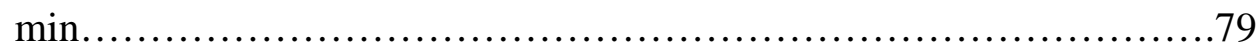

Figure 5.11: Relative energy distribution of power and exhaust 12-18 min.......80

Figure 5.12: Relative energy distribution of power and exhaust 12-18 min (with

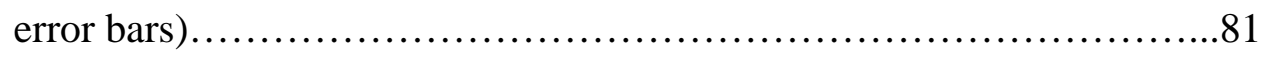

Figure 5.13: Comparison of relative energy distribution between biodiesel and

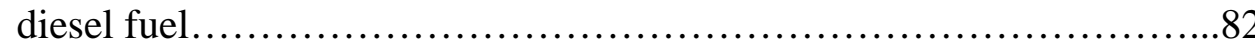


Figure 6.1: Comparison of thesis results (top) to Canakci and Hosoz (2006)

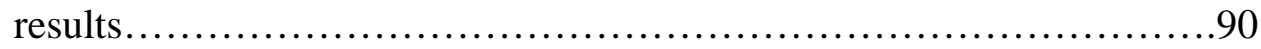




\section{Chapter 1: Introduction}

\section{1) Purpose}

The purpose of this thesis was to perform an energy balance or energy appropriation study on a compression ignition or "diesel” engine. Understanding where the energy gets transferred for different fuel sources sets a baseline for future testing. The specific fuel sources included No. 2 diesel fuel and B100 which is 100 percent neat biodiesel. These fuel sources met the American Society for Testing and Materials (ASTM) standards of D975 and D6751 respectively (ASTM Standards 2004).

\subsection{A) Goals and Objectives}

This energy balance study was an initial step for studying algal-based biofuels as an alternative fuel source in the near future. This is the program's main objective and the work in this thesis will make a contribution towards achieving the final goal. The thesis objectives were to monitor the amount of energy going into the engine provided by the fuel source and then measure the energy output and losses throughout the system. This main focus was intended to do three things:

A) Aid in validating the diagnostic system's functionality

B) Find out how the energy was transferred through the system for different fuel sources 
C) Use applicable heat transfer modes of conduction, convection, and radiation to determine energy transferred and learn how to properly design a controlled and instrumented energy management system

\section{A) Validation:}

It was very important to use the results of this energy balance study to aid in the validation of the engine diagnostic testing system. This was critical because there was not a testing apparatus previously developed or in use, so one had to be implemented for the first time requiring validation. A diesel engine, along with all of its necessary mechanical and electrical components, was connected to a dynamometer for this testing to take place. This also involved properly mounting the engine to a test stand and developing a coupling system to the dynamometer. There were many thermal, torsional, vibrational, and other factors that had to be accounted for in the development of this system. Once the system was in operation, the energy balance study helped to make sure that the system was operating properly. If there were significant losses through certain parts of the system (uncharacteristic of those of benchmarked systems), the energy balance study would show this and help identify the cause. It is necessary to have a validated engine diagnostic testing system to perform meaningful research because the precision and accuracy of the research is dependent on properly calibrated, accurate equipment. Since this testing system was required for the energy balance study to take place, its development is considered a task or deliverable and only the portions pertinent to the study at hand will be covered in detail in this document. 
B) Energy Transfer:

This energy balance study was specifically designed to be done with No. 2 diesel fuel and B100. The reason for this is that No. 2 diesel fuel has been in the past and still is the most common fuel source used in diesel engines. It was used as a baseline comparison for all results obtained with B100. The main reason that biodiesel was chosen as the second fuel to study is that its use is increasing due to its renewability, safety, environmental impacts, financial incentives, similar performance to No. 2 diesel fuel, and other factors that are discussed in greater detail throughout this thesis. Therefore it made sense to study how each of these fuels perform in a compression ignition engine.

One goal for studying how each specific fuel transferred its energy throughout the system was to help indirectly draw conclusions on performance, combustion, lubrication, or other characteristics of one fuel source compared to the other. Biodiesel can be blended with No. 2 diesel fuel in any concentration from 0 up to 100 percent by volume. A 100 percent blend or B100 was chosen for use in this study because it exhibited characteristics furthest from that of No. 2 diesel fuel than any other biodiesel blend. This was important because the energy appropriation for No. 2 diesel fuel and B100 was very similar. Maximizing the measurable differences enabled the use of standard measuring devices such as flow meters, thermocouples, etc. 
C) Transfer Modes:

Portions of the combusted fuel's energy were transferred into thermal losses by one of the heat transfer modes of conduction, convection, or radiation. Therefore, these needed to be implemented in the design of the thermal management system to insure consistency in testing and proper data collection. This involved the use of a data logger and instrumentation. It was also important to have a brief understanding of these to help draw conclusions on the reaction each fuel source had in the engine to suggest further studies to perform. For these reasons part of the chapter 2 focused on the modes of heat transfer and, specifically, how they are accounted for.

\section{2) Context}

In order to set the proper context for the this thesis, it is important to have a brief discussion of the diesel engine’s development up to date, biodiesel background information as well as the need for alternative fuels, and some of this program's background information.

\subsection{A) Diesel Engine Development}

The compression ignition engine was developed in 1892 by the German engineer, Dr. Rudolf Diesel (Leduc 2007). It was developed for using a variety of fuel sources such as coal dust or peanut oil and it was shown at the 1900 World Exhibition in Paris, France (Leduc 2007). Here peanut oil was the chosen fuel for the demonstration. In the early 1900’s, Dr. Diesel was making statements implying that the use of the diesel engine with 
renewable fuels would help stimulate agricultural markets and that the renewable oils may someday be as valuable as petroleum and coal products (Leduc 2007). It seems that day is fast approaching.

The standard diesel engine operates on the principal that air in the engine cylinder is compressed to an extremely high pressure and temperature at which time the fuel is injected into the combustion chamber causing ignition. This is different from a gasoline engine which compresses both the air and fuel at the same time. Once the air and fuel is compressed, the gasoline engine relies on a spark to ignite the mixture causing combustion. The spark ignition or gasoline engine’s need for electrical ignition requires the use of many components such as spark plugs, ignition coil, distributor, and a carburetor. The mechanical nature of the diesel engine's design makes it simpler, more rugged, more versatile, and its higher compression ratio makes it more efficient than the gasoline engine. It is because of these basic principles of the diesel engine's design that make it such a good candidate for a near term solution to our renewable energy needs. Figure 1.1 shows a basic schematic of a diesel and gasoline engine, respectively. 

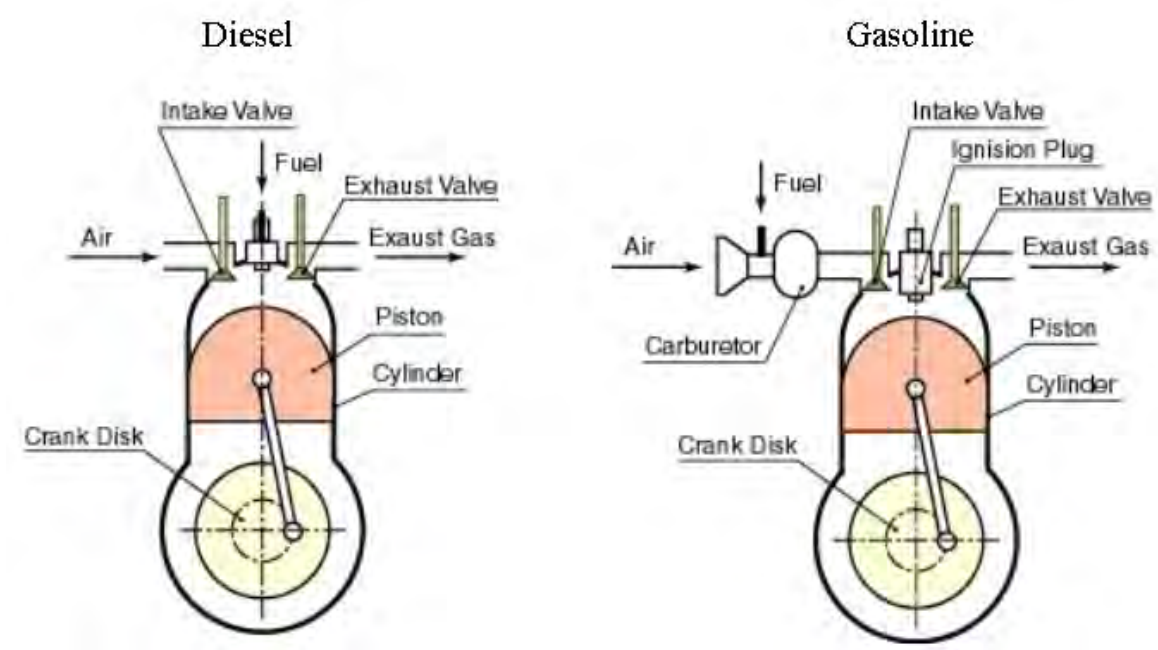

Figure 1.1: Schematic layout of diesel and gasoline engines, respectively (NMRI, 2008)

The traditional drawbacks of the diesel engine are their cold weather operation, noisiness, pollution, and lack of power. However, with advancements in technology, almost all of these issues have been resolved. The most significant improvements were due to improvements to the fuel injection and air induction systems. Traditional diesel engines used indirect injection (IDI) systems where the fuel would enter a prechamber and partially combust there. Currently most diesel engines use direct injection (DI) systems where the injector tip is directed straight into the cylinder's combustion chamber. The result of this improved design is a quieter, cleaner, and more powerful engine. Improvements to injection pumps and fuel injectors including higher pressures, multiple injections per stroke, and optimized spray patterns have improved combustion efficiencies resulting in more power, quieter delivery, and lower emissions from more complete combustion. 
Advancements in diesel engine air induction systems have really propelled their use into a variety of applications. The use of turbo chargers takes advantage of otherwise wasted exhaust gases to help deliver more intake air to the engine's combustion chambers. The force from hot exhaust gases entering the turbocharger spins a turbine connected to a compressor. The compressed air is then supplied to the engine increasing power and lowering emissions. Figure 1.2 shows the 2003 Cummins 5.9L diesel engine and its common rail fuel system.
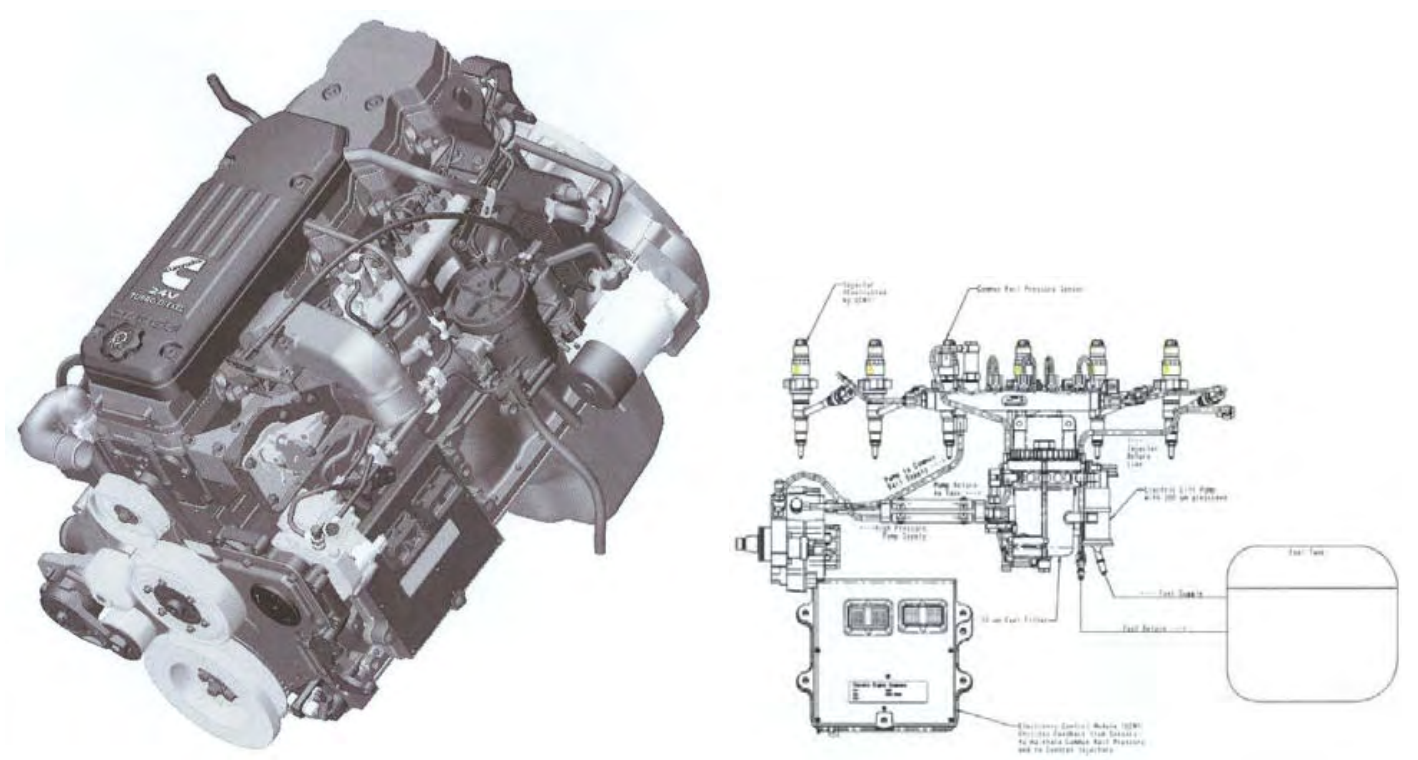

Figure 1.2: Cummins 5.9L diesel engine and common rail fuel system (Memmolo 2008)

With the addition of the common rail fuel system in 2003, Cummins was able to achieve 24\% more power, $10 \%$ more torque, and a wider powerband over its 2002 engine series (Memmolo 2008). Utilizing the common rail fuel system’s high pressures and multiple injections per combustion cycle, increased throttle response, reduced noise, and improved 
cold-start times were all achieved, as well as NOx and hyrodcarbon emissions reductions of 25\% over the 2002 series (Memmolo 2008). In 2007, Cummins was able to make this engine series almost 50\% quieter with 10\% higher common rail fuel pressures as well as other improvements (Cummins, Inc.). Additionally, “This engine unilizes cooled exhaust gas recirculation (EGR) and other air-handling concepts, including Cummins own proprietary sliding-nozzle Variable Geometry Turbocharger to give optimum boost level as a function of engine rpm and load. The multi-injection-capable fuel system is then used to manage in-cylinder conditions to limit emissions. The particulate filter reduces Particulate Matter (PM) levels by 90\% of pre-2007 levels” (Cummins, Inc.). These are all real-world examples of advanced diesel technology and their resulting improvements.

Diesel engine technology is a significant industry today. There is a lot of research being done to maximize efficiencies, power, durability, and meet stringent emissions standards. The basics of the diesel engine have been explained but there are many specifics that have not been covered. To learn more about the current technologies including the designs of injectors, pumps, heads, valves, turbochargers, intercoolers, and much more see some of the manufacturer's websites including Cummins, Caterpillar, Detroit, John Deere, Kubota, or others. Another very good source is the Engine Manufacturer's Association (EMA). They are an association committed to improving engine technology as well as emissions controls both domestically and internationally. They provide the latest publications, legislations, position statements and news reports about issues in 
engine development. Their website is http://www.enginemanufacturers.org (Accessed May 2007).

\subsection{B) Biodiesel Background}

Since the use of biodiesel was so important for this thesis it is important to have general background information about it. Biodiesel is a renewable fuel source produced from natural oils through a chemical process to meet the specifications set forth by ASTM D6751 (ASTM Standards 2004). It is intended to be used in conjunction with or as a replacement for petroleum diesel fuel with little or no modification to the engine.

\subsection{C) Biodiesel Benefits}

There is increased interest in biodiesel because of positive environmental impacts, safety, energy security, economic impacts, and financial incentives. Global warming and other environmental issues are starting to take precedence in the outlook for the future.

Biodiesel has proven to be a viable option to help address the issue of global health. The use of biodiesel instead of petroleum diesel fuel will significantly lower the emissions of hydrocarbons, carbon monoxide, sulfur dioxide, and particulate matter. Nitrogen oxide emissions are not fully understood but many studies have shown that they increase up to as much as $10-15 \%$ which is the only increase of emissions and this is an area of intense study for potential improvements. Biodiesel also decreases the health risks of transporting, storing and handling the fuel. Biodiesel is classified as biodegradable, nontoxic, and non-flammable (ASTM Standards 2004; Leduc 2007). These properties make 
it safe in the event of accidental contamination into the environment. Since it is biodegradable, spills will not require as much attention making transportation easier. Because it is non-toxic, water supply contamination or exposure to skin is not a problem. The high flash point of biodiesel makes storage much safer because it will not catch on fire as easily as petrol diesel fuel.

With the prices of petroleum reaching record highs and the instability of imported oil increasing annually, it is clear that there is a need to utilize more renewable fuel sources. Biodiesel may help sustain the U.S. economy while providing a higher level of energy security. Since biodiesel takes advantage of animal fats and vegetable oils, increased use has helped stimulate agricultural markets and created many jobs in biodiesel production. Besides stimulating our economy by providing our own fuel, it decreases the need for military protection over foreign oil supplies which has be a major political issue for years. Biodiesel helps preserve natural resources and create jobs which have prompted our government to offer financial incentives to those producing the fuel. The government subsidizes the fuel based on the amount and type of biodiesel blended into the petrol diesel fuel. This helps make the prices competitive in an aggressive market. For the most up-to-date information regarding issues related to the need for biodiesel visit the home of the National Biodiesel Board: http://www.biodiesel.org/ (Accessed May 2007). 


\subsection{D) Biodiesel Production}

Biodiesel can be produced from one of many processes. Some of the most common are transesterification, pyrolysis, and microemulsions (Jha, Sharma and Marwaha 2004). The vast majority of production facilities use a base-catalyzed transesterification process using virgin (unused) oil from a domestic feedstock such as soybeans, rapeseed, mustard seed, peanut, sunflower, or other oil producing plants. Biodiesel can also be made from waste (used) vegetable oils or animal fats, but biodiesel from algae oil has the potential to become dominant in the near future. Algae are becoming a feedstock of interest due to its ability to rapidly reproduce as well as its high oil content. Studies have shown that algae may be one of the most feasible ways to produce the amount of oil necessary to fulfill the US diesel fuel needs (Sheehan, et al. 1998). For these reasons, our program's final goal is to be able to produce algal-based biodiesel through a transesterification process and test it for performance and emissions characteristics.

In the tranesterification process, a fat or oil (triglyceride) is reacted with an alcohol (usually methanol or ethanol) to form three esters and one glycerol. To speed up the reaction an increase the yield, a catalyst (usually $\mathrm{NaOH}$ or $\mathrm{KOH}$ ) is used. During the reaction, the triglyceride is broken down and the alcohol combines with the esters and the catalyst combines with the glycerin. When this reaction is complete the result is complete separation of the methyl or ethyl ester (biodiesel) and the glycerin soap. The glycerin soap settles to the bottom and is siphoned off for addition processing. The biodiesel is also processed further to insure that there are no un-used reactants left over. 
This is usually done through a washing process and then a drying process insures no water contamination.

These are the basics of transesterification biodiesel production. The process is very sensitive to catalysts, water contamination, molar ratio of alcohol to triglyceride, time, temperatures, and other factors. It is extremely important to know that the quality of the biodiesel used will affect all aspects of the system it is used in from performance to emissions to engine wear. For these reasons, purchasing biodiesel from a supplier that meets the ASTM D 6751 standard, is critical to receive all the benefits biodiesel has to offer. There is also a Quality Management Program referred to as BQ-9000 that insures proper storage, sampling, testing, blending, shipping, distribution, and fuel management practices (BQ-9000 The National Biodiesel Accreditation Commission 2007).

Purchasing fuel from a marketer in this program is highly recommended for any research application. For in-depth information about proper biodiesel production, contact one of the BQ-9000 (http://www.bq-9000.org/ May 2007) certified suppliers such as Peter Cremer North America, LP (http://www.petercremerna.com/ May 2007).

\subsection{E) Program Background}

Our biofuels program is in its first year of existence. Graduate student Dhruv Kohli helped me with the deliverable of ordering components and setting up the general testing apparatus. We both performed tests on the system. I did the energy balance study and Dhruv did NOx emission testing. We are both under the direction of Dr. Greg Kremer, 
our advisor. There are two other graduate students working on algae production and there are about five other faculty members in the areas of mechanical, civil, and chemical engineering as well as a botany professor on the biofuels committee. This program is funded by the Ohio Coal Research Center (OCRC) under the direction of Dr. David Bayless who is also on the biofuels committee. Within the Russ College of Engineering, the OCRC falls under the direction of the Institute for Sustainable Energy and Environment (ISEE) headed by Mike Prudich. At the university level, everything falls under CE3 which is Ohio University’s Consortium for Energy, Economics and the Environment. "CE3 is a multidisciplinary organization that brings together Ohio University's George V. Voinovich Center for Leadership and Public Affairs, the Russ College of Engineering and the College of Arts and Sciences to explore ways to develop safe, reliable, affordable and non-polluting sources of energy” (Reed 2007). Figure 1.3 shows a visual representation of the program hierarchy just discussed.

CE3 - OU's Consortium for Energy, Economics and the Environment - Russ College, Voinovich Center, College of Arts and Science

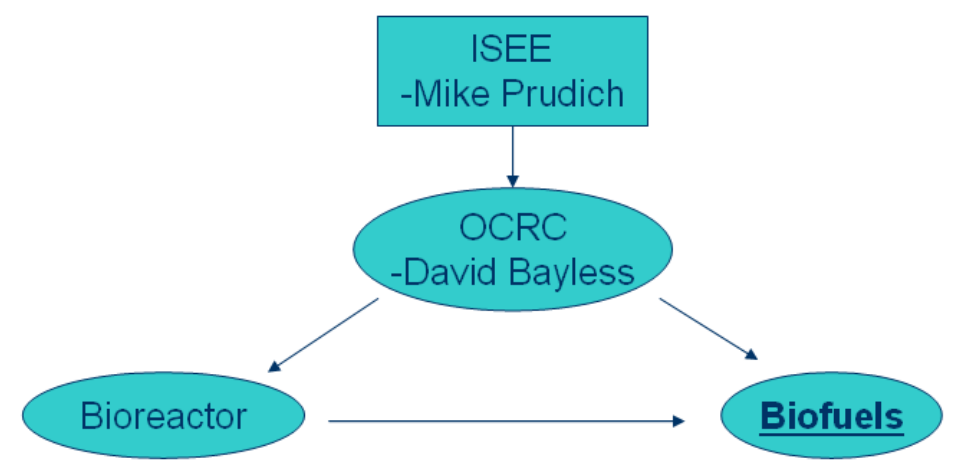

Figure 1.3: Program hierarchy 


\section{3) Scope}

In order to perform the research for this thesis there were certain deliverables that were necessary to complete through collaboration with the other team members. These, along with the individual tasks necessary to accomplish the work of this thesis, will be briefly discussed to show the scope of this project.

\subsection{A) Preparation of Laboratory and Base Test Apparatus}

The main deliverables for this project were in the basic layout of the engine diagnostic testing system. These deliverables were performed in collaboration with Dhruv Kohli and occasionally other students or faculty. The first thing we did was make room in lab for our testing equipment. This involved removing aspects of the previous electric vehicle testing equipment such as part of the chassis dynamometer, scraping the old electric test vehicle, and removing the external battery supplies. Next we acquired an engine which was specked out for our particular needs and supplied by Cummins Inc. out of Columbus, Ohio. This engine was part of a complete power unit included all electrical and cooling systems. It was mounted on a stand and needed a battery and fuel tank to be operational. To couple the engine to our dynamometer we used the services of a driveline shop to make a short driveshaft which connected the flywheel of the power unit to the input shaft on the dynamometer. In order to insure that the exhaust properly exited the lab, 3" exhaust tubing was run approximately 50' into lower temperature flexible 
tubing which reached the exterior of the building. An exhaust back pressure gauge was implemented and compared with factory specifications to insure that high exhaust pressures did not affect the diesel engine.

After everything was set up, the system was calibrated and run so that we could begin to focus on our respective research areas. To make sure the existing dynamometer was operating properly, the engine's power curve was compared to the manufacturer's supplied data. The data collected for our engine compared very well throughout the operating range showing only slightly less torque at high speeds, likely due to the fact that the manufacturer's data was for the engine operating without a mechanical cooling fan and alternator. In all it took about 12 weeks to complete the basic engine diagnostic testing system. With all of the purchases we had to make for equipment and miscellaneous items, the total cost of the basic system was around $\$ 2000$ which included the engine power unit, the fuel and exhaust systems, the mounting and coupling equipment, and other miscellaneous parts.

My personal research area involved the development of the thermal measuring and control systems for the engine’s lubrication, coolant and exhaust systems. In addition to this, I set up the system to control and monitor the air and fuel going into the engine. This involved monitoring the air and fuel's temperatures and flow rates. Finally I had to monitor the environmental and atmospheric conditions to insure accuracy and 
repeatability of the experiments. All of these things will be discussed in greater detail in chapter 3.

\subsection{B) Testing Platform Validation}

The expectations for comparing the results in this thesis were to use the experimental results obtained from testing and compare them to similar results found through the literature search. This was done to help validate that the implemented measuring systems were recording meaningful data. The other analysis of the results came from the theory behind the energy balance. Through energy conservation, the legitimacy of the results was determined based on how much of the energy was accounted for in the measuring systems implemented. This was also able to be compared with results found in other energy appropriation studies. The results of this research helped to validate and improve the understanding of the engine diagnostic testing system. This system is intended to be used in the research and testing of algal-based biodiesel. The conclusions that were made in this thesis for soy based biodiesel were intended to serve as a starting point to understand the effects of algal-based biodiesel.

\subsection{C) Overview}

The first chapter of this thesis was intended to serve as an introduction to the rest of the thesis by stating the goals, objectives, proper context, and scope. The second chapter is the literature review where the current uses of energy balance studies will be shown as well as the measurement techniques and equipment used. The third chapter will cover 
the details of the experimental apparatus. The fourth chapter discusses test, modeling, and analysis plans. Chapter five shows the results of this thesis and chapter six talks about the conclusions. Chapter seven is the future work that this thesis will help to accomplish. 


\section{Chapter 2: Literature Review}

This literature review covers the databases and sources used for acquiring accurate information used for this thesis. Characteristics of energy balances performed by others on internal combustion engines will be covered in addition to the effects of specific heat transfer modes. This section also includes a comparison of No. 2 diesel fuel and biodiesel and an explanation of how the work in this thesis fits into the body of biodiesel knowledge.

\section{1) Databases and Sources}

In order to insure that information used for this literature review was accurate and accepted as scholarly work, the sources and databases searched were limited to certain areas. Through Ohio University's library resources most of this information was found. The Engineering and Technology portion of Info Tree (the university’s information gateway) granted access to Compendex which is “A worldwide database, beginning in 1969, that indexes scholarly literature for all engineering disciplines, as well as related fields in science and management” (Info Tree Ohio University Libraries, 2003). This also granted access to INSPEC and Science Citation Index Expanded which both index

thousands of scholarly articles and journals from around the world. Other sources used through Ohio University’s library were Ohio Link’s electronic thesis and dissertation center and Academic Search Primer which can be accessed through EBSCO Host Research Databases. Examples of the key words used in search are: energy balance, 
energy appropriation, engine energy balance study, heat loss analysis, diesel engine, biodiesel energy balance, thermal balance, heat transfer, heat loss etc. Once results were returned, the abstracts were read to determine relevance and full versions were acquired accordingly.

Some internet sources were used for gaining both general and specific information. Some scholarly journals were found through Google Scholar (http://scholar.google.com/ May 2007), and for up-to-date information on biodiesel, the home of the National Biodiesel Board (www.biodiesel.org May 2007) was used.

\section{2) Energy Balances of Internal Combustion Engines}

In order to better understand the operation of heat engines, people have been studying energy transfer throughout history dating back to the 1820's with Sadi Carnot's thermodynamic model of the Carnot engine (Leduc 2007). Since then there have been many energy studies done on different types of internal combustion engines varying in both scale and application. This portion of the literature review will focus on the purposes, methods, and results found for similar energy balance studies performed by other researchers. The energy balance studies researched on internal combustion engines used both spark ignition and compression ignition engines. They varied in power from about 5 - 200 Hp and had 1- 6 cylinders. They were all four-stroke engines with both naturally aspirated and turbo charged air-induction systems. These tests were also performed under steady-state conditions. Tests with these characteristics were focused 
on because they involved similar equipment, procedures, and objectives to the work in this thesis.

\subsection{A) Alternative Fuel Energy Balance Studies and their Results}

There are many reasons to perform an energy balance study on an engine. “The knowledge of how the energy is lost will help in finding means to reduce the same to improve the performance of the engine in terms of efficiency and power output” (Kumar, et al. 2004). This seems to be the main reason behind most energy studies performed on engines. By improving the efficiency of the engine, the result is a higher percentage of the fuel's energy getting converted into power output. This is noticed as improved performance. Although the goal of understanding engine operation to improve efficiency is common, there are many different reasons an energy balance study helps to reach this goal. Energy balance studies help characterize the impact a change has on the overall system. Once the impact is identified by the energy balance, one can attempt to either maximize or oppose its use due to the benefits and drawbacks. These changes include variations in fuel, physical changes to engine design, or adjustments of engine settings.

\section{A) Hydrogen Supplementation}

With the increased interest in alternative fuels, variations in fuel sources have been a recent interest. A thermal balance was done to investigate the effects of hydrogen addition to the gasoline-air mixture on a four stroke SI engine (Yuksel and Ceviz 2003). From this study they were able to conclude that hydrogen addition improved 
performance, significantly reduced heat loss to coolant and unaccounted losses (36 and $30 \%$ respectively), had little effect on exhaust losses, and was most efficiently used under high loading conditions (Yuksel and Ceviz 2003).

\section{B) Octane Ratings}

Energy analyses can also be used for testing different grades of the same type of fuel. One study performed an energy balance study on a four-cylinder SI engine using gasoline with three different octane numbers $(91,93$, and 95.3) to test various performance parameters for each fuel (Sayin, et al. 2006). In this study it was found that the engine was less efficient when using higher octane fuel than the designed engine rating, increased thermal losses from high octane fuel were through the exhaust, and energetic performance parameters increased with increasing engine speed due to "a more homogenous mixture and a boosted turbulence in the combustion chamber” (Sayin, et al. 2006).

\section{C) Biodiesel Blends}

Perhaps the most pertinent journal to the work in this thesis was "Energy and Exergy Analysis of a Diesel Engine Fuelled with Various Biodiesels” (Canakci and Hosoz 2006). Here, a four-cylinder, turbo-charged diesel engine was studied to determine the heat transfer rates and performance parameters during operation using No. 2 diesel, SME (soybean oil methyl ester), YGME (yellow grease methyl ester), and 20\% blends of the two biodiesels (Canakci and Hosoz 2006). This study concluded that the brake specific 
fuel consumption (BSFC) "is inversely proportional with the lower heating value of the fuel” resulting in a 12-13\% increase in fuel consumption (Canakci and Hosoz 2006). It was also concluded that the "pure SME and YGME biodiesels yield approximately 1.6\% higher thermal efficiencies compared to No. 2 diesel fuel” due to better combustion characteristics from the oxygenated fuels (Canakci and Hosoz 2006). Overall, it was found that "biodiesels and their blends show almost the same energetic performance with No. 2 diesel fuel in terms of the fuel energy input, brake thermal efficiency, combustion efficiency, heat loss, and exhaust loss” (Canakci and Hosoz 2006). The distribution of energy from the use of pure biodiesel resulted in approximate differences in heat loss, exhaust loss, and brake work of $2.3 \%,-2.9 \%$, and $0.6 \%$ respectively when compared to No. 2 diesel (Canakci and Hosoz 2006).

\section{D) Ethanol Supplementation}

The final journal found that studied the effects of energy balances based on fuel blends was “Thermal balance of a single cylinder diesel engine operating on alternative fuels" (Ajav, Singh and Bhattacharya 2000). Here blends of 5, 10, 15, and 20\% ethanol-diesel

where tested and compared to $100 \%$ diesel fuel and fumigated ethanol was also compared to diesel (Ajav, Singh and Bhattacharya 2000). From the data it was concluded that at a 5\% significance level, only the 15 and 20\% ethanol-diesel blends had a positive impact (Ajav, Singh and Bhattacharya 2000). In general, this energy balance showed that "as the load on the engine increased, the percentage of useful work increased, while the other losses decreased. At the initial stage, the increase was more pronounced than at the latter 
stages of the loading conditions. This trend is due to the fact that the engine attains optimum operation at the latter stages of loading conditions, and as such, the differences in useful work is minimal” (Ajav, Singh and Bhattacharya 2000). Also, “As the percentage of ethanol in the ethanol-diesel blends increased, there was an increase in the quantum of useful work done by the engine as compared to diesel fuel operation. This is because of the cooling effect of ethanol as well as more efficient combustion as compared to diesel. Since both the exhaust gas temperature as well as the lubricating oil temperatures were lower in the case of ethanol-diesel blend operations, there was less heat loss through theses channels, and as such, more useful work was available at the engine crankshaft” (Ajav, Singh and Bhattacharya 2000). These four different studies are examples where the author's theories could not have been adequately supported without the energy balance data to back up these claims.

\subsection{B) Efficiency Tests with Equipment Modifications}

Energy balance studies have recently been used to test for increases in efficiency due to engine design changes such as improved injectors, pumps, heads, valves, turbochargers, intercoolers, and other advanced technologies (Engine Manufacturers Association 2002). Another engine design development that thermal balances have helped to evaluate is the Low Heat Rejection Engine (LHRE). The literature shows that there has been a lot of research done on this topic. In general, the energy balance checks to see if an application of ceramic material to parts of an engine’s combustion chamber, cylinder head, valves, and pistons will decrease the amount of energy lost to the cooling system and therefore 
increase crankshaft work (Taymaz 2006). There are many different conclusions that have been made about LHRE's through energy balances and the findings vary considerably based on engine configurations, test conditions, and analysis techniques (Jaichandar and Tamilporai 2003).

The literature shows that energy balance studies are also done to optimize engine settings or system settings. Depending on the application, it may be important to have an engine run for long periods of time under a single loading condition. For this reason it is important to understand what range the engine will operate most efficiently (Kopac and Koturk 2005). The effectiveness of advanced fuel delivery and variations in engine timing has been evaluated based on energy conversion principles (Experiment 3: Performance of an Internal Combustion (I.C.) Engine 2004). An energy balance was done to show how performance parameters and exhaust emissions were influenced by the temperature of the engine coolant (Abdelghaffar, et al. 2002). The finding from this study showed that the volumetric efficiency (rate of combustion of air) is significantly affected by the coolant temperature (Abdelghaffar, et al. 2002). Therefore, “increasing coolant temperature decreases the mass flow rate of fuel consumption and the cooling losses. As a result, the brake specific fuel consumption decreases and the brake thermal efficiency increases” (Abdelghaffar, et al. 2002). 


\subsection{C) Energy Balance Theory}

The methods and techniques for performing the energy balances found in this literature review all followed the same basic principles. "Energy balance for a direct injection diesel engine shows that about one-third of fuel energy input is lost to environment through heat transfer, another third is wasted as exhaust heat and only one-third is available as shaft work” (Sharma and Jindal 1989). While the percentages vary between engines, this seems to be the accepted rule of thumb. Stated more precisely, energy enters the engine in the form of fuel and "leaves as energy in the exhaust, cooling water, brake power and heat transfer. Heat losses must be decreased to improve the engine efficiency. Therefore, it is very important to know the fraction of the heat loss mechanisms” (Yuksel and Ceviz 2003). Aside from energy transfer to power output, exhaust, and engine components/coolant, all of these energy balance studies find the "unaccounted for" losses which is the remainder of what was not measured (found from energy conservation). Depending on the loading conditions, the percentage of the unaccounted for losses ranged between 1 and 23\% (Kumar, et al. 2004; Taymaz 2006; Ajav, Singh and Bhattacharya 2000).

The equations for calculating the energy transferred to the different areas of the diesel engine in this thesis were all developed from a handout titled "Energy Balances on Internal Combustion Engines,” dated August 1997. This handout was put together and supplied by Dr. Jon Van Gerpen, professor and chair of the biological and agricultural 
engineering department at the University of Idaho-Moscow. The input energy going into the engine, $\dot{Q}_{l n}$, was given by the equation:

$$
\dot{Q_{l n}}=\dot{m}_{f} \cdot L H V
$$

Here, $\dot{m}_{f}$ is the fuel mass flow rate and $L H V$ is the lower heating value or energy content of the supplied fuel.

The brake power output, $P_{b}$, was calculated with the following equation:

$$
P_{b}=\tau_{b} \omega
$$

Here, $\tau_{b}$ is the brake torque of the engine and $\omega$ is the angular velocity of the engine crankshaft.

The losses through the exhaust were determined by measuring the air and fuel flow rates, making the assumption of complete combustion to determine exhaust gas constituents, and determining the exhaust gas temperature. Using ideal gas behavior concepts and the supplied chemical composition of the fuel, the energy losses through the exhaust can be determined. Here the air/fuel (A/F) ratio is calculated on a molar basis:

$$
\frac{A}{F}=k_{1} \frac{l b_{m} \text { air }}{l b_{m} \text { fuel }}=k_{2} \frac{l b_{\text {mol }} \text { air }}{l b_{\text {mol }} \text { fuel }}
$$

Then the chemical reaction needs to be balanced (diesel shown):

$$
C_{14.09} \mathrm{H}_{24.78}+k_{2}\left[0.21 O_{2}+0.79 N_{2}\right] \rightarrow \theta_{1} \mathrm{CO}_{2}+\theta_{2} \mathrm{H}_{2} \mathrm{O}+\theta_{3} \mathrm{~N}_{2}+\theta_{4} \mathrm{O}_{2} .
$$

After solving for the unknown values of $\theta$, the input energy transferred into the exhaust, $\dot{Q}_{e x}$, is given by:

$$
\dot{Q}_{\text {ex }}=\sum_{\text {products }} n \bar{h}_{\mathrm{T}_{\mathrm{ex}}}-\sum_{\text {products }} n \bar{h}_{\mathrm{T}_{\mathrm{a}, 77}}
$$


Here, $n$ represents the molar ratio of each exhaust component per unit of fuel based on the balanced $\theta$ values. $\bar{h}$ represents the enthalpy values for these exhaust components at the exhaust gas temperature $\left(\bar{h}_{\mathrm{T}_{\mathrm{ex}}}\right)$ and at an air temperature of $77^{\circ} \mathrm{F}\left(\bar{h}_{\mathrm{T}_{\mathrm{a}, 77^{\circ} \mathrm{F}}}\right)$.

To measure the energy transferred through conduction of engine components, the losses to the coolant, $\dot{Q}_{c}$, are calculated by:

$$
\dot{Q}_{c}=\dot{m}_{c} C_{p_{c}}\left(\mathrm{~T}_{\mathrm{c}, \mathrm{o}}-\mathrm{T}_{\mathrm{c}, \mathrm{i}}\right)=\dot{V}_{c} \rho_{c} C_{p_{c}}\left(\mathrm{~T}_{\mathrm{c}, \mathrm{o}}-\mathrm{T}_{\mathrm{c}, \mathrm{i}}\right)
$$

Here, $\dot{m}_{c}$ and $\dot{V}_{c}$ are the mass and volume flow rates of the engine coolant respectively. $C_{p_{c}}$ is the specific heat of the coolant at the temperature half way between the temperature of the coolant coming out and going into the engine $\left(\mathrm{T}_{\mathrm{c}, \mathrm{o}}\right.$ and $\left.\mathrm{T}_{\mathrm{c}, \mathrm{i}}\right)$. Likewise, $\rho_{c}$ is the density of the coolant half way between $\mathrm{T}_{c, \mathrm{o}}$ and $\mathrm{T}_{\mathrm{c}, \mathrm{i}}$.

Similarly, the input energy transferred to the fuel $\left(\dot{Q}_{f}\right)$ and inlet air $\left(\dot{Q}_{a}\right)$ is given by:

$$
\dot{Q}_{f}=\dot{m}_{f} C_{p_{f}}\left(\mathrm{~T}_{\mathrm{f}, \mathrm{o}}-\mathrm{T}_{\mathrm{f}, \mathrm{i}}\right)
$$

and

$$
\dot{Q}_{a}=\dot{m}_{a} C_{p_{a}}\left(\mathrm{~T}_{\mathrm{a}, \mathrm{amb}}-\mathrm{T}_{\mathrm{a}, 77^{\circ} \mathrm{F}}\right)
$$

respectively. The nomenclature for equations 7 and 8 follow that of equation 6 with the exception that $\mathrm{T}_{\mathrm{a}, \mathrm{amb}}$ is the actual temperature of the ambient air entering into the engine and $\mathrm{T}_{\mathrm{a}, 77^{\circ} \mathrm{F}}$ is the temperature of air at $77^{\circ} \mathrm{F}$. 


\subsection{D) Measurement Techniques}

The measurement methods and equipment were very similar for most of the energy balance studies that were examined. In order to measure the brake power of the engines dynamometers were used. Hydraulic brake dynamometers were used in most cases examined, however, it should be noted that other dynamometers such as water brake, fan brake, prony brake, eddy current, direct current, or electric motor/generator dynamometers could have been used (Winther 1975). For measuring losses to the exhaust, there are two prominent methods used. The first involves finding the mass flow rate of the exhaust by direct measurement or from adding the air and fuel flow rates into the engine (Taymaz 2006). Then maximum heat can be found from cooling the exhaust to ambient temperature (Taymaz 2006). Another method used takes advantage of known chemical formulas for the fuel, air and fuel flow rates, and exhaust gas temperatures to calculate losses through a balanced chemical reaction (Kumar, et al. 2004; Sayin, et al. 2006). Calorimeters can also be used to determine the losses through the exhaust (Yuksel and Ceviz 2003). There are some common assumptions that have to be made such as complete combustion, no water vapor in combustion air, and ideal gas behavior (Kumar, et al. 2004; Sayin, et al. 2006).

Heat loss to the engine coolant was usually measured by finding the difference in coolant temperature at the engine's inlet and outlet. However, one study measured the heat loss to the cylinder liner directly by placing chromel-alumel thermocouples at four axial locations and two radial depths around it (Kumar, et al. 2004). This allowed them to 
examine how the temperature was distributed through the liner which helped them understand the combustion characteristics (Kumar, et al. 2004). This study also estimated the frictional power loss by calculating the indicated power from P- $\theta$ (pressure vs. crank angle) diagrams produced by a storage oscilloscope (Kumar, et al. 2004). Other studies attempted to measure friction losses through the heat transferred to the lubricating oil (Taymaz 2006). It should be noted that for almost all temperature measurements of the exhaust gases, engine coolants, and lubricating oils, type-K thermocouples where the measuring devices chosen. It should also be noted that all studies used a data acquisition system to constantly record all measurements. Figure 2.1 shows a schematic layout example of the experimental set up from Taymaz (2006).
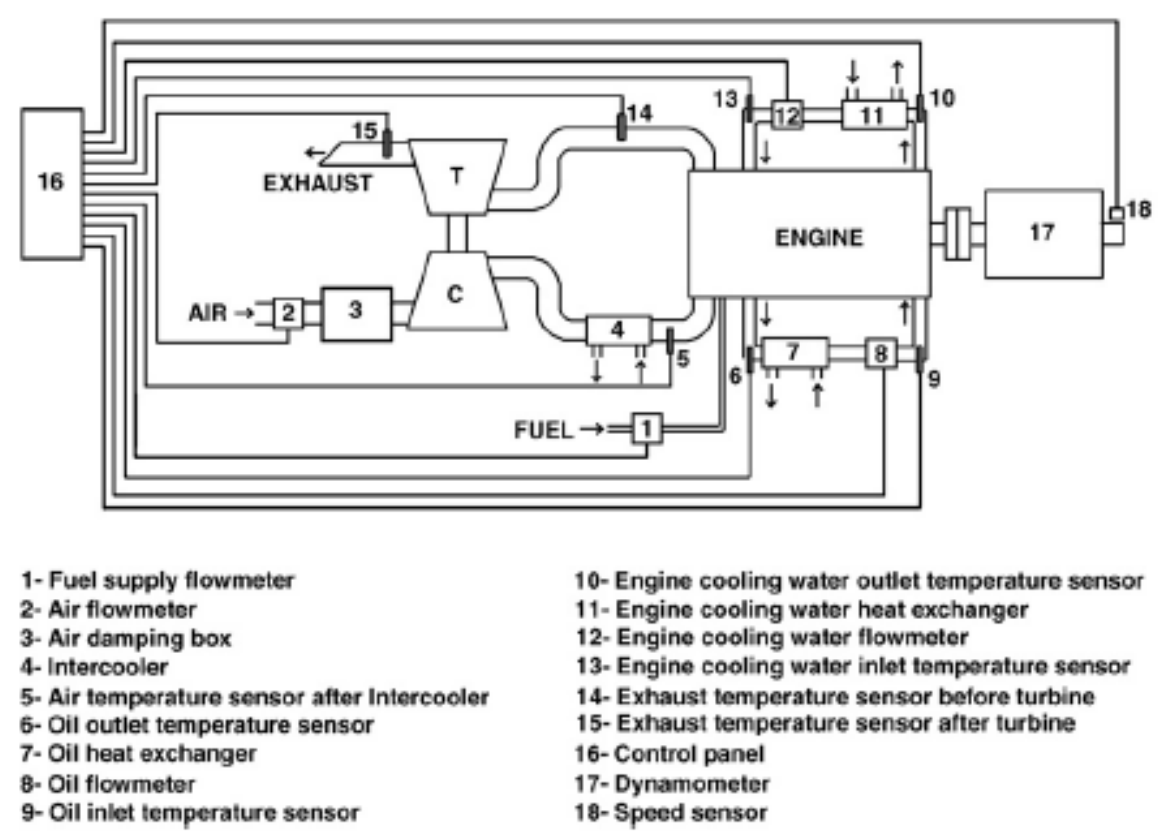

10- Engine cooling water outlet temperature sensor 11- Engine cooling water heat exchanger 12- Engine cooling water flowmeter 13- Engine cooling water inlet temperature sensor 14- Exhaust temperature sensor before turbine 15- Exhaust temperature sensor after turbine 16- Control panel

17- Dynamometer 18- Speed sensor

Figure 2.1: Schematic layout of the experimental set-up (Taymaz 2006) 
Air flow rates were measured with either some kind of flow meter or by a pressure change (manometer) in a flow element (Kumar, et al. 2004; Sayin, et al. 2006). Fuel flow rates were measured with flow meters or else by measuring the volume of fuel consumed and the specific time of consumption (Kumar, et al. 2004; Yuksel and Ceviz 2003). Most engine speeds were measured with tachometers. All tests measurements were taken under steady state conditions and some studies mentioned that a no load preconditioning period was implemented into their procedures (Kumar, et al. 2004). All steady state tests were performed one of two ways. Either a constant speed was maintained and the loading was changed, or the dynamometer maintained a constant load on the engine and measurements were recorded at different engine speeds (Kumar, et al. 2004; Sayin, et al. 2006).

One other technique for performing an energy balance on an engine is through a computer simulated mathematical model. This form of analysis is common but is generally used for transient testing and which is unnecessary for the research of this thesis (Rakopoulos and Giakoumis 2006; Yuan, et al. 2005).

\section{3) Heat Transfer}

All of the heat transfer that takes place in an engine happens in the form of conduction, convection, or radiation. The energy transfer takes place through many different interactions within the engine but the area of particular interest is in the combustion process. This has a significant impact on engine performance and emissions and may be 
better understood through an energy balance study. Many studies have been done to characterize combustion processes successfully, however, in the area of emissions, particularly with biodiesel, "fundamental principles of the NOx increase are still unclear" (Yuan, et al. 2005). It is known that combustion is the process that produces NOx emissions (Monyem, Van Gerpen and Canakci 2001). Therefore, the effects of ignition delay, overall cylinder temperatures, injection timing, and combustion timing are all being intensely studied (Yuan, et al. 2005; Monyem, Van Gerpen and Canakci 2001).

Increases in overall cylinder temperatures tend to increase NOx emissions in oxygen rich conditions (Spliethoff, et al. 1996). It has been found through modeling that biodiesel fuels have higher overall cylinder temperatures than diesel fuel (Yuan, et al. 2005). This makes sense with the NOx increase; however, the literature also shows that "the flame temperature for biodiesel is slightly below that for diesel fuel. This indicates that flame temperature changes alone cannot adequately explain the higher levels of NOx observed with biodesel” (Monyem, Van Gerpen and Canakci 2001). In this study the adiabatic flame temperatures of biodiesel were consistently lower than that of diesel fuel (Monyem, Van Gerpen and Canakci 2001). This leads to the question of what causes the higher cylinder temperatures (and therefore increased NOx emissions) when using biodiesel.

One theory on this issue is that biodiesel actually could have a higher actual flame temperature than diesel fuel but, since biodiesel produces lower in-cylinder soot 
concentrations, diesel fuel combustions have more heat radiated away from soot particles in the flame region (Cheng, Upanieks and Mueller 2006). Through thorough examination it was concluded that "differences in adiabatic flame temperature cannot be a cause of higher NOx from biodiesel” (Cheng, Upanieks and Mueller 2006). Instead they claim that actual flame temperature is affected by radiative heat transfer and that "radiative heat transfer from in-cylinder soot particles may play an important role in limiting peak flame temperatures and therefore NOx emissions. Although the correlation cannot be interpreted definitively as an indication of causation, previous work has suggested that soot radiative heater transfer can significantly affect flame temperature and NOx formation” (Cheng, Upanieks and Mueller 2006). This is an area that the energy balance performed in this thesis could add validation and therefore add to the body of biodiesel knowledge.

\section{4) Performance of Biodiesel}

In this thesis, the energy transfer rates through a diesel engine have been examined using a 100\% neat biodiesel fuel and No. 2 diesel fuel. Consequently, it is important to have some background information on biodiesel as it compares to No. 2 diesel fuel. Refer to the home of the National Biodiesel Board: http://www.biodiesel.org/ (Accessed May 2007) for information about the biodiesel performance parameters of: energy content, fuel economy, lubricity, compatibility with engine components, and cold weather applications. This information is located through the website’s “Fuel Fact Sheets” link located on the main page. 


\section{5) Adding to the Body of Knowledge}

Another way the work in this thesis adds to the overall body of knowledge for biofuel testing is that it serves as a source of validation for our overall engine diagnostic testing system. By understanding what variables affected the operating conditions of the engine, an instrumented and justified testing platform was developed for the first time of this program's existence. This thesis also established testing and safety procedures for others to follow. This testing platform will be used for future work in performance and emissions testing of algal-based biodiesel which is the program’s overall goal. 


\section{Chapter 3: Experimental Apparatus}

Figure 3.1 shows the instrumented engine energy balance testing apparatus. The considerations and details of this will be discussed in this chapter.

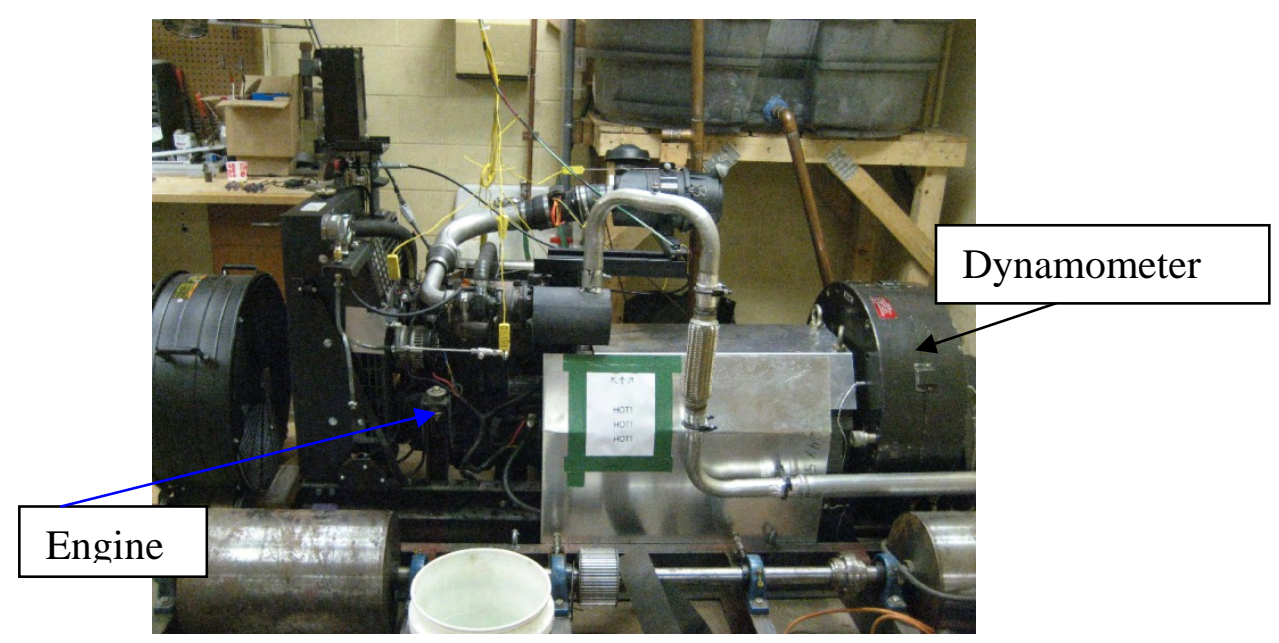

Figure 3.1: Testing apparatus

The testing apparatus for the work involved in this thesis was all located in Stocker Center's 012 laboratory which had previously been used for electric vehicle testing. The only existing equipment in the lab that was used for this thesis was a $250 \mathrm{~kW}$ (335 hp) eddy-current dynamometer and its control system. This liquid-cooled dynamometer was set up and operational at the time the lab space was acquired. This unit had previously been integrated into a roller carriage for chassis dynamometer testing which needed to be disconnected and partially removed to make room for coupling the diesel engine directly to the dynamometer. The manufacturer's data for the Digalog AE 250 dynamometer can be found in Appendix A. 


\section{1) Engine Selection}

The diesel engine selection was based on the available lab space, the compatibility with the existing engine dynamometer system, fuel consumption rate, and budget. Due to the dynamometer's location in the room and utilized space of other lab projects, the whole diesel power unit including mounting and coupling systems had to fit within a tight footprint of 3'x 6' putting a significant restriction on the size of the engine. The diesel engine also had to fall within an acceptable power range for the dynamometer. The concern was that the dynamometer system would not be able to accurately read and control the torque applied to the engine at low levels. It was determined from the manufacturer's data that the load cell in dynamometer was very precise and accurate but that the controller for the dynamometer was the limiting factor. There was insignificant information on the controller so it was determined experimentally from the previous electric vehicle tests that the engine would have to be over 10 bhp to get into the controller's accuracy range. Fuel consumption rate was a factor in the engine selection because the availability of algal based biodiesel is extremely limited. Since the other student working on this project (Dhruv Kohli) was using an algal biodiesel blend, he determined an acceptable fuel consumption rate which for most engines limited the power output to less than 100 bhp. Budget was the final constraint and while specifics where not discussed it was stressed that getting the best value possible was very important. 
The final engine selection was a 60 bhp, four cylinder, turbo charged, rotary IDI power unit supplied by Cummins Inc. It was chosen because it met all of the criteria mentioned. Figure 3.2 shows a rear and side view of the engine, stand and radiator combination with dimensions listed in inches supplied by Cummins, Inc.

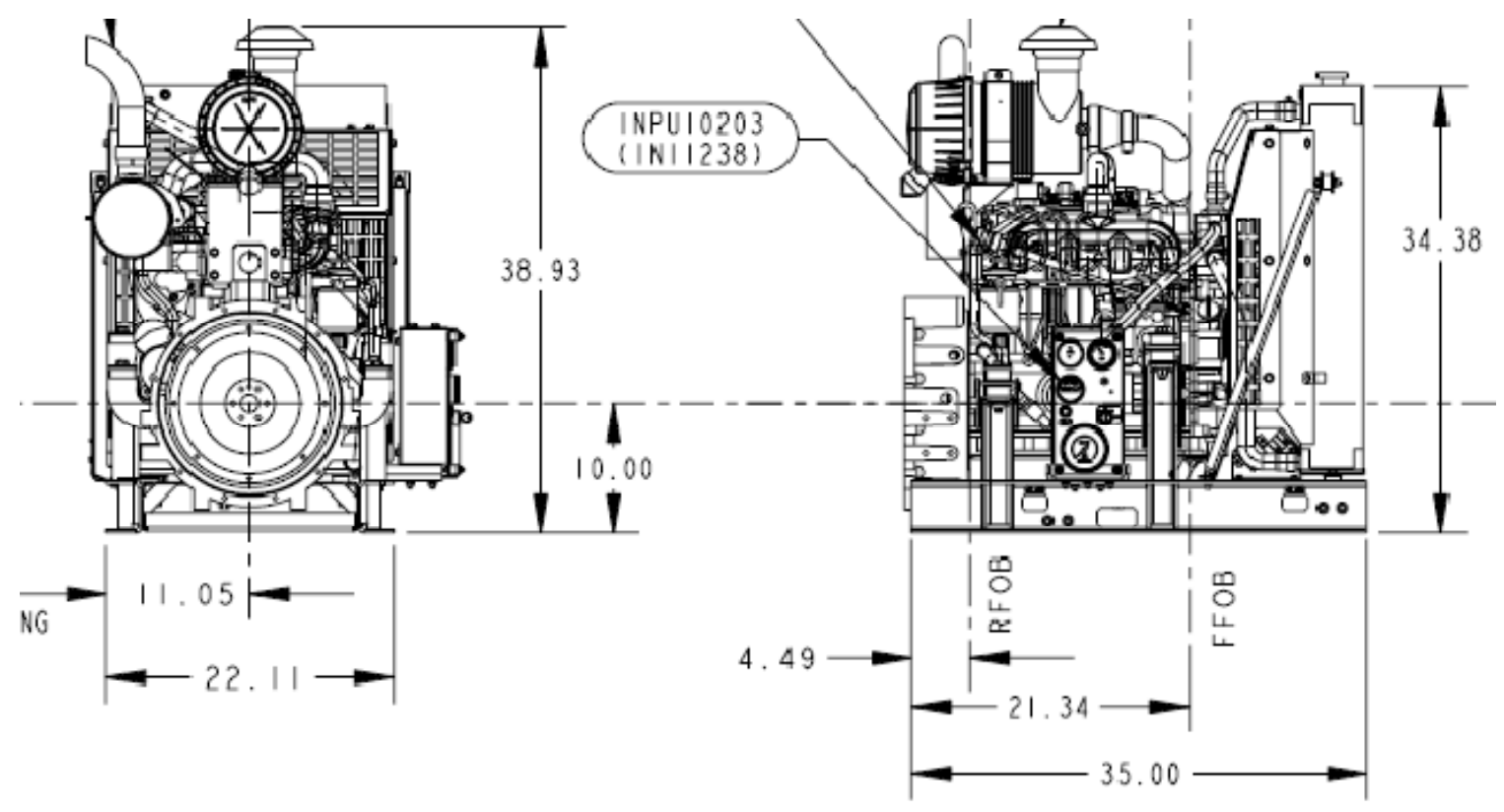

Figure 3.2: Drawing of engine, stand, and radiator combination (Cummins, Inc.)

It came as a complete power unit so it was already mounted on a stand, it was complete from the radiator to the flywheel, and it came with everything to be operational besides a battery and fuel tank. The power unit's footprint was 2.25'x3' which allowed for additional mounting equipment and a coupling system. The compact unit fell in the middle of the power range desired due to the turbo charger which also increased efficiency helping meet the fuel consumption requirements. Best of all, the engine was 
broken in by Cummins Inc. and they gave us a significant discount. All of the manufacturer's data was supplied with the power unit and is located in Appendix B. This information was used with the permission of the distributor that supplied the engine and is only intended for use within this project at Ohio University.

\section{2) Coupling the Engine to the Dynamometer}

In order to couple the engine to the dynamometer, a shop recommended by Cummins Inc. supplied a short (17”) shaft with universal joints at each end. Due to angle restrictions of the universal joints the power unit had to be raised up about 7”. To do this, two 6” Ibeams were used to support the power unit. They were bolted to the floor with concrete anchors. Between the I-beams and the power unit framework, additional spacers were placed to get the final desired height. Figure 3.3 show the I-beams, concrete anchors, and additional spacers.

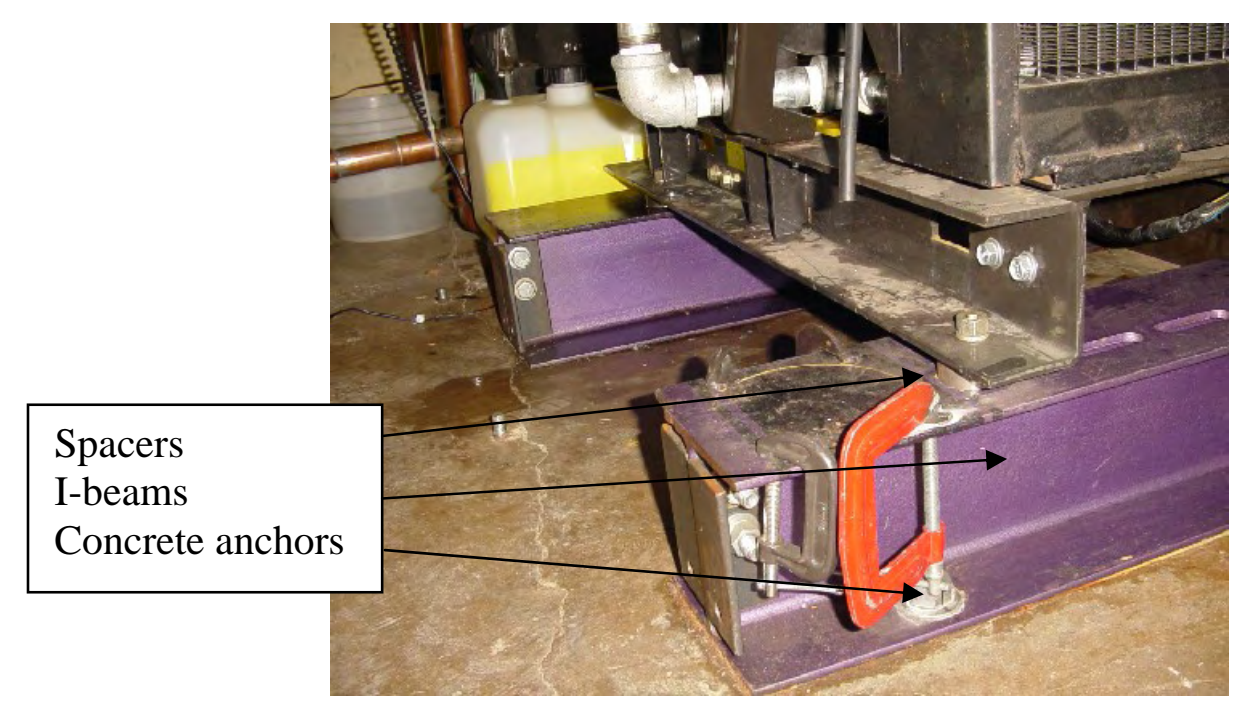

Figure 3.3: Mounting system 
Connecting the driveshaft to the engine's flywheel involved machining the surface flat and tapping mounting holes for the driveshaft flange. Figure 3.4 shows the flywheel and the driveshaft flange bolted on via the tapped mounting holes.

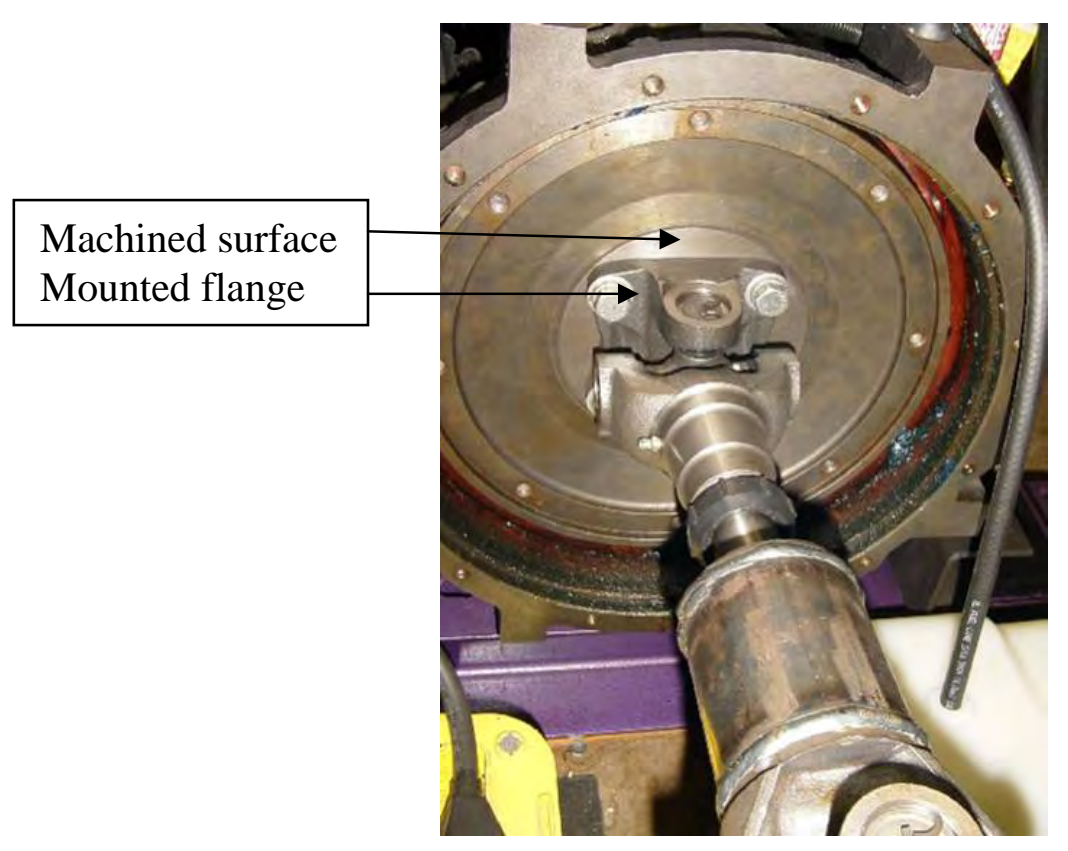

Figure 3.4: Machined flywheel with mounted driveshaft flange

On the dynamometer end, an 8” long 1 3/4” diameter solid 1040 steel shaft with 3/8” cut keyways connected the driveshaft and dynamometer couplings. This shaft also had snapring groves added to it and caps which constrained the shaft from moving horizontally inside the couplings. Figure 3.5 shows this arrangement. 


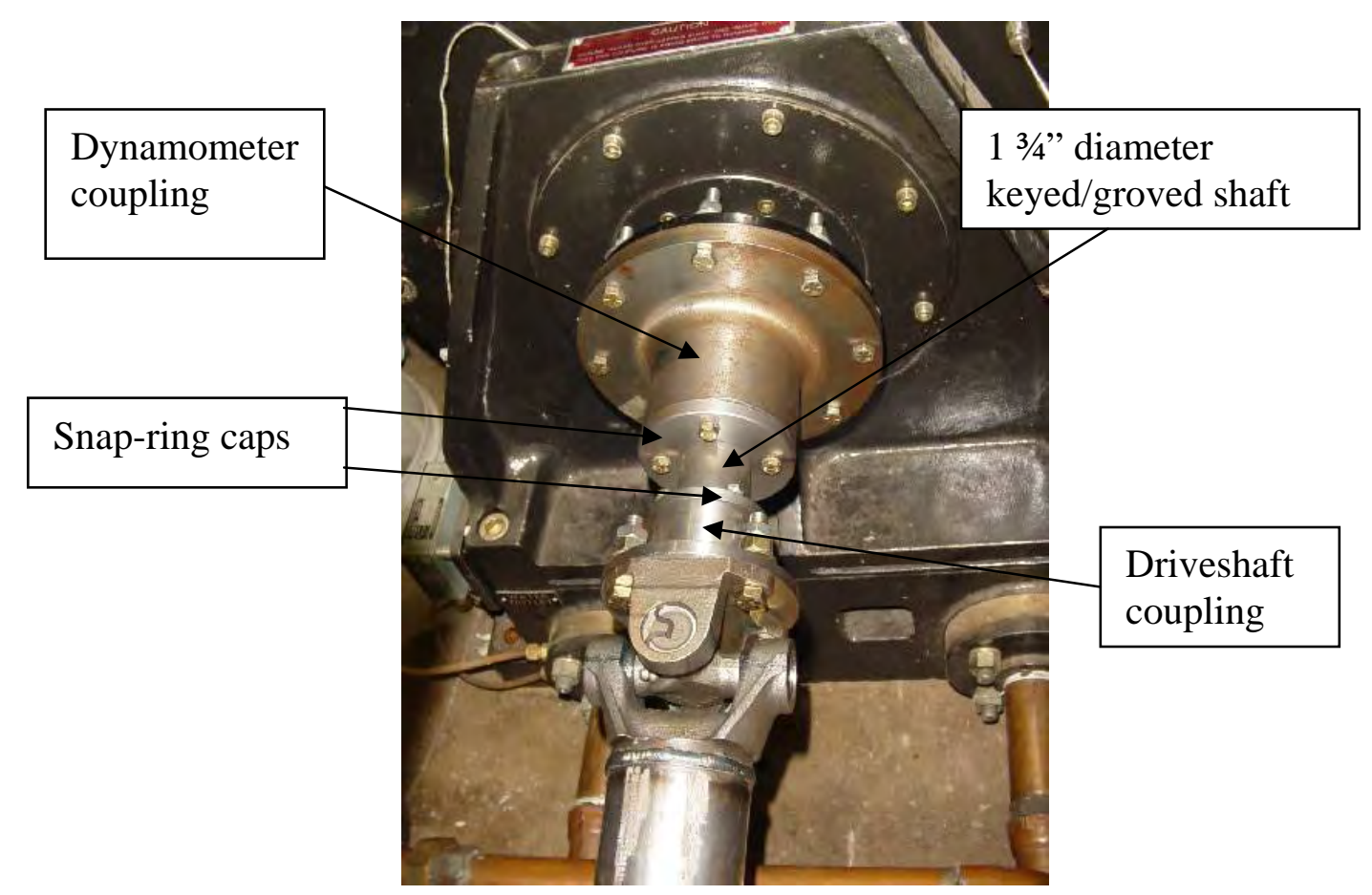

Figure 3.5: Keyed and grooved shaft between couplings with caps

This completed the mounting and coupling of the diesel power unit to the dynamometer which was an essential deliverable that needed to be completed before the remainder of the energy balance measurement equipment could be implemented.

\section{3) Measurement Equipment}

Table 3.1 contains the specific measurements, the type of measuring equipment, equipment locations on the test apparatus, and the equipment resolution or accuracy need to perform the energy balance on the system. 
Table 3.1: Measurements, equipment, locations, and resolution/accuracies

\begin{tabular}{|c|c|c|c|c|}
\hline Measurement & Symbol & Equipment & Location & Accuracy/Resolution \\
\hline Brake torque & $\tau_{\mathrm{b}}$ & Dynamometer & Driveshaft & $\pm 0.5 \mathrm{lb}-\mathrm{ft}$ \\
\hline Engine speed & $\omega$ & Dynamometer & Driveshaft & $\pm 0.5 \mathrm{Rpm}$ \\
\hline Brake power & $\mathrm{P}_{\mathrm{b}}$ & Dynamometer & Driveshaft & $\pm 0.5 \mathrm{Hp}$ \\
\hline Intake air temp. & $\mathrm{T}_{\mathrm{a}, \mathrm{i}}$ & $\begin{array}{l}\text { Type-K } \\
\text { thermocouple }\end{array}$ & Turbo outlet & $\pm 3.6^{\circ} \mathrm{F}$ \\
\hline Fuel in temp. & $\mathrm{T}_{\mathrm{f}, \mathrm{i}}$ & $\begin{array}{l}\text { Type-K } \\
\text { thermocouple }\end{array}$ & Supply line & $\pm 3.6^{\circ} \mathrm{F}$ \\
\hline Fuel out temp. & $\mathrm{T}_{\mathrm{f}, \mathrm{o}}$ & $\begin{array}{l}\text { Type-K } \\
\text { thermocouple }\end{array}$ & Return line & $\pm 3.6^{\circ} \mathrm{F}$ \\
\hline $\begin{array}{l}\text { Coolant in } \\
\text { temp. }\end{array}$ & $\mathrm{T}_{\mathrm{c}, \mathrm{i}}$ & $\begin{array}{l}\text { Type-K } \\
\text { thermocouple }\end{array}$ & $\begin{array}{l}\text { Water pump } \\
\text { inlet }\end{array}$ & $\pm 3.6^{\circ} \mathrm{F}$ \\
\hline $\begin{array}{l}\text { Coolant out } \\
\text { temp. }\end{array}$ & $\mathrm{T}_{\mathrm{c}, \mathrm{o}}$ & $\begin{array}{l}\text { Type-K } \\
\text { thermocouple }\end{array}$ & Radiator inlet & $\pm 3.6^{\circ} \mathrm{F}$ \\
\hline $\begin{array}{l}\text { Fuel mass flow } \\
\text { rate }\end{array}$ & $\dot{m}_{\mathrm{f}}$ & $\begin{array}{l}\text { Scale and } \\
\text { stopwatch }\end{array}$ & Fuel tank & $\pm 0.01 \mathrm{lb}$ and $1 \mathrm{sec}$ \\
\hline $\begin{array}{l}\text { Fuel } \\
\text { composition }\end{array}$ & $\mathrm{C}_{\mathrm{x}} \mathrm{H}_{\mathrm{x}} \mathrm{O}_{\mathrm{x}}$ & Table & N/A & $\mathrm{N} / \mathrm{A}$ \\
\hline Fuel LHV & LHV & Table & N/A & $\pm 7 \%$ \\
\hline Exhaust temp. & $\mathrm{T}_{\mathrm{ex}}$ & $\begin{array}{l}\text { Type-K } \\
\text { thermocouple }\end{array}$ & $\begin{array}{l}\text { Exhaust } \\
\text { manifold }\end{array}$ & $\pm 3.6^{\circ} \mathrm{F}$ \\
\hline $\begin{array}{l}\text { Lubricating oil } \\
\text { temp. }\end{array}$ & $\mathrm{T}_{\text {oil }}$ & $\begin{array}{l}\text { Type-K } \\
\text { thermocouple }\end{array}$ & Oil pan & $\pm 3.6^{\circ} \mathrm{F}$ \\
\hline $\begin{array}{l}\text { Air mass flow } \\
\text { rate }\end{array}$ & $\dot{M}_{a}$ & $\begin{array}{l}\text { Mass air flow } \\
\text { meter }\end{array}$ & $\begin{array}{l}\text { Air cleaner } \\
\text { outlet }\end{array}$ & $\pm 2 \%$ \\
\hline $\begin{array}{l}\text { Coolant } \\
\text { volumetric flow } \\
\text { rate }\end{array}$ & $\dot{V}_{c}$ & Flow meter & $\begin{array}{l}\text { Water pump } \\
\text { inlet }\end{array}$ & $\pm 5 \%$ \\
\hline Amb. Air temp. & $\mathrm{T}_{\mathrm{a}, \mathrm{amb}}$ & $\begin{array}{l}\text { Type-K } \\
\text { thermocouple }\end{array}$ & $\begin{array}{l}\text { Air cleaner } \\
\text { inlet }\end{array}$ & $\pm 3.6^{\circ} \mathrm{F}$ \\
\hline
\end{tabular}

Note: Most measurements were recorded with a data logger. 
The laboratory environment is shown in Figure 3.6.

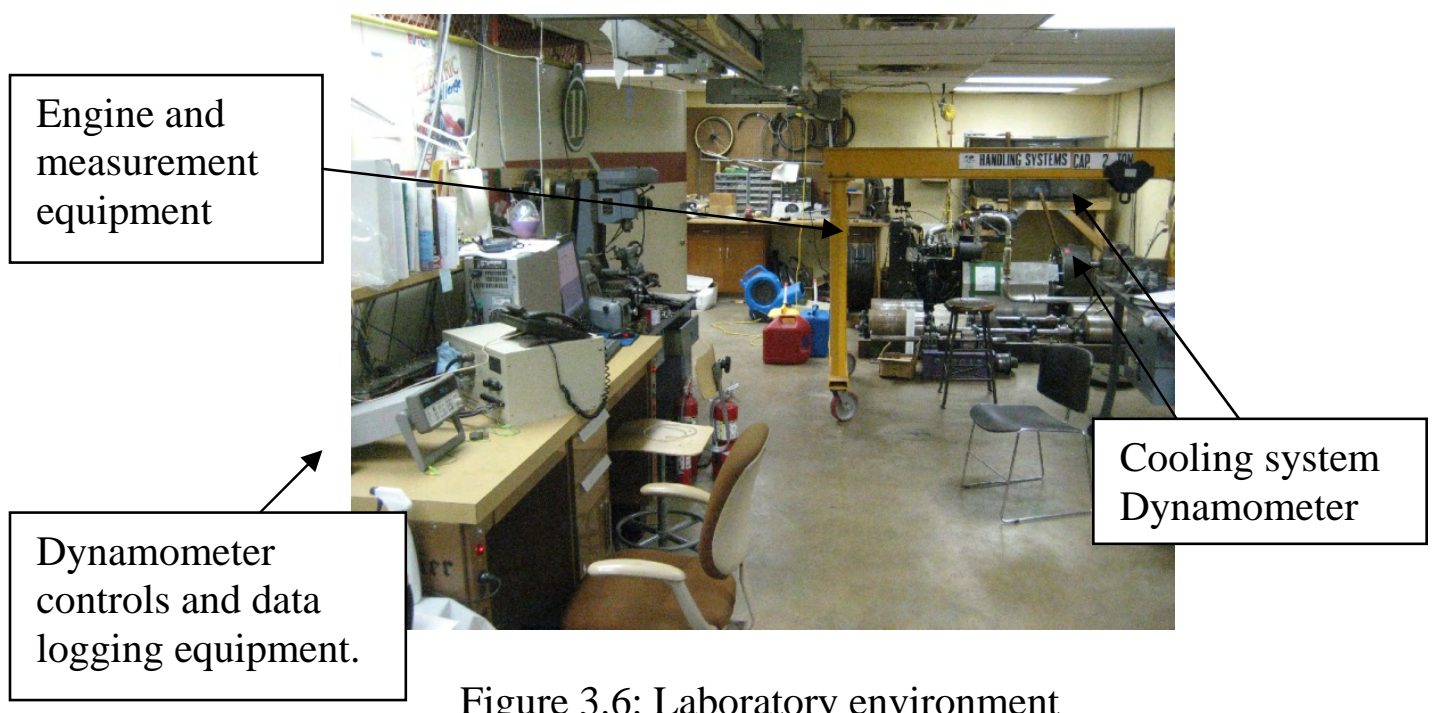

Figure 3.6: Laboratory environment

Figure 3.7 shows the computer used to log the data during testing, the 12 volt power supply for the mass air flow sensor, the data logger, and the dynamometer controls and readout.

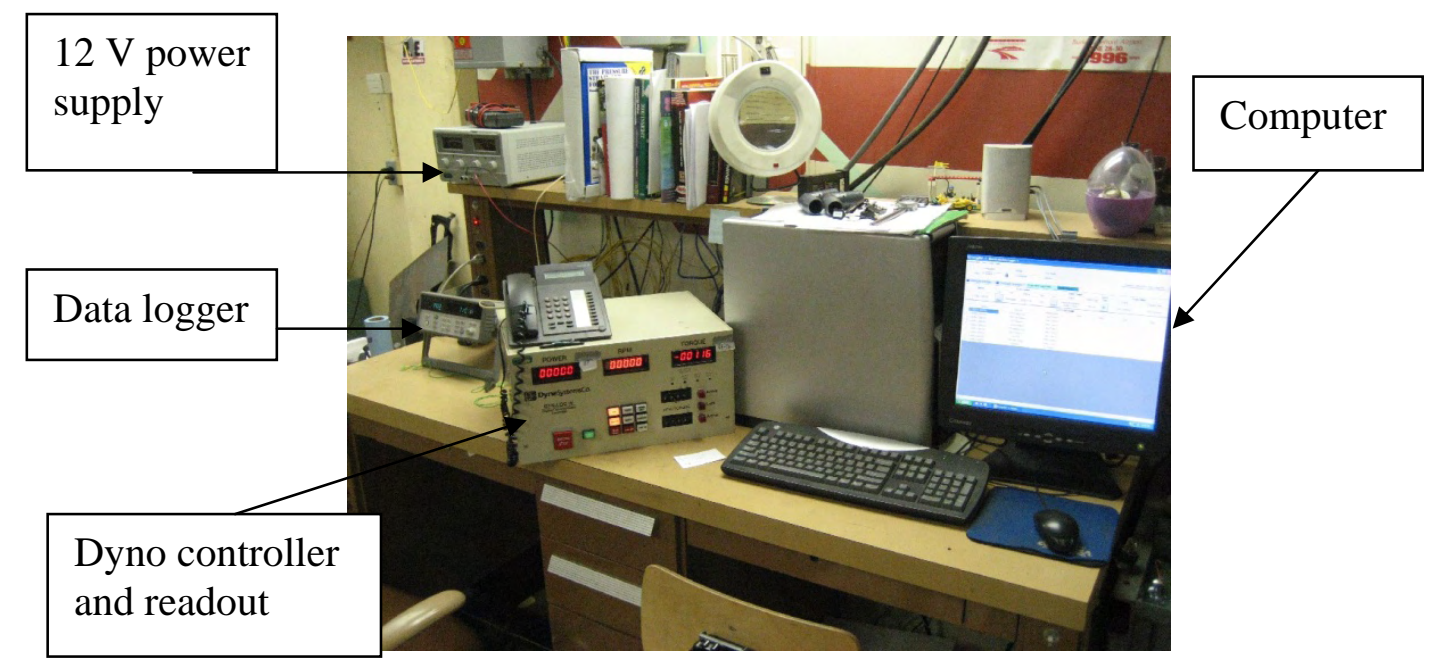

Figure 3.7: Data logging station 
Figure 3.8 shows a closer look at the experimental set up.

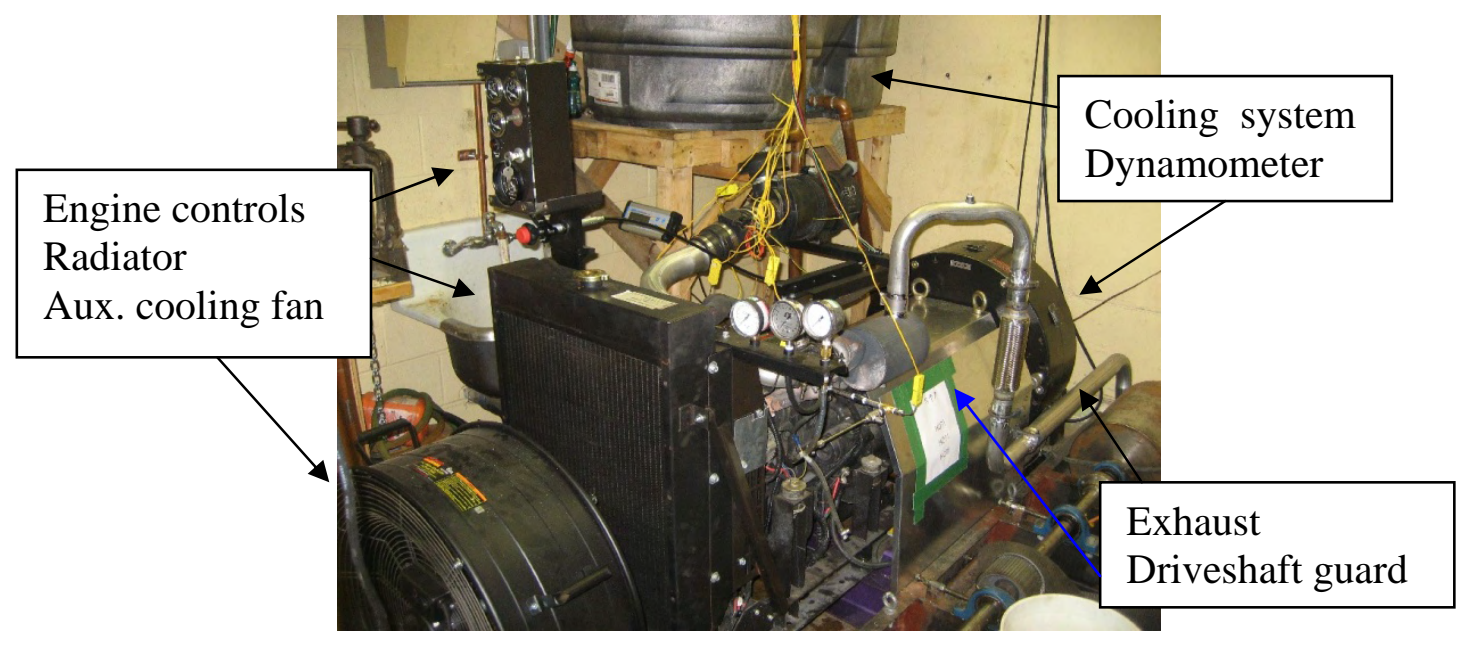

Figure 3.8: Test apparatus accessories

Figure 3.9 shows the test apparatus from a different angle.

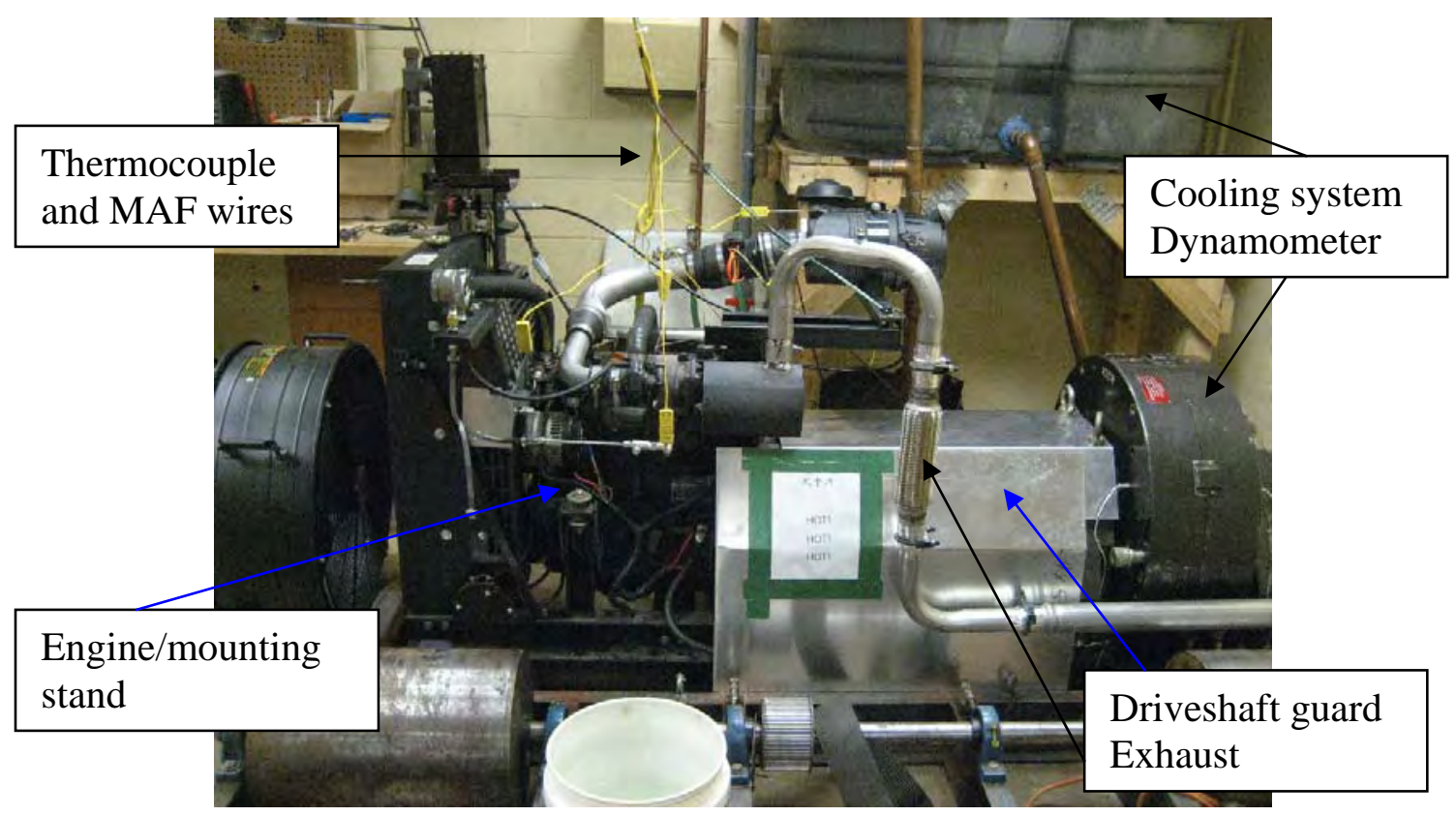

Figure 3.9: Test apparatus 
The following series of pictures shows the actual placement of the measurement equipment on the engine. Figure 3.10 shows the exhaust, coolant out, and ambient air thermocouple locations as well at the mass air flow sensor location (as labeled in the picture).

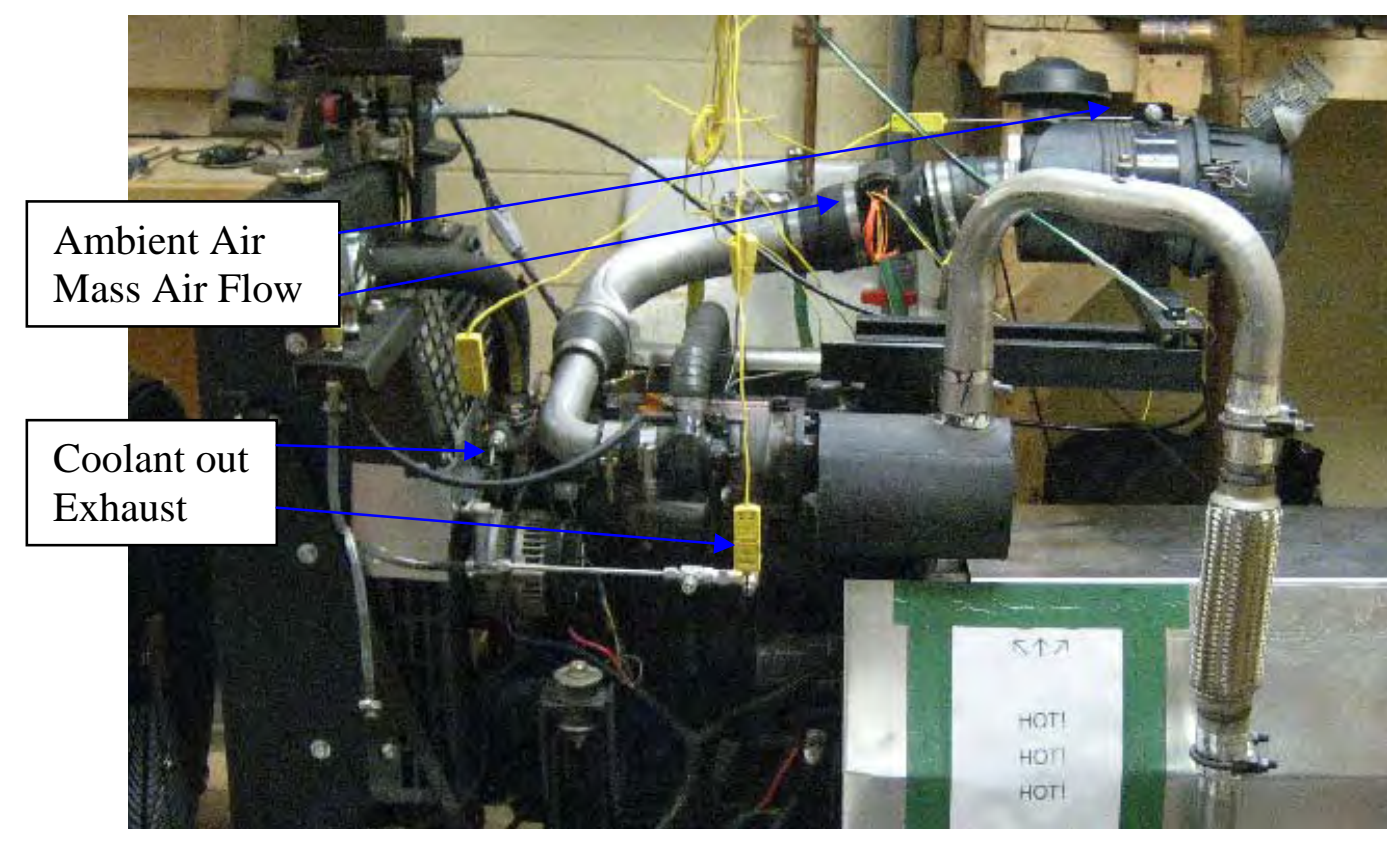

Figure 3.10: Measurement equipment placement

Figure 3.11 shows the other side of the engine. Pictured are the coolant in, fuel supply, and oil thermocouple locations. It also shows the fuel tank on top of its scale, the mass air flow sensor, and the coolant flow meter location. 


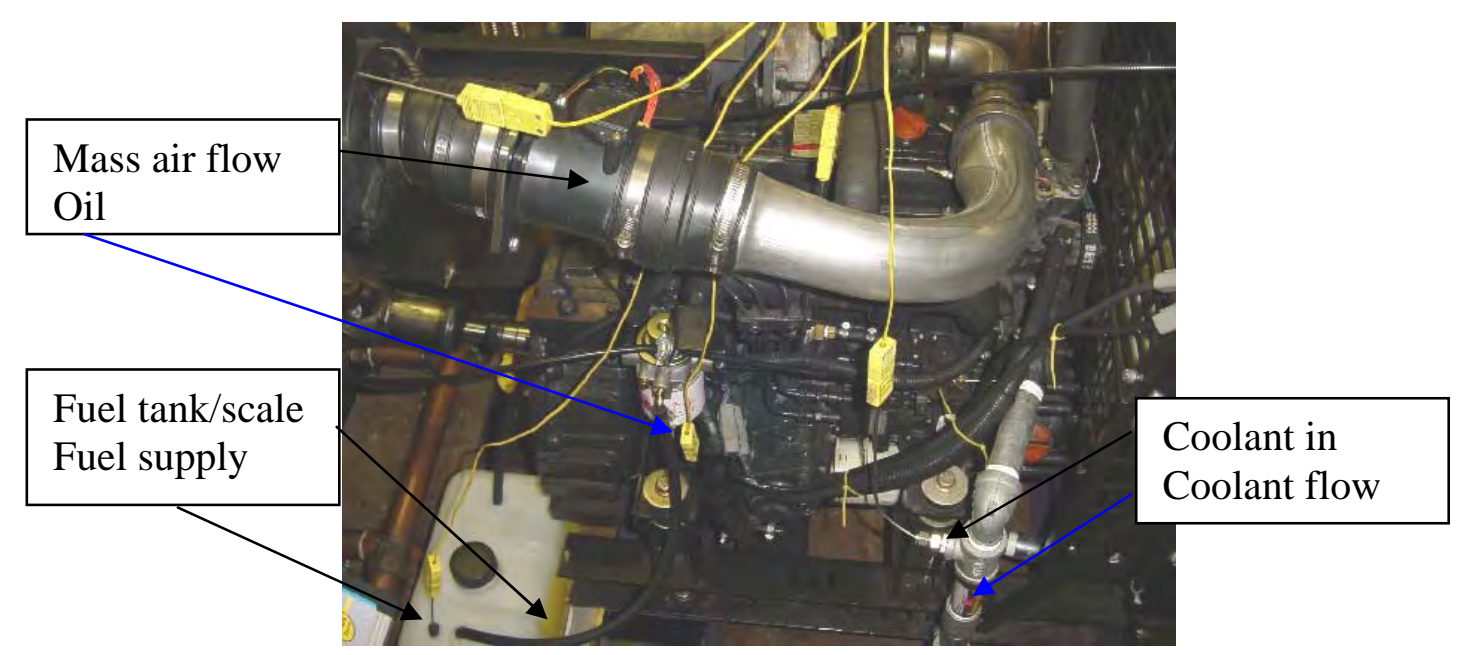

Figure 3.11: Measurement equipment placement (other side of engine)

Figure 3.12 shows the coolant flow meter. The coolant flow path was out the bottom of the radiator, up through the flow meter, and into the water up.

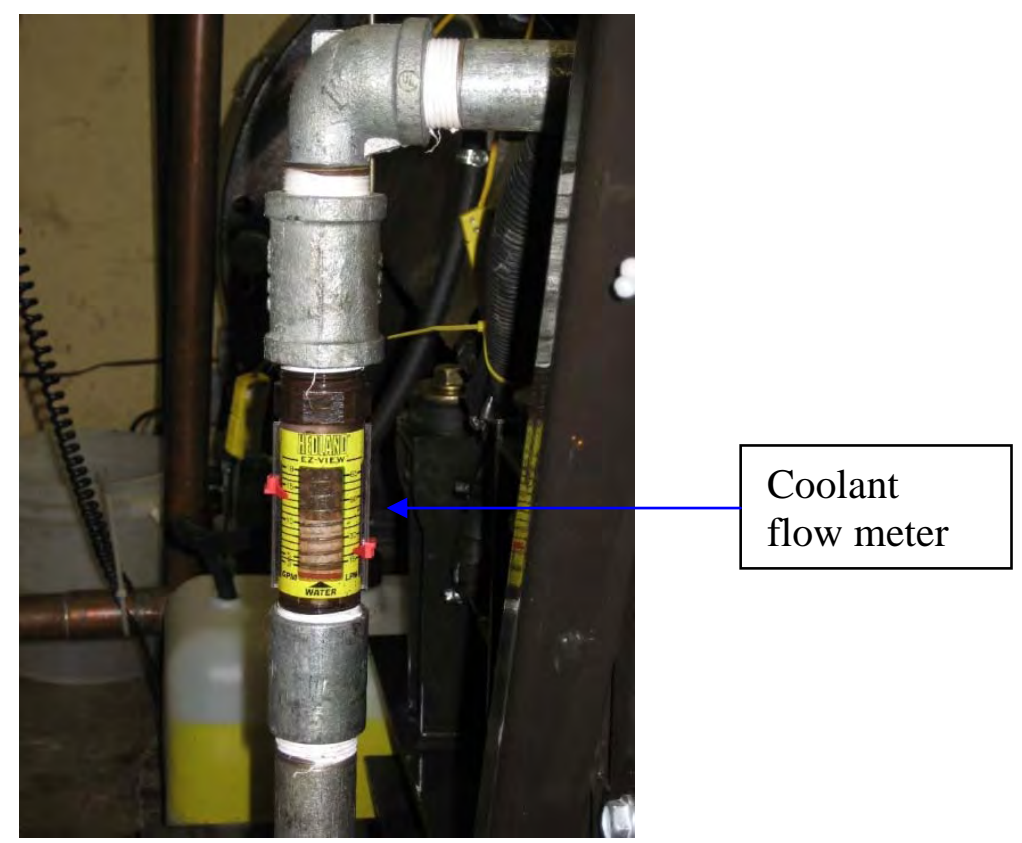

Figure 3.12: Coolant flow meter 
Figure 3.13 shows the thermocouple placement to measure the coolant going into the engine. It is located just above the coolant flow meter shown in the previous figure.

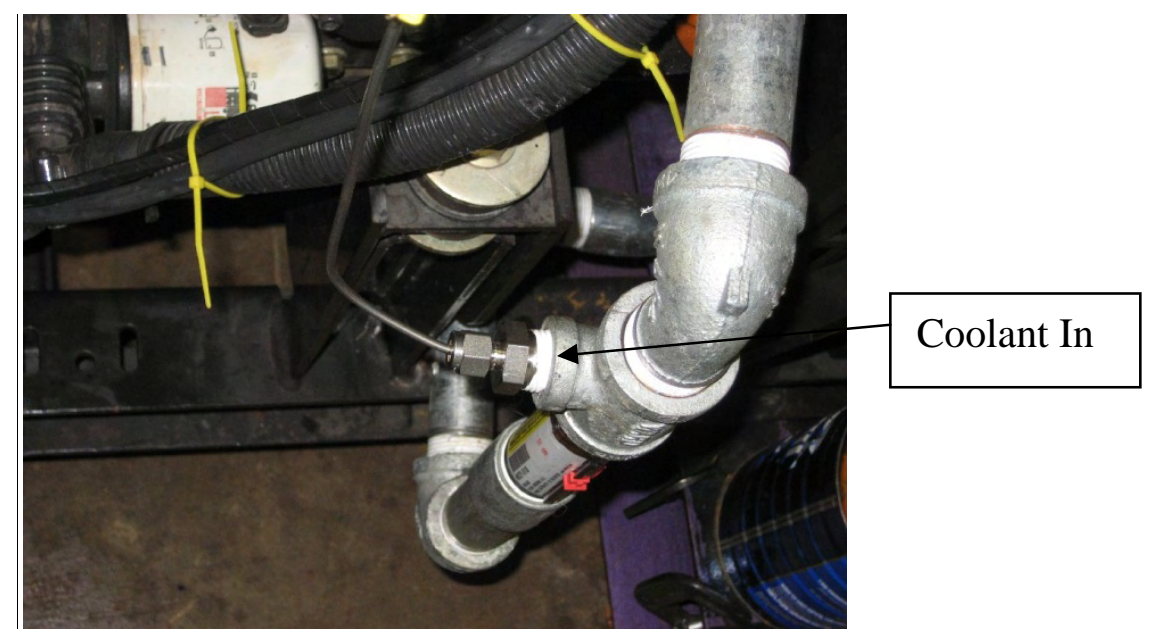

Figure 3.13: Coolant in thermocouple

Figure 3.14 shows the thermocouple placement to measure the engine’s lubricating oil temperature. This thermocouple was inserted in place of the oil dipstick.

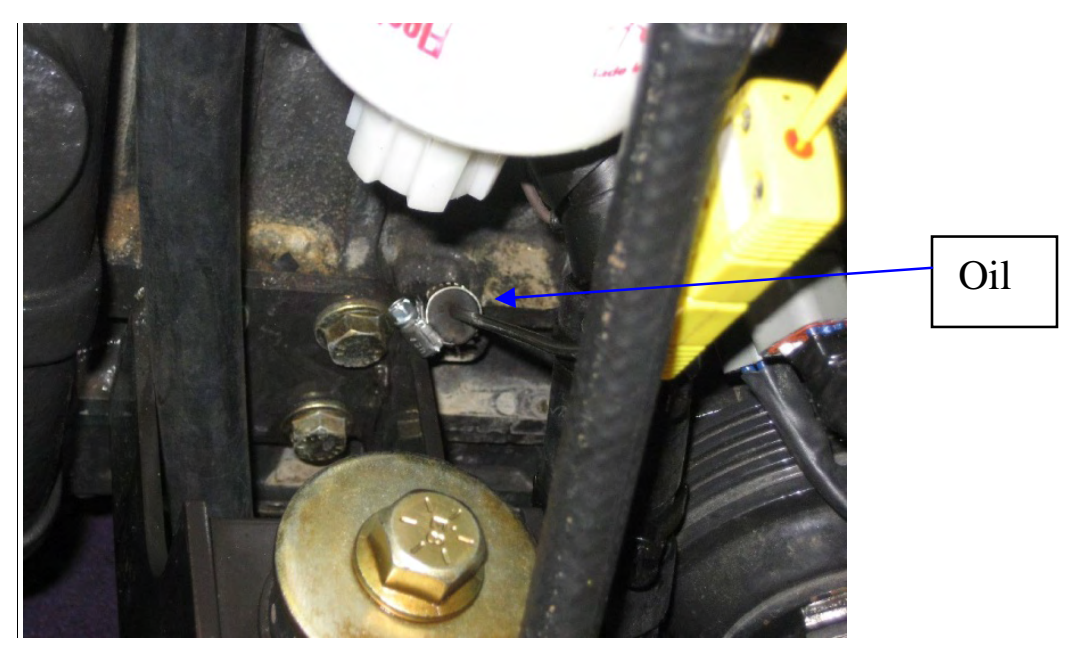

Figure 3.14: Engine oil thermocouple 
Figure 3.15 shows the thermocouple placement to measure the temperature of the fuel returning to the fuel tank from the injection pump.

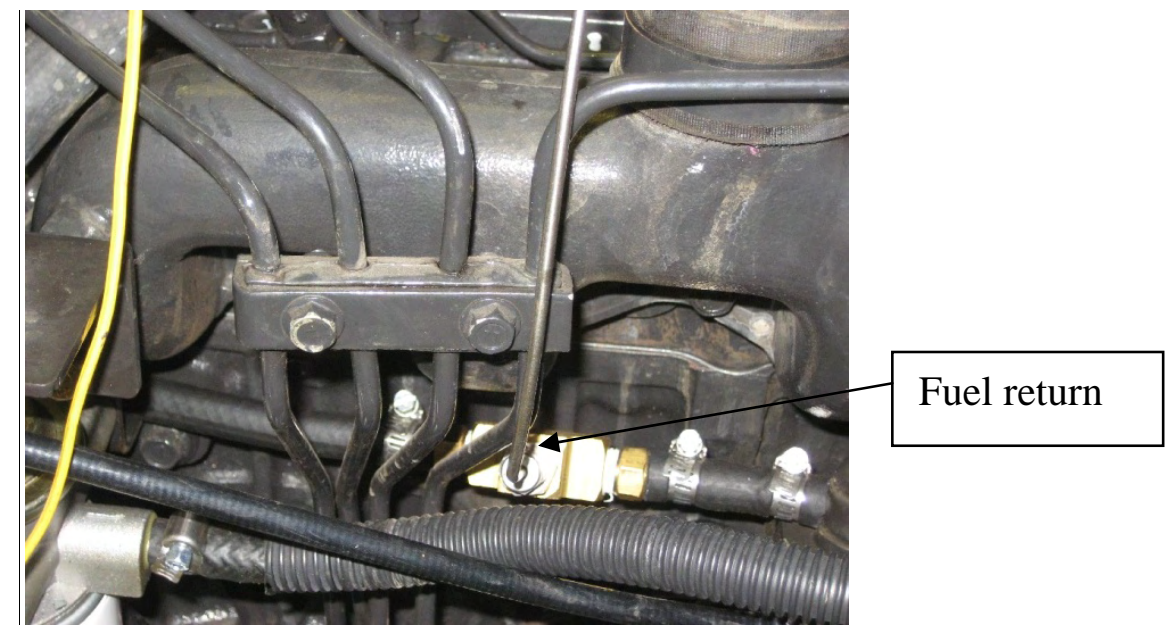

Figure 3.15: Fuel return thermocouple

Figure 3.16 shows the thermocouple placement to measure the intake air temperature flowing through the intake manifold.

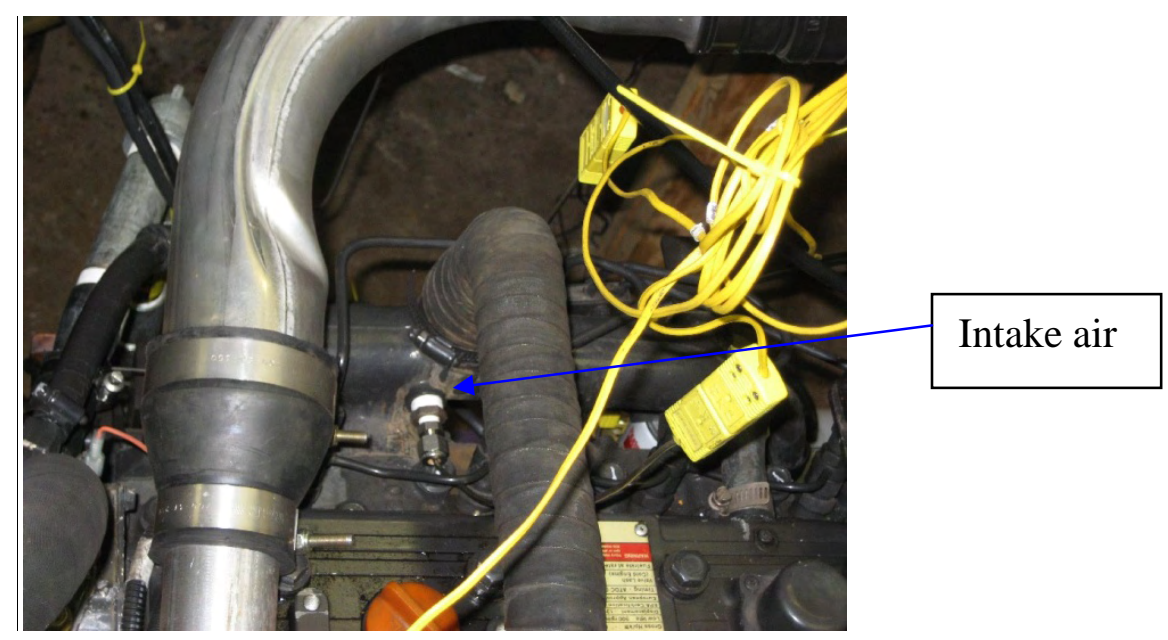

Figure 3.16: Air intake thermocouple 
Figure 3.17 shows the thermocouple placement to measure the temperature of the engine coolant leaving the engine and flowing into the radiator.

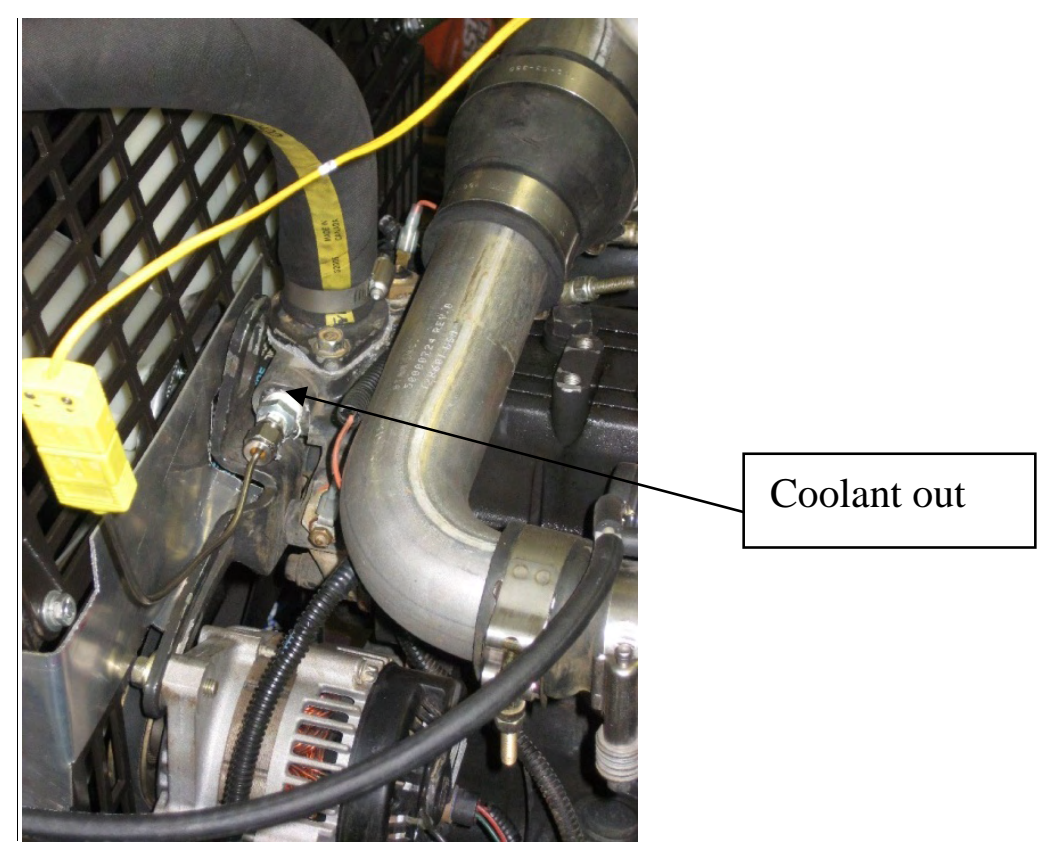

Figure 3.17: Coolant out thermocouple

Figure 3.18 shows the thermocouple placement to measure the temperature of the exhaust flowing through the exhaust manifold. Also shown are the turbocharger's boost gauge and the exhaust back-pressure gauge. 


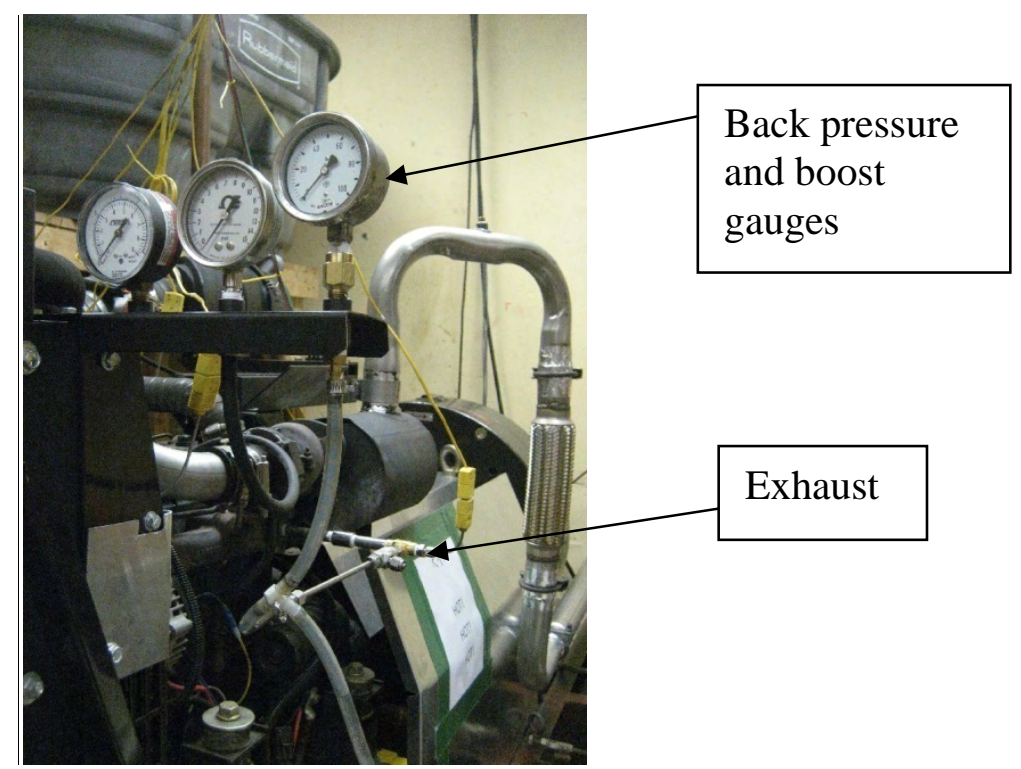

Figure 3.18: Exhaust thermocouple and gauges

Figure 3.19 shows the electronic stopwatch and readout for the scale used to measure the weight of the fuel.

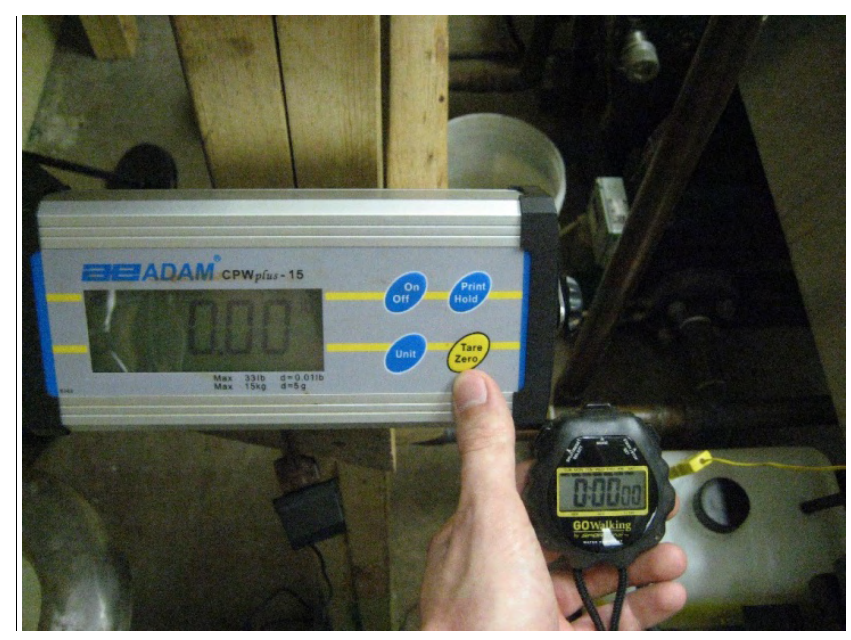

Figure 3.19: Scale readout and stopwatch 
Figure 3.20 shows the fuel tank with the fuel supply thermocouple sitting on top of the digital scale.

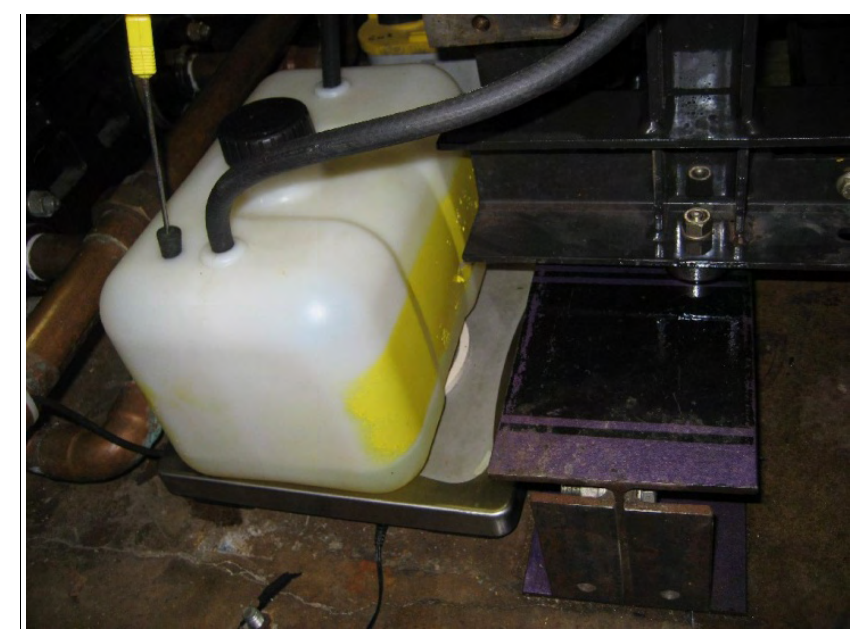

Figure 3.20: Fuel tank/digital scale 


\section{Chapter 4: Test Plan}

In this energy balance study, a direct comparison on the appropriation of energy was made between No. 2 Diesel fuel and B100. In order to insure accuracy and repeatability there were many monitored factors as shown in Table 3.1. With respect to the environmental conditions in the lab, the ambient air temperature was the most difficult condition to deal with due to the amount of heat given off by the engine in such a small lab space. The laboratory lacked both adequate ventilation and a direct source of cool outside air. For these reasons, the ambient air temperature in the room increased significantly after the engine was running. To deal with this challenge, the test plan specified running steady-state trials consecutively in an attempt to keep the air temperature in the lab as consistent as possible. Air circulation fans were used to keep the room temperature more consistent during testing. Prior to starting the first trial of a series of tests, the engine was run through a preconditioning period to get the engine and room up to a consistent temperature before each data collection trial was started. This involved running the engine under a full load condition at 2800 RPM (peak power point) for about 15 minutes. Energy was supplied to the system (or diesel engine power unit) by means of the respective fuel sources (No. 2 diesel and B100).

The energy content or lower heating value (LHV) of each fuel source was reported by "Energy and Exergy Analysis of a Diesel Engine Fuelled with Various Biodiesels” (Canakci and Hosoz 2006). This along with all other fuel data, such as the chemical 
composition, can be found in Appendix C. It was determined through an uncertainty analysis that due to the high uncertainty of the fuel's energy content (7\%), the energy balance measurements needed to be analyzed based on a relative energy distribution instead of a direct measurement corresponding to the fuel's energy input. This meant that regardless of the amount of energy inputted by the fuel, the amount of energy transferred to different areas of the engine was directly measured and compared to the total amount measured on a percentage basis. This allowed for a direct energy balance comparison between diesel and biodiesel fuels. This also made the uncertainties of the results based primarily on the accuracy of the measurement equipment. This is important because the uncertainties for the measurements need to be small to distinguish statistically significant differences in energy appropriation between the fuel sources.

An energy balance analysis based on the input energy from was still performed to get an indication of how much of the total energy was accounted for by the measurement system. However, these results had higher uncertainties due to the inability to measure the energy content of samples from each fuel type.

\section{1) Throttle Position}

The trials for biodiesel (which had lower benchmarked values for LHV than No. 2 diesel) were run at full throttle. This should have insured repeatable fuel (and therefore energy) supplies to the engine. The No. 2 diesel fuel trials were run at a slightly lower throttle position in an attempt to keep the same amount of energy entering the system for the 2 
fuel sources. The main reasons for keeping the energy input constant for both No. 2 diesel fuel and B100 was to minimize differences in energy appropriation from different engine efficiency ranges and characteristics of combustion efficiency could be directly compared between the different fuels. To approximate the correct throttle position that should be used to keep the diesel energy input the same as the biodiesel energy input, the torque output for the biodiesel, running at full throttle, was recorded. Then under the same operating conditions, diesel fuel was run at full throttle and then slowly backed down until the torque output equaled that of the recorded biodiesel full throttle torque output. The gap between the throttle lever and its stop was then measured with a set of feeler gauges as shown in Figure 4.1.

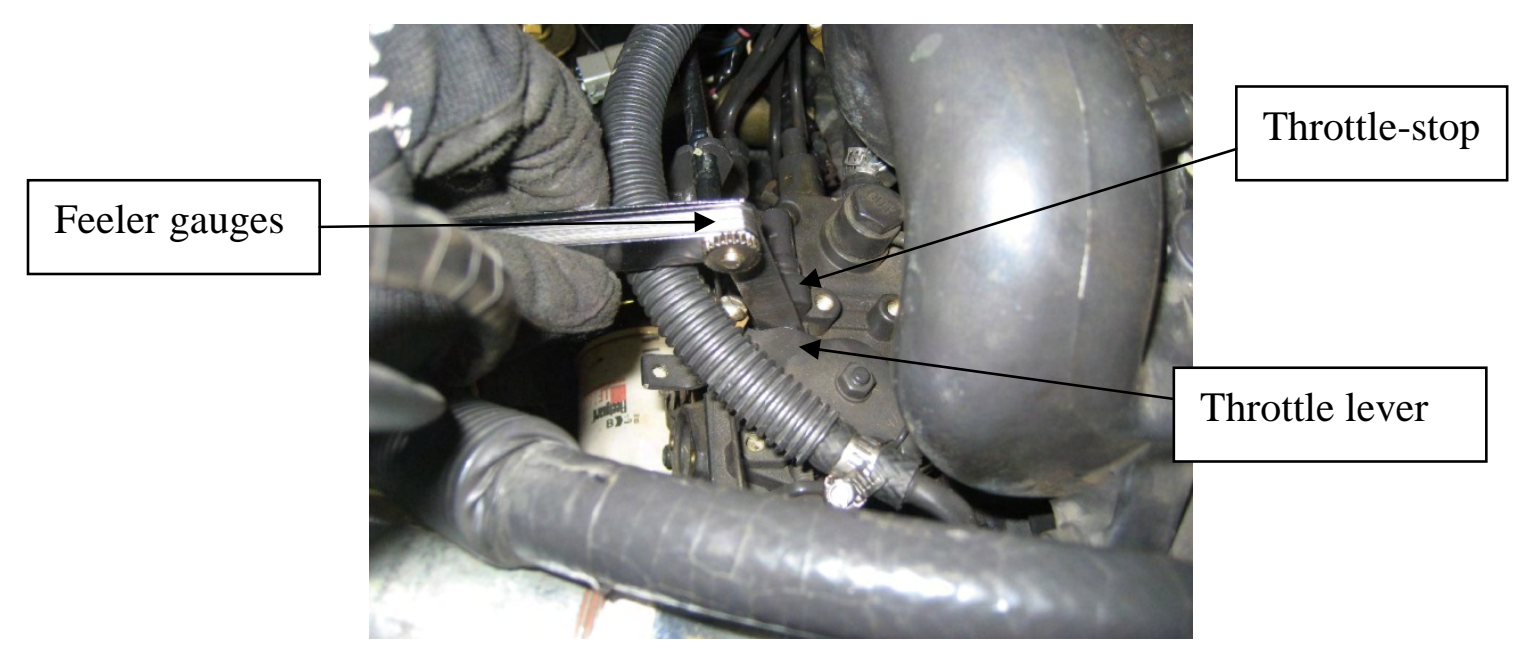

Figure 4.1: Throttle position for No. 2 diesel fuel only

The feeler gauge shim needed to achieve the same torque was found to be 0.045 ”. With the shim inserted next to the stop and the throttle lever tightened up against it, the same throttle position for the diesel fuel trials could be insured. 
The engine was run at these respective throttle positions for biodiesel and diesel fuel. The engine was also run at an engine speed of 2800 RPM. According to the engine's fuel consumption curves located in Appendix B, this speed required the highest fuel flow rate in the engine's operating capabilities. This therefore inputted the most energy making it easier to measure the distribution through the engine. The measurement equipment used for determining fuel flow rate was a calibrated scale accurate to $0.01 \mathrm{lb}$ and a hand-held timer realistically accurate to a 1 second human response (see Figure 3.19).

\section{2) Energy Balance Method}

The specific equations used for the energy balance calculations in this thesis have all be described in section 2.2C along with the rest of the energy balance theory information.

The energy converted into power output was measured by the dynamometer. The dynamometer was used to keep the engine speed at the constant, fixed value. With the recorded speed and its respective torque value, the brake power output was calculated. The losses through the exhaust were determined by measuring the air and fuel flow rates, making the assumption of complete combustion to determine exhaust gas constituents, and determining the exhaust gas temperature. Using ideal gas behavior concepts and the supplied chemical composition of the fuel, the energy losses through the exhaust were determined. 
To measure the energy transferred through conduction of engine components, the engine coolant (convection media) temperature was determined with thermocouples placed at the inlet (Figure 3.13) and outlet (Figure 3.17) of the engine's water pump. These positions gave the largest change in temperature for calculating the heat rejected to the engine coolant.

Energy transferred to the lubricating oil from friction of moving engine components were also accounted for in the engine coolant. The reason for this is because the engine has an external oil cooler that the engine coolant passes through to lift off the heat transferred to the oil. The remainder of energy transfer that was not measured was grouped into the unaccounted losses.

All of the calculations for this thesis were performed in the "EngineCalc" tab of

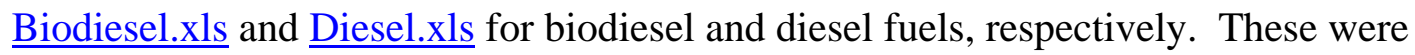
developed in Microsoft Excel worksheets as part of this thesis and this engine analysis program is included as a supplement to the thesis. By linking the proper data to a table in EngineCalc, all of the calculations are solved based on the inputs and the predetermined constants. EngineCalc was also used to predict the proper enthalpy values for the corresponding exhaust temperatures and it was used to automatically balance the chemical reactions for the different fuels. As EngineCalc solves the energy balance equations, it performs a measurement uncertainty analysis for each area of energy transfer. It also determines the total system's measurement uncertainty. EngineCalc was 
also used to determine the uncertainty sensitivity of the A/F ratio on the exhaust losses because a direct uncertainty calculation was very complicated. All of the calculations for energy transfer and measurement uncertainty performed in EngineCalc were verified with hand calculations and are included in Appendix D.

\section{3) Test Details}

Six independent trials for each of the two fuel sources were conducted in an attempt to obtain high accuracy and research quality results. The trials were staggered between fuel sources to insure that no deposits from the fuel supply system or products of incomplete combustion affected the results. The trials were all performed under the same steadystate conditions and the preconditioning period was used if necessary to insure that proper engine conditions were present at the beginning of each trial. The official start to a trial was based on the time that the engine's coolant temperature coming out of the engine reached $180^{\circ} \mathrm{F}$. At this time, the weight of the fuel on the scale was "zeroed" and the stopwatch was started. The data logger was set up to record the temperature measurements and the mass air flow measurements at a rate of 1 measurement/second.

During each trial the values for the torque output and the time at which they changed were manually recorded. The end of each trial was exactly 20 minutes from the start and at this time the final weight of the fuel consumed was recorded. This 20 minute time period was based on the capacity of the engine's fuel tank. Upon completion of a trial the engine was shut down and the fuel sources were changed in preparation for the next trial. 
The break between trials was kept at about 10 minutes so that the conditions in the room would not take long to re-stabilize and if there was a longer break, the 15 minute engine preconditioning period described earlier was followed. A detailed outline of the engine operating procedures and fuel changing is described in the standard operating procedures (SOP) located in Appendix E.

Steady-state tests were chosen because they allow many measurements to be taken under similar conditions reducing the precision or "random" errors by averaging. Additionally, the engine and dynamometer controls do not allow for transient tests to be performed with a degree of reproducibility need for research. Based on the six trials for each fuel source and the number of measurements taken during each trial, EngineCalc was used to validate that the system was measuring all areas of energy transfer and reporting the level of accuracy based on the measurement equipment uncertainty. The goal of the equipment selection and the number of readings taken were to be able to achieve the final percentage of total energy transferred throughout the system with power, coolant, and exhaust uncertainties of $0.25 \%, 0.50 \%$, and $0.50 \%$ respectively. These uncertainty values are based the accuracy needed to distinguish between the differences in energy appropriation based on the benchmarked values given by (Canakci and Hosoz 2006) in 2.2C.

\section{4) Safety}

Safety was one of the main concerns during the tests for this thesis. Since the engine was being tested within the confined space of the laboratory, exhaust emissions were a major 
concern. To insure that the exhaust emissions did not leak into the lab, a solid steel exhaust was run from the engine to the laboratory exit with all joints sealed by high temperature tape. A hand-held gas analyzer was always present in the lab as well as a wall-mounted carbon monoxide detector. Protection from rotating objects was addressed by a driveshaft guard. Personal protection equipment such as gloves, safety glasses, and ear protection was always provided and tests were only run with at least two people present. The SOP and SER (failure modes and effects analysis) located in Appendix E addresses these safety concerns. 


\section{Chapter 5: Results}

\section{1) Coolant and Air Temperatures}

Data was collected for the work in this thesis on a trial by trial basis. The data from all 6 trials of each fuel was sorted and combined to plot the results for the individual measurements (i.e. temperatures of coolant in, coolant out, ambient air, etc.). An example of this is Figure 5.1 which shows all of the temperature measurements (with the exception of the fuel and exhaust temperatures) for the 6 trials of B100 plotted over the 20 minute trial time period.

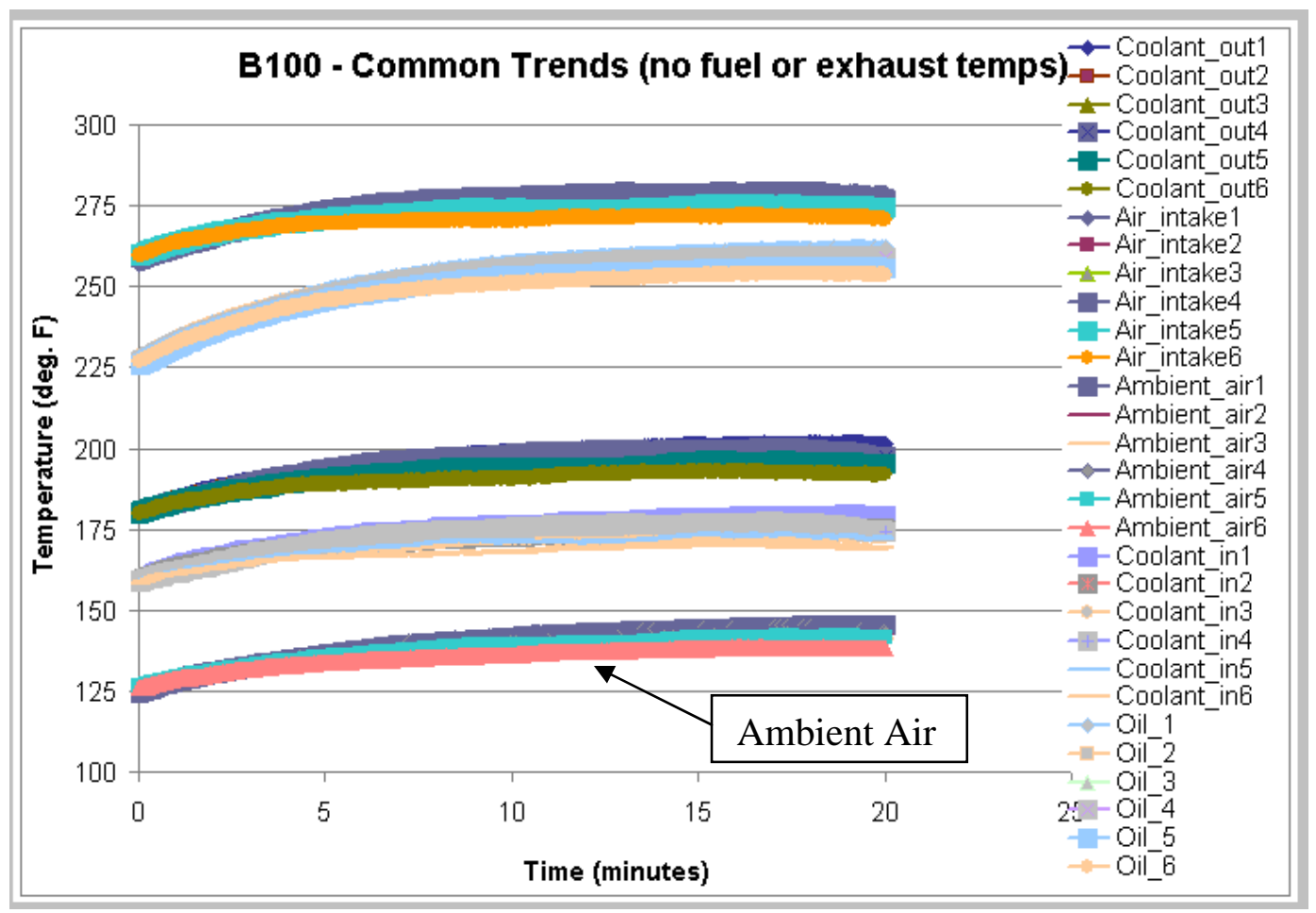

Figure 5.1: B100 temperatures (except fuel and exhaust) for 20 min. trial 
The goal of the test plan was to achieve steady-state test conditions during most of the trial. The temperatures shown in Figure 5.1 suggest that most of the measurements taken began to stabilize around the 5-10 minute mark. It is also shown that the measurements follow the same trends which were determined to be the result of the ambient air temperature (bottom data set) controlled by the environmental conditions outside the testing laboratory. The dependence the measurements had on the ambient air temperature will be shown in greater detail later in this section. The trends and measured values for the diesel fuel trials were very similar to the biodiesel trials; therefore, the diesel fuel plots are only shown in comparisons with biodiesel when needed. All temperature measurements and the mass air flow measurements (not shown) were data logged at a rate of 1 reading per second.

A closer examination of the individual measurements revealed that the values did not reach a true steady state condition and that the values were not consistent from trial to trial. Figure 5.2 shows a closer view of the engine coolant temperatures going in and out of the engine. 


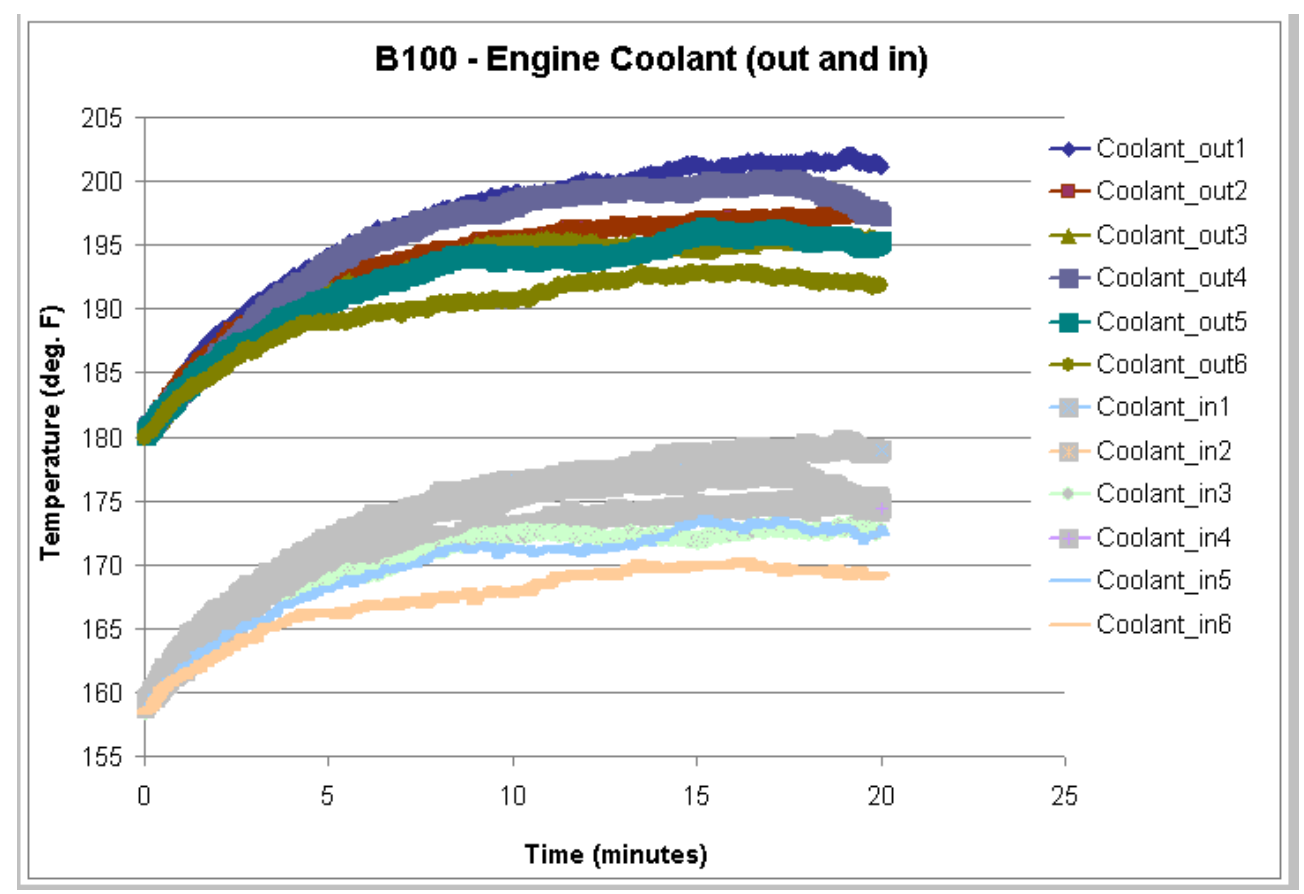

Figure 5.2: B100 coolant in and out temperatures 0-20 min.

Figure 5.2 shows that the temperature readings in most trials increased throughout but approached steady-state conditions in the later half of the trials. Additionally, the overall temperatures decreased in most cases as the number of trials progressed. The data in trial 4 falls out of place with the other trials and it shows an uncharacteristic drop in the last two minutes of testing.

\section{2) Explanation of Data Averaging}

After examining all of the data recorded in the full 20 minute trials, it was determined that the best way to analyze the results was to pick a time period based on the most consistent trial-to-trial data that could be averaged together and given an uncertainty based on a 95\% confidence interval. It was reasonable to average the data together for 
each fuel source because the data for both followed the same trends. Figure 5.3 shows the coolant data for B100 and diesel fuel respectively. They are shown on the same scales.
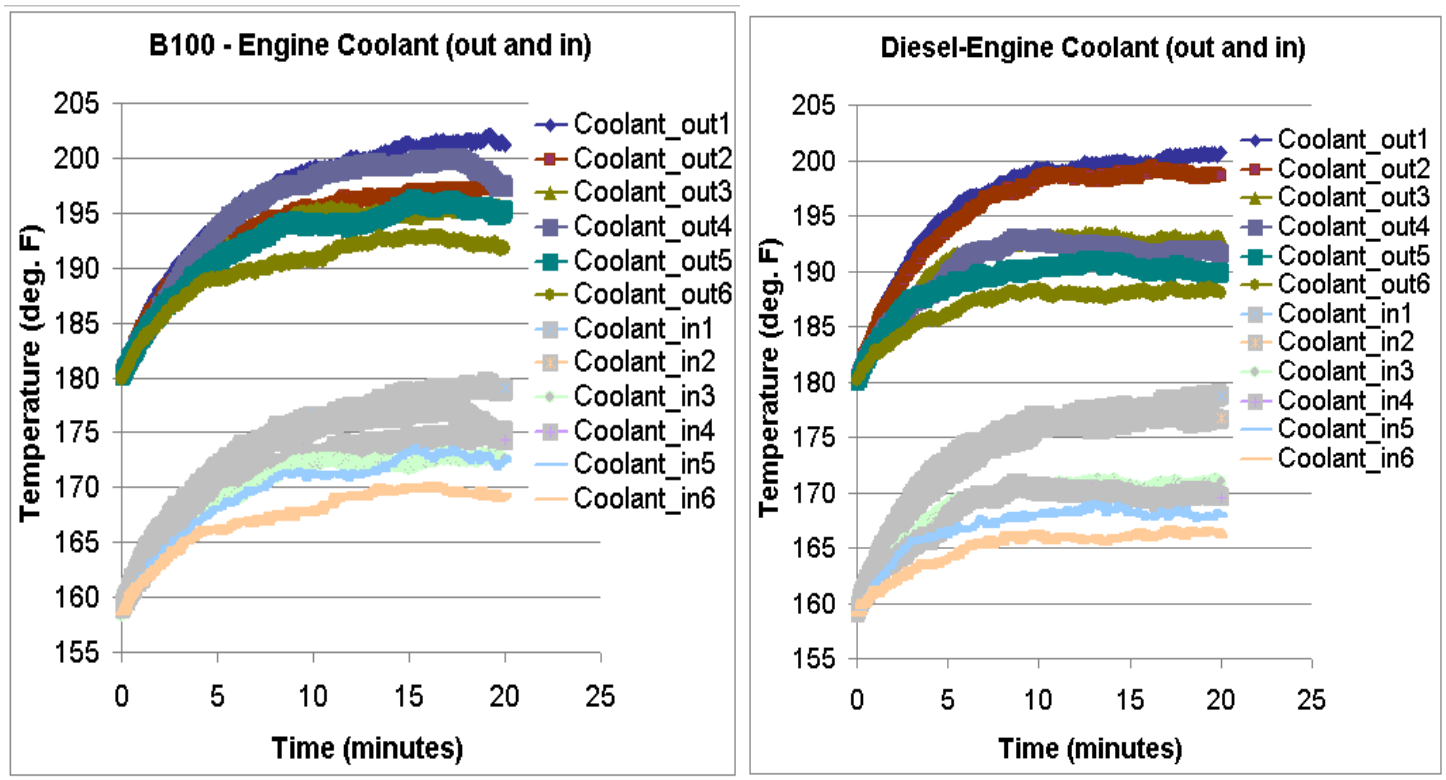

Figure 5.3: Coolant data for B100 and diesel fuel respectively 0-20 min.

As shown in Figure 5.3, both fuel sources exhibit the same trend of decreasing temperatures as the number of trials progressed. It is also shown that generally, the measured temperature values and temperature change from trial to trial correlated well between the two fuel sources. As mentioned earlier, it was discovered that these trends can be attributed to the ambient air temperature on which they are dependent. Figure 5.4 shows the correlation between the ambient air trends and the coolant measurements for B100. 

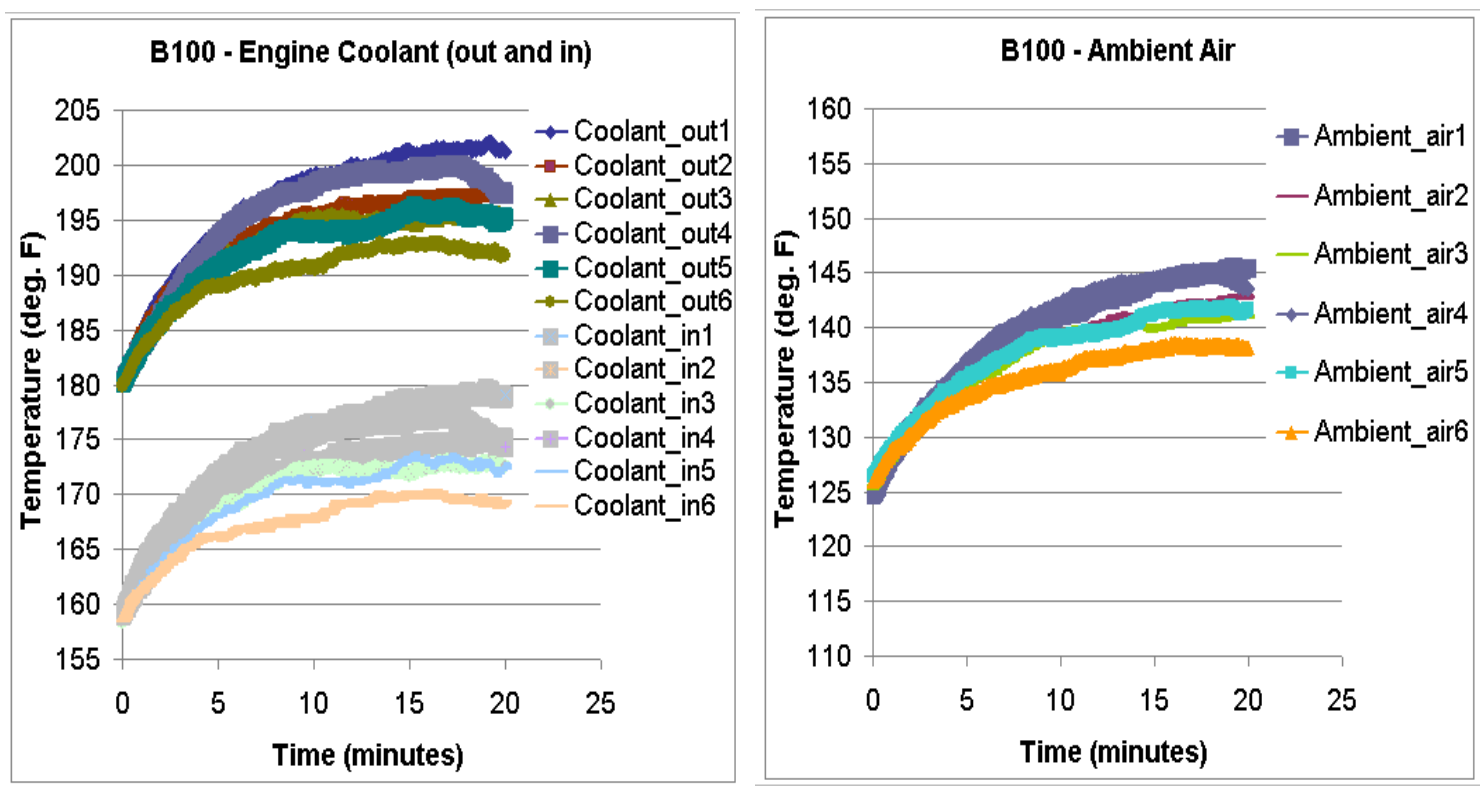

Figure 5.4: Comparison of ambient air and coolant measurements for B100 0-20 min.

Here it is shown that trends are very similar including the uncharacteristic drop in temperature in the last 2 minutes for trial 4. The ambient air data also supported the larger than normal temperature drop shown between trials 2 and 3 of the diesel coolant values shown in Figure 5.3. The ambient air entering into and surrounding the engine had a strong correlation on all of the temperatures with the exception of the fuel and exhaust temperatures.

The trial temperatures generally decreased as the number of trials increased because the ambient air temperature outside of the lab decreased throughout the evening. Since the trials were staggered between fuel sources and run with less than a 15 minute break between respective trials, this method of averaging each fuels' trials is appropriate. However, it was important to approximate the measurement uncertainty independent of 
the variability in the data due to ambient temperature. This insured that the measurement uncertainty values were developed from the actual data of the individual trials for each fuel source.

\section{3) Data Analysis}

Upon inspection of all the measurement trials for both fuel sources, it was determined that analyzing the data between 12 and 18 minutes for each trial would give consistent temperatures, small fluctuations, and an acceptable number of data points for each trial (360). Figure 5.5 shows the 12-18 minute time period selected to analyze for the same data shown in Figure 5.2.

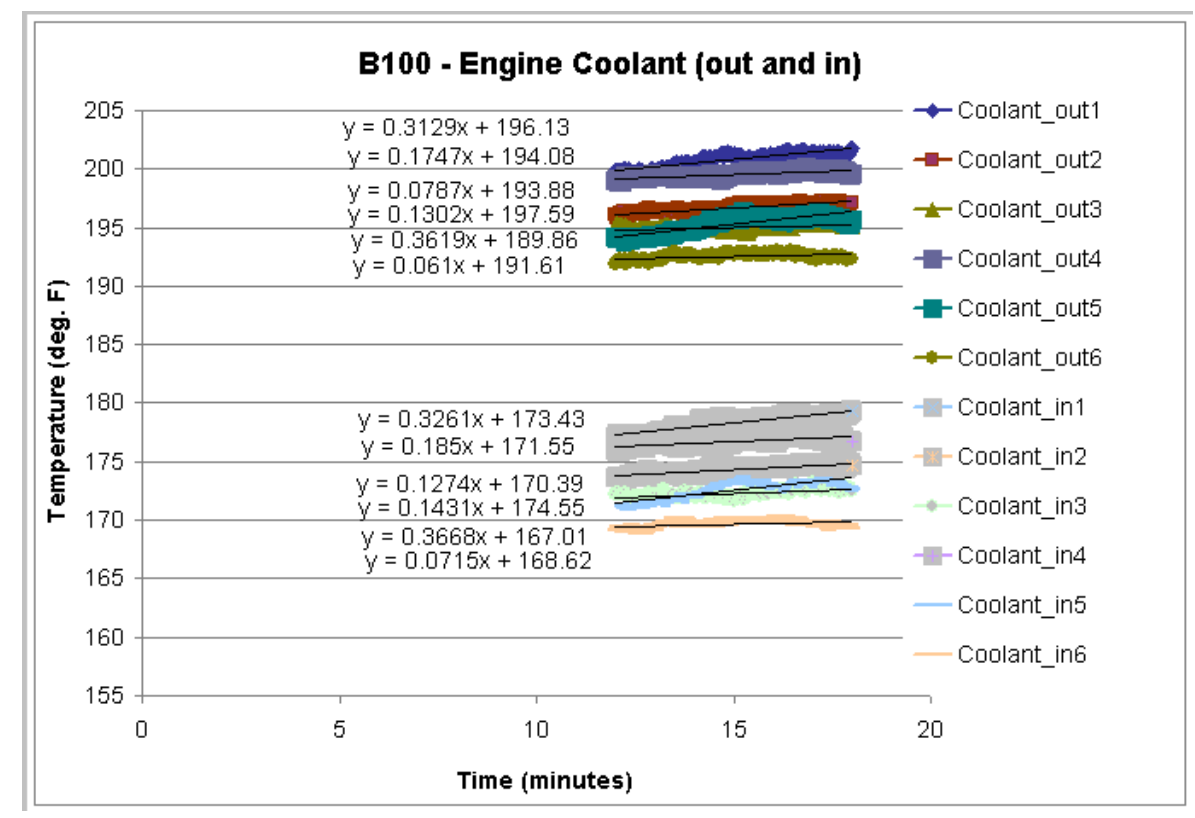

Figure 5.5: B100 engine coolant (out and in) 12-18 min. 
Due to the slightly increasing trend of the data evident in Figure 5.5, linear trendlines with their respective equations were applied. The slopes and y-intercepts were averaged to come up with a single equation for temperature as a function of time used to model the trials as a single average. The individual trendline equations also provided approximated values for the coolant temperatures as a function of time for the 6 individual trials. Linear trendlines were chosen to model the data collected for each trial because this gave more conservative estimates than a polynomial fit trendline. In order to approximate the measurement uncertainty independent of the variability in the data due to ambient temperature, the difference between the approximated and measured values for each trial were determined and the standard deviation of this difference was calculated. Then to compute the uncertainty based on a 95\% confidence interval, the average of the 6 standard deviations ( $\sigma_{a}$ ) was divided by $\sqrt{n}$ where $n=360$, and multiplied by the table value from the Student's T-distribution for 95\% confidence with 6 trials. Equation 10 shows the standard equation just described.

$$
\text { Mean } \pm \frac{\sigma_{a}}{\sqrt{n}}(2.571)
$$

All of the graphed data with trendlines, raw data and calculations for Equation 10 can be found in B100 StDev 12-18min.xls and Diesel StDev 12-18min.xls for biodiesel and diesel respectively. These are included as a supplement to the thesis along with Biodiesel.xls and Diesel.xls. 


\section{4) Engine Torque}

The B100 torque values, used for determining power output, for all 6 trials are shown in Figure 5.6. Here it is clear that the torque values steadily decreased over time. The torque values were all manually recorded off of the dynamometer readout during the trials.

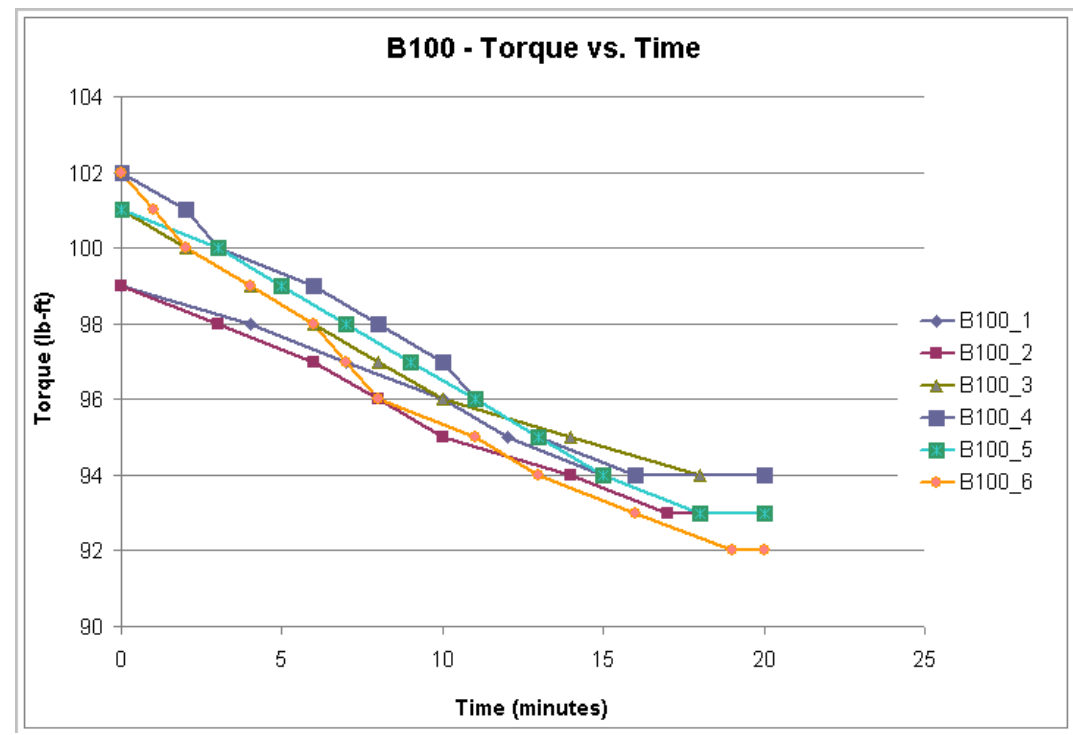

Figure 5.6: B100 torque values as a function of time 0-20 min.

In a similar fashion to the temperature values the torque data in the 12-18 minute time period was selected, and the same analysis was performed using Equation 10. Figure 5.7 shows these torque values for B100 with their linear trendlines. 


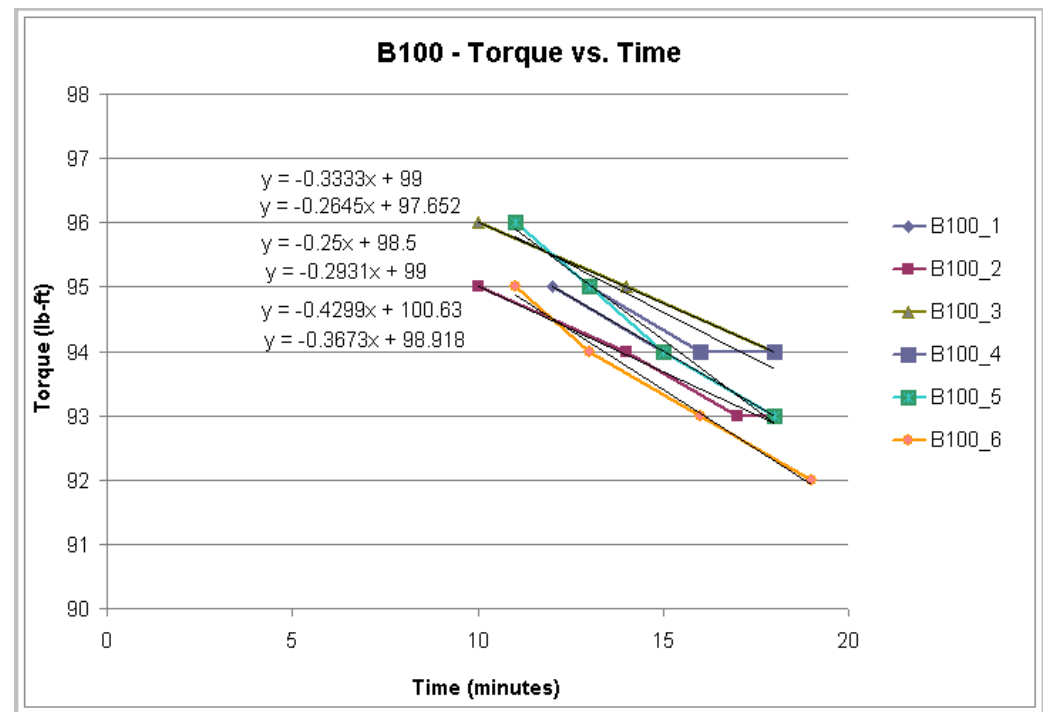

Figure 5.7: B100 torque as a function of time 12-18 min.

The raw data, calculations, and graphs for the torque and fuel consumption can be seen in the “Torques and Fuel Consumption” tab with Biodiesel.xls and Diesel.xls. 


\section{5) Fuel and Exhaust Temperatures}

Figure 5.8 shows the temperatures for the fuel supply, fuel return and the exhaust.

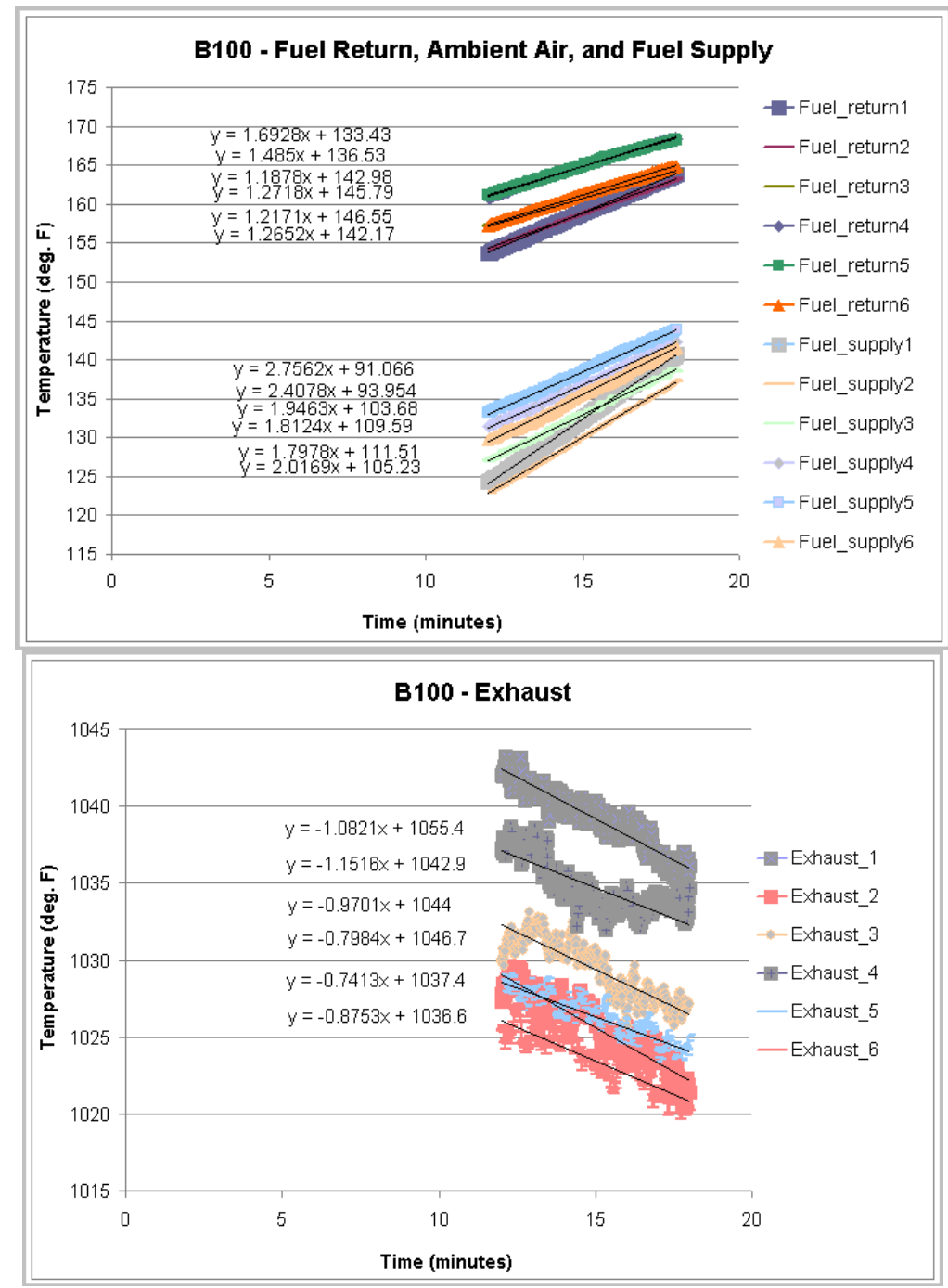

Figure 5.8: Fuel supply, fuel return, and exhaust temperatures 12-18 min.

Figure 5.8 shows that the fuel and exhaust temperatures which, as stated earlier, did not correspond with the steady-state ambient air temperature. The fuel temperatures steadily increased and the exhaust temperatures steadily decreased. The average fuel supply and 
return temperatures increased 9.5\% and 5.0\% respectively over the evaluated 12-18 minute time period shown in Figure 5.8. The exhaust changes were much less significant; the average exhaust temperature decreased $0.5 \%$ over the same time period. This is the same percentage change as all of the other temperature measurements that followed the trends of the ambient air (everything except fuel temperatures). The characteristic that sets the exhaust apart from the other measurements is the fact that the temperatures were slowly decreasing instead of increasing.

\section{6) Energy Distributions}

With all of the average measurement values and their uncertainties calculated in the “Data” tabs of Biodiesel.xls and Diesel.xls, EngineCalc was used to compute the amount of energy appropriated to the areas of power output, the engine coolant, exhaust, fuel, and intake air as well as their respective uncertainties based on the 95\% confidence measurement intervals. The values were then computed in EngineCalc between the trial time periods of 12-18 minutes at 30 second intervals. Each fuel type was therefore analyzed at 12 different time periods and the nominal energy distributions as well as their respective uncertainties were averaged and computed for final representative values.

These calculations were done in the "Final Distribution” tabs of Biodiesel.xls and Diesel.xls. 
Figure 5.9 shows the results of the relative energy distribution for biodiesel and diesel fuels.

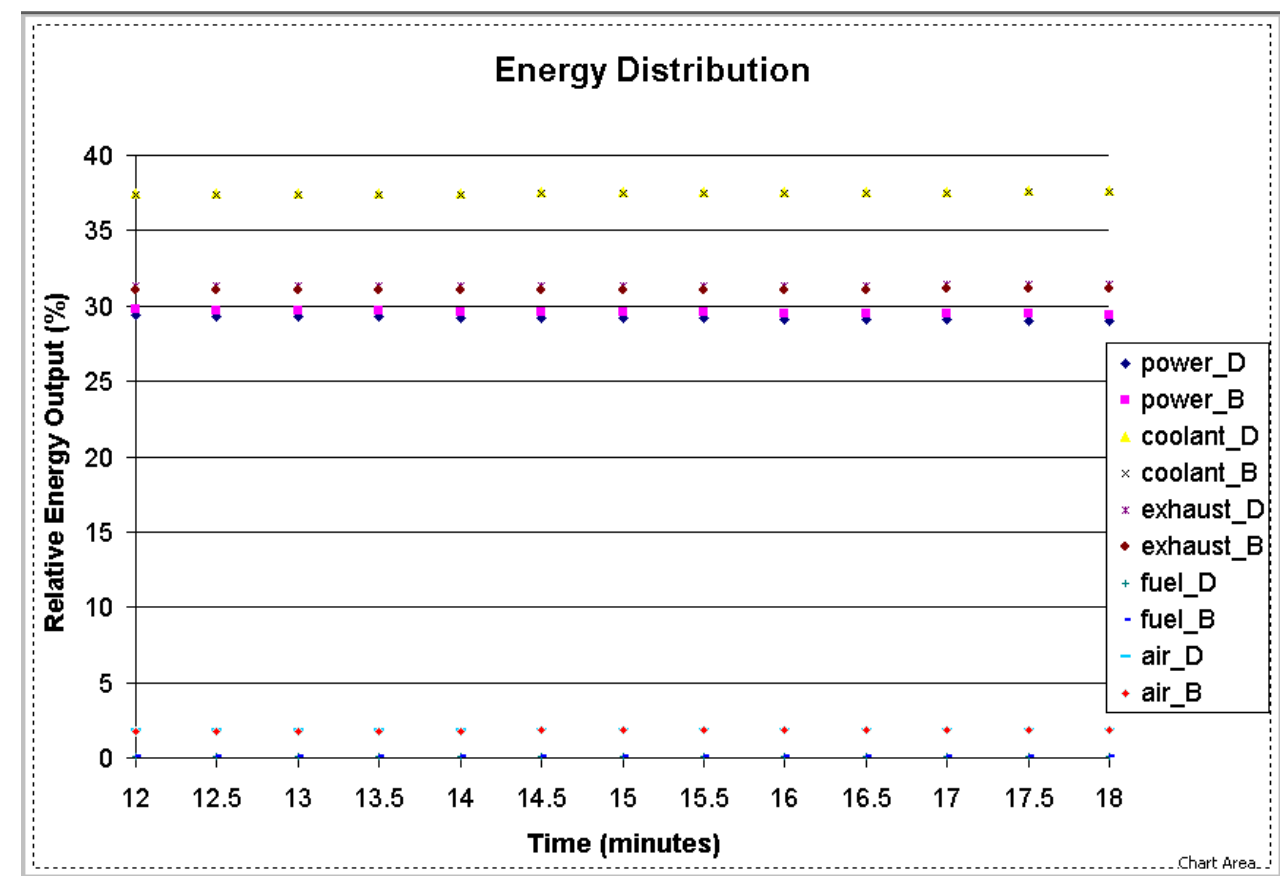

Figure 5.9: Relative energy distribution-power, coolant, exhaust, fuel, and air 12-18 min.

From Figure 5.9 it appears that the values between the two respective fuels are very close because the points are overlapped. It also shows that the energy transferred to the fuel and ambient air is very small compared to the power, coolant, and exhaust. It should be noted that each point shown on the graph represents the energy distribution of its respective area for the "snap shot in time" period shown. These points were computed using the average trendline evaluated every 30 seconds throughout the 6 minute time period. The same holds true for figures $5.10-5.12$. 
Figure 5.10 shows a closer look at the significant areas of energy distribution: power, coolant, and exhaust.

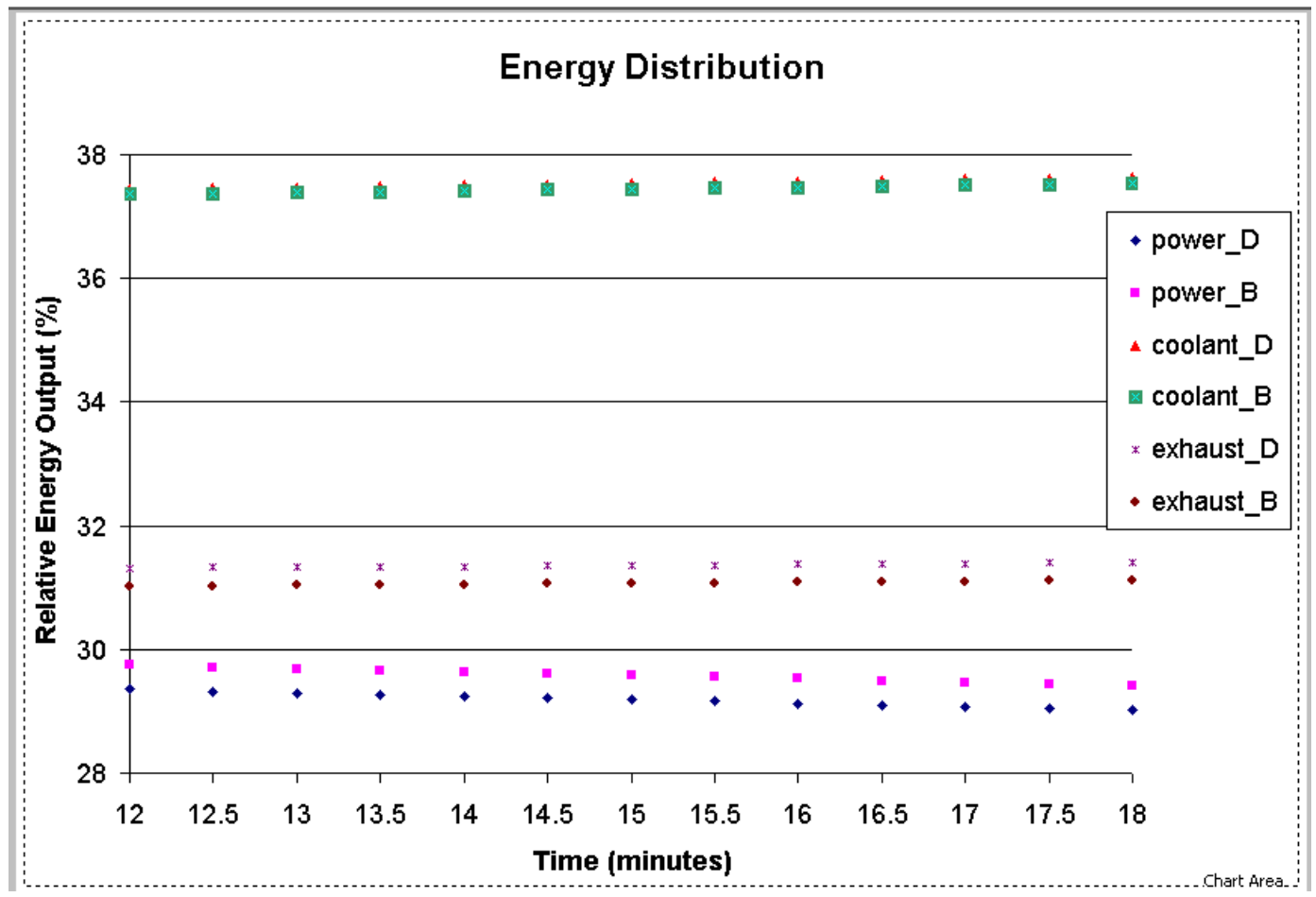

Figure 5.10: Relative energy distribution of power, coolant, and exhaust 12-18 min.

Figure 5.10 shows that the relative energy distributions for the coolant are very similar but it also indicates that there is a measurable difference between the exhaust and power losses of the different fuels. 
Figure 5.11 is a closer look at the biodiesel and diesel relative energy outputs as a function of time for the power and exhaust.

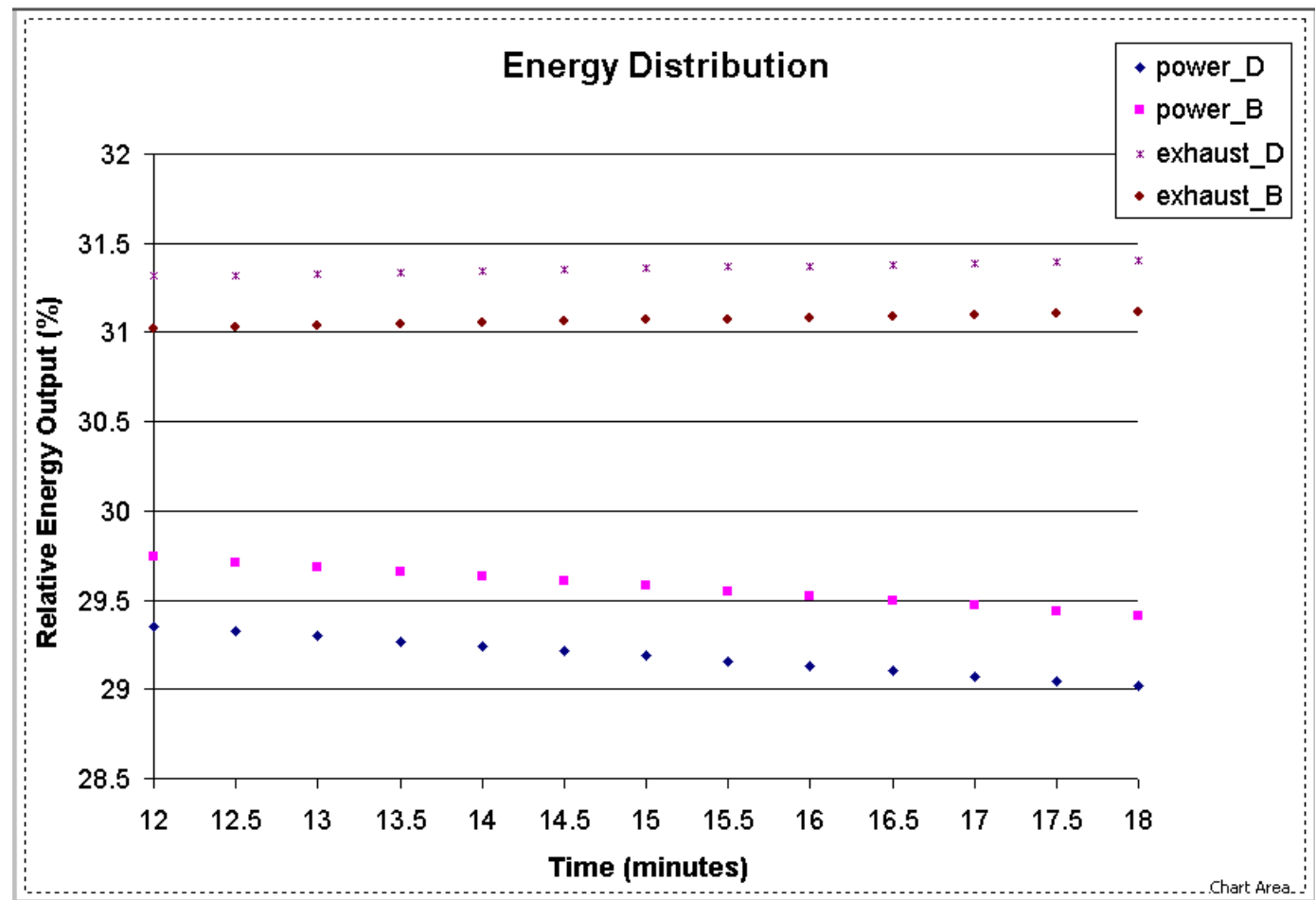

Figure 5.11: Relative energy distribution of power and exhaust 12-18 min.

Figure 5.11 shows that there is a small $(<0.5 \%$ difference) but measurable difference between the power and exhaust energy losses between biodiesel and diesel fuel. It also shows that the amount of energy transferred into power output decreased over time and the energy transferred to the exhaust increased over time. 
Figure 5.12 shows the same results as Figure 5.11 with the addition of the final uncertainty values for this data.

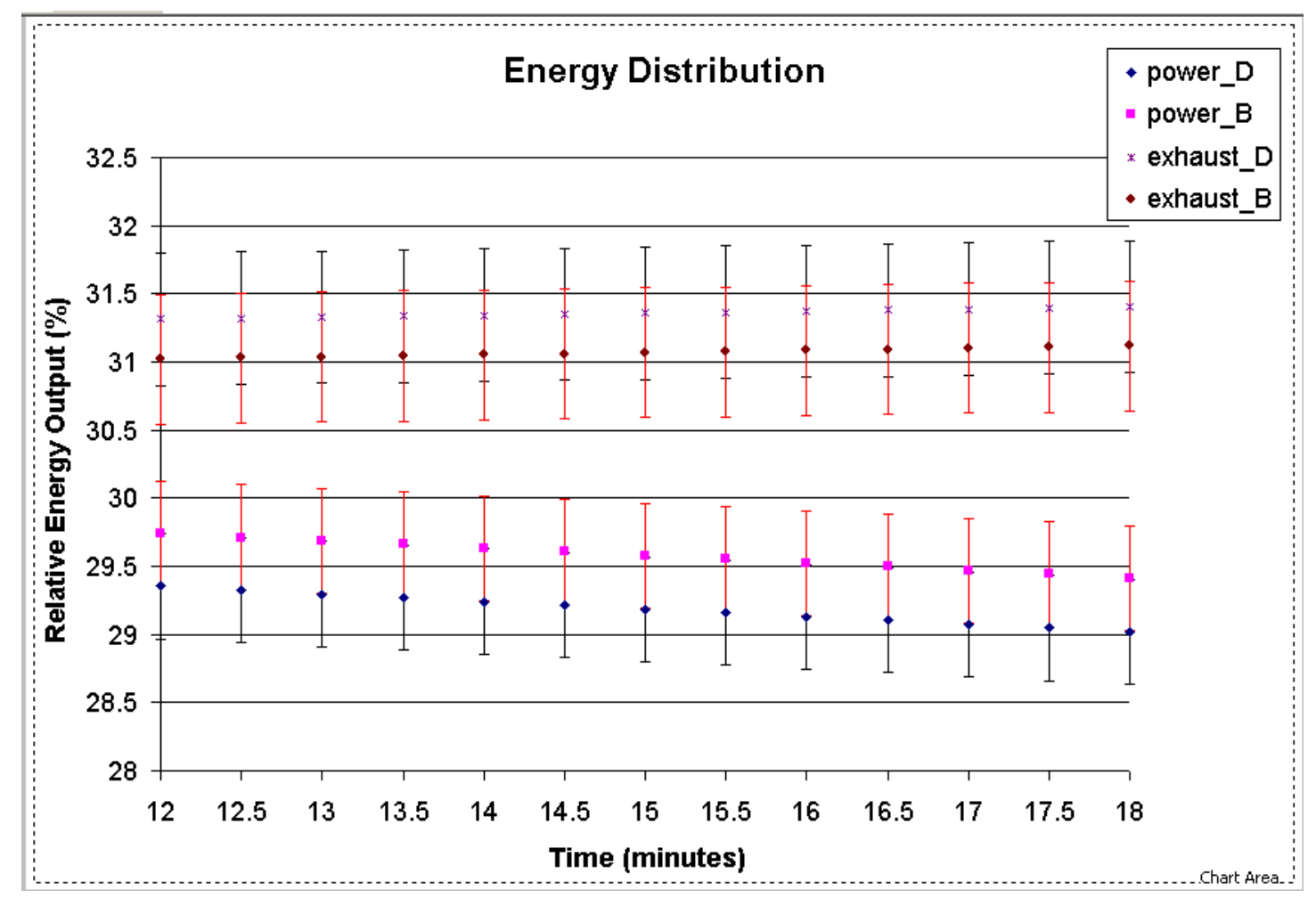

Figure 5.12: Energy distribution of power and exhaust 12-18 min. (with error bars)

Figure 5.12 shows that the error bars, representing the total uncertainty values for this data, do overlap. 
Figure 5.13 shows the comparison between the average values of the relative energy distribution between B100 and diesel fuel.
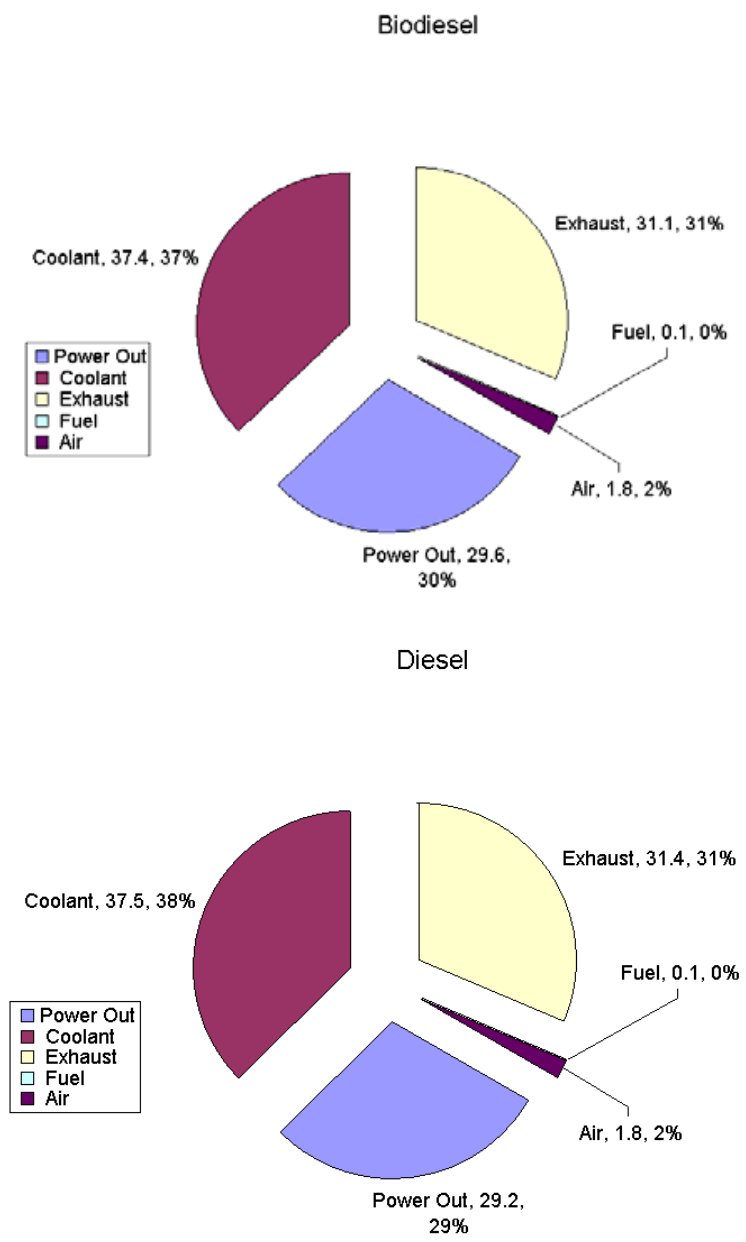

Figure 5.13: Comparison of relative energy distribution between biodiesel and diesel fuel 
Table 5.1 shows the relative energy distribution values from Figure 5.13 with their respective uncertainties.

Table 5.1: Relative energy distribution values and uncertainties

\begin{tabular}{|l|r|l|l|}
\hline B100 & $\begin{array}{c}\text { Distribution } \\
\text { (\%) }\end{array}$ & \pm & $\begin{array}{l}\text { Uncertainty } \\
\text { (\%) }\end{array}$ \\
\hline $\begin{array}{l}\text { Power } \\
\text { Out }\end{array}$ & 29.6 & & 0.39 \\
\hline & & & \\
\hline Coolant & 37.4 & & 1.36 \\
\hline & & & \\
\hline Exhaust & 31.1 & & 0.48 \\
\hline & & & \\
\hline Fuel & 0.1 & & 0.01 \\
\hline & & & \\
\hline Air & 1.8 & & 0.18 \\
\hline
\end{tabular}

\begin{tabular}{|l|r|l|l|}
\hline Diesel & \multicolumn{1}{|c|}{$\begin{array}{c}\text { Distribution } \\
\text { (\%) }\end{array}$} & $\mathbf{\pm}$ & $\begin{array}{l}\text { Uncertainty } \\
\text { (\%) }\end{array}$ \\
\hline $\begin{array}{l}\text { Power } \\
\text { Out }\end{array}$ & 29.2 & & 0.38 \\
\hline & & & \\
\hline Coolant & 37.5 & & 1.37 \\
\hline & & & \\
\hline Exhaust & 31.4 & & 0.49 \\
\hline & & & \\
\hline Fuel & 0.1 & & 0.01 \\
\hline & & & \\
\hline Air & 1.8 & & 0.19 \\
\hline
\end{tabular}

From Table 5.1 we find the difference between the biodiesel nominal values and the diesel nominal values are: $0.4 \%,-0.1 \%$, and $-0.3 \%$ for power out, coolant, and exhaust respectively. 
Table 5.2 shows the amount of energy that was accounted for based on the known amount of energy input from the fuel sources used.

Table 5.2: Energy distribution based on input energy

\begin{tabular}{|c|c|c|}
\hline & \% of total energy & \\
\hline & B100 & Diesel \\
\hline Energy In & 100.0 & 100.0 \\
\hline & & \\
\hline Power Out & 29.5 & 29.1 \\
\hline Coolant & 37.4 & 37.5 \\
\hline & & \\
\hline Exhaust & 31.0 & 31.3 \\
\hline & & \\
\hline Fuel & 0.1 & 0.1 \\
\hline & & \\
\hline Air & 1.8 & 1.8 \\
\hline & & \\
\hline & Unaccounted & Unaccounted \\
\hline & 0.1 & 0.1 \\
\hline
\end{tabular}

Note: Uncertainties for measurements are over $5 \%$ due to uncertainties of fuel energy 


\section{Chapter 6: Conclusions}

This chapter will focus on conclusions that were able to be made based on the results and any future work that should be done in accordance with them. Also, the goals and objectives that were outlined in chapter 1 will be discussed to show how well the work in this thesis met the expectations.

\section{1) Test Condition Conclusions}

The results in chapter 5 show that goal of achieving true steady-state values for all measurements taken throughout each trial was not achieved. This is evident from Figure 5.1 showing most of the temperature measurements and how they quickly approach but do not reach a true steady-state condition for the majority of the trials. The results show that the goal of maintaining constant environmental conditions in the testing laboratory, particularly the ambient air temperature, was not feasible. The correlation between the ambient air temperature and other measurements is shown closer in Figure 5.4. The ambient air temperature did not reach steady-state values quickly due to the lack of cool, outside air flow through the room. The circulation fans in the room helped to distribute the hot air, but the overall temperature continued to slowly increase because doors to the laboratory were at the opposite end of the room. Since there is only one opening to the room, an adequate draft never developed to remove hot air. The conclusion was that the laboratory's insulative qualities were too high for the ambient air temperature, and 
therefore most other temperatures, to reach steady-state values throughout the majority of each individual trial.

The second conclusion that can be made about the ambient air temperature in the lab during each individual trial was that it was dependent on the outside air temperature. Figure 5.2 shows how the average temperature for each trial usually decreased as the number of trials progressed. It was concluded that this was the result of the outside air temperature dropping throughout the evening that the trials were performed on. The 10$15^{\circ} \mathrm{F}$ temperature drop seen throughout the course of the 6 trials for each fuel source was consistent with the ambient air temperature change outside of the testing laboratory.

Looking at Figure 5.3 it appears as though the temperatures for the diesel fuel did reach steady-state conditions in trials 3-6, halfway through the trials. This suggests that the outside air temperature was low enough to maintain stable engine temperatures despite the poor air circulation. This indicates that the balance between the amount of energy released in the form of heat form the engine and the cooling capabilities of the lab were the same for those parts of the diesel trials. The reason that the same trend was not shown with the biodiesel is that the results from EngineCalc show the biodiesel trials released $2.5 \%$ more energy than the diesel trials. This is consistent with temperatures for those biodiesel trials staying about $4^{\circ} \mathrm{F}$ (or $\sim 2.5 \%$ ) higher than those of the steady-state diesel trials. This is the result of slightly different energy inputs that were not completely offset by the throttle position adjustments for diesel fuel outlined in chapter 4 . 


\section{2) Energy Distribution Conclusions}

The results of the relative energy balance comparison that were modeled at 30 second intervals throughout the analyzed (12-18 minute) time period are shown in Figures 5.95.12. Figure 5.9 shows that of the 5 distribution areas (power out, coolant, exhaust, fuel, and ambient air), the power output, coolant, and exhaust losses are the areas to focus on for finding definable differences between the two fuel sources because over $98 \%$ of the total energy losses measured fell into these 3 areas. Figure 5.10 shows that of these 3 areas, the distinguishable measured differences in energy appropriation were seen in the power output and exhaust which are shown in greater detail in Figure 5.11.

Figure 5.11 helped conclude that the measured differences in energy appropriation between the two fuel sources stayed relatively constant throughout the analyzed portion of the trials. This is evident by the consistent gaps between the data of respective fuel sources for the power out and exhaust. Similarly, these trends were found, but not shown, in the evaluated data for the other areas of energy appropriation. These nonconverging trends add validity to the final values for energy appropriation which are averaged from these results.

Figure 5.11 also shows that the percentage of total energy measured in the system was decreasing for the power output of the engine at a rate of $0.055 \% /$ minute for both fuels. For the exhaust, this rate was increasing at rates of 0.017 and $0.013 \% /$ minute for 
biodiesel and diesel, respectively. These trends indicate that the relative energy distribution for an engine will vary a small amount at different times depending on the variations in operating conditions. However, since the changes are so small, the averaged energy distribution values reported should represent the performance of this particular engine well. It should also be noted that, since these energy distribution rates were evaluated under consistent operating conditions between fuel sources, the comparative values of the data was not compromised.

Figure 5.12, showing the same data as Figure 5.11, includes the error bars representing the total uncertainties associated with these measurements. The error bars for the power out extend to points just shy of the nominal values of the other fuel source. For the exhaust, the error bars extend beyond the nominal values of the other fuel source. In both cases, the error bars, for each fuel type, clearly overlap. This implies that there is not a statistically significant difference between the two sets of data and that it is not possible to discern between the measurements with a 95\% level of confidence. Table 5.1 shows the relative energy distribution numerical values and uncertainties for all 5 areas of energy distribution.

Looking at the uncertainty values from Table 5.1 for the measurements of the power out, coolant, and exhaust, the only value that met the desired level of accuracy was the exhaust. The goal (stated in Chapter 4) was to determine the percentage of energy transferred throughout the system with power, coolant, and exhaust uncertainties of 
$0.25 \%, 0.50 \%$, and $0.50 \%$ respectively. The uncertainties for the power out and coolant were close but did not reach the target values. It can be concluded from the uncertainty analyses that the final coolant uncertainty would have been below the targeted value if multiple flow meter measurements could have been logged throughout the experiment. This was a known fact but, due to budget restrictions, a flow meter without data logging capabilities was purchased. The final power uncertainty was just slightly higher than the target value of $0.25 \%$. The uncertainty analysis showed that with the improvements to the coolant uncertainty, the target power uncertainty would be achieved. This is due to the dependence that the power uncertainty has on the total uncertainty of the areas of energy distribution. For this reason, no changes need to be made to the equipment for measuring the engine torque or speed that is used to calculate power output.

The results of the work in this thesis show that meeting the target uncertainty values would not have been sufficient to accurately distinguish measurable differences between the relative energy distributions of the power out, coolant, and the exhaust for the 2 different fuel sources. The relative energy distribution differences calculated for the two fuels were much smaller than the benchmarked values shown from the work of Canakci and Hosoz (2006). Figure 6.1 shows the comparison of the result in this thesis with the results of Canakci and Hosoz (2006). 
Biodiesel
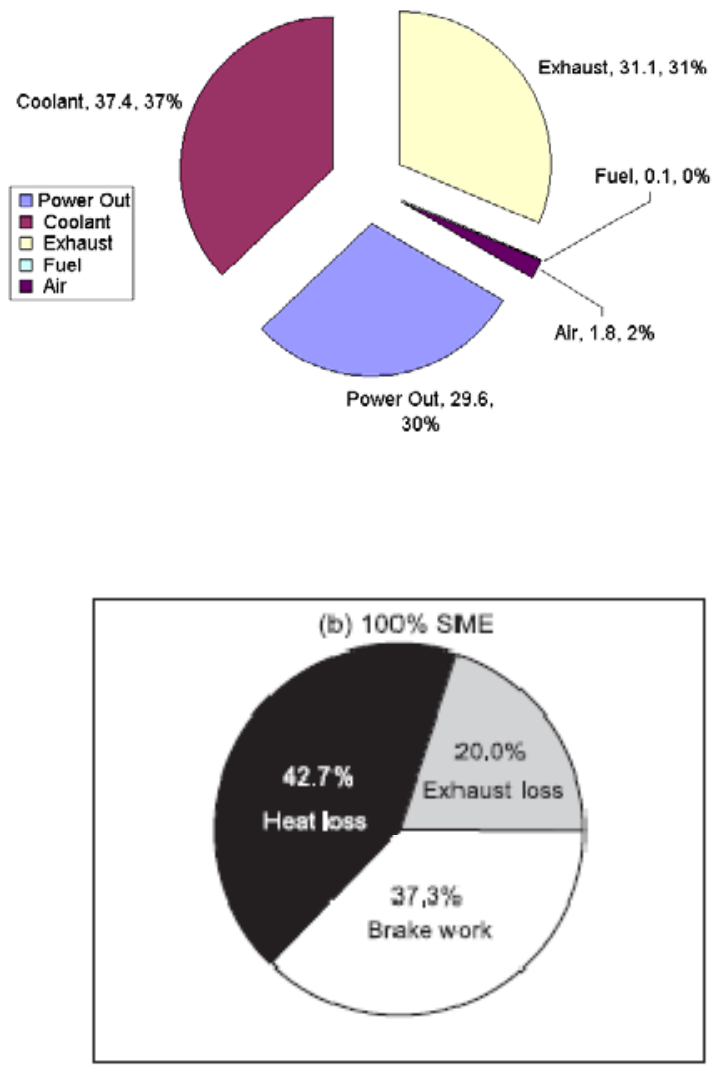

Diesel

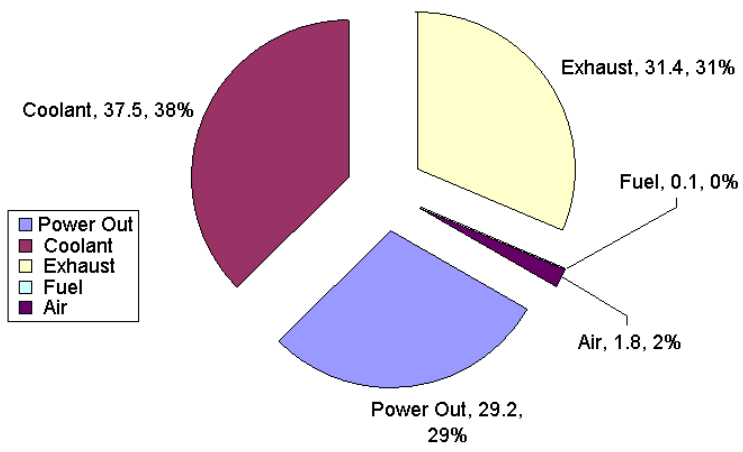

(a) No. 2 diesel fuel

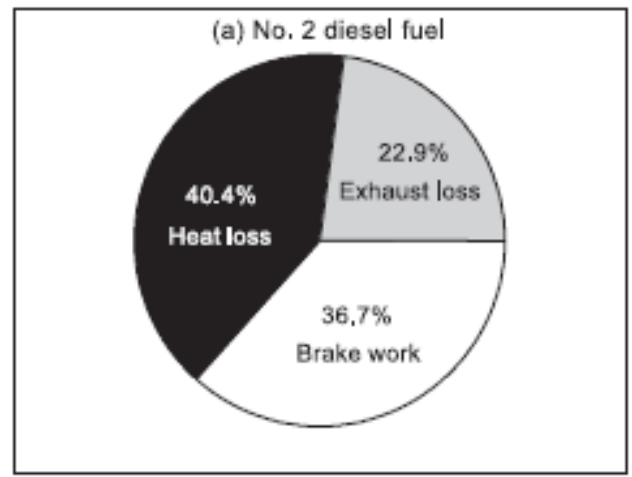

Figure 6.1: Comparison of thesis results (top) to Canakci and Hosoz (2006) results

Our results from Figure 6.1 show that the difference between the biodiesel nominal values and the diesel nominal values are: $0.4 \%,-0.1 \%$, and $-0.3 \%$ for power out, coolant, and exhaust respectively. Canakci and Hosoz (2006) results show that the difference between the biodiesel nominal values and the diesel nominal values are: $0.6 \%, 2.3 \%$, and $-2.9 \%$ for brake work (power out), heat loss (coolant and all other losses), and exhaust respectively. Since the fuel types and testing procedures were the same, these were the expected ranges for energy distribution differences that the test apparatus was designed to 
measure. Rather than trying to improve the measurement equipment accuracies, further tests should be run with all of the recommendations made in this chapter (especially section 6.3) to determine if the relative energy distribution differences fall into the measurable range of this testing system.

Figure 6.1 also shows notable differences in the distribution of the input energy between the two energy balance studies. It is not surprising that Canakci and Hosoz (2006) found a higher percentage of input energy transferred into brake work because the engine they used had a direct injection fuel system known to be more efficient. It also had a 98\% larger displacement, it made $27 \%$ more power, and it ran at $25 \%$ lower speeds. All of these characteristics traditionally found in larger engines, increase efficiency. The engine used in this thesis is designed to be power dense (small and light weight) but not extremely efficient. Canakci and Hosoz (2006) also probably saw much lower exhaust losses because of their higher efficiency engine. During an efficient combustion, there is a more homogenous temperature distribution throughout the combustion chamber. This results in more heat transferred through the cylinder head and cylinder walls and fewer “hot spots” resulting in high-temperature, uncombusted products being carried out through the exhaust. Canakci and Hosoz (2006) had slightly higher "heat losses” which is what they call all energy that was not measured at the engine crankshaft or through their exhaust. This value makes sense because additional heat transferred to the cylinder head and cylinder walls will be transferred to the engine coolant which has passages 
surrounding these areas. Their losses to the fuel and from ambient air are also lumped into this category.

Considering the likely efficiency differences between the two engines from which the data in Figure 6.1 was taken, the individual fuel's distribution values for the tests in this thesis seem very believable. Additionally, it supports the claims of Sharma and Jindal (1989) that, "Energy balance for a direct injection diesel engine shows that about onethird of fuel energy input is lost to environment through heat transfer, another third is wasted as exhaust heat and only one-third is available as shaft work”. Based on this claim, one would expect the efficiency and, therefore available shaft work, to be slightly lower than one-third for an indirect injection diesel engine, which is our case. Finally, the results from Table 5.2 indicate that based on the energy content values for the respective fuel sources, the energy balance testing system accounted for over $99.8 \%$ of the energy that got transferred within the system. While these values had uncertainties of over $5 \%$ due to a lack of information about the fuel sources used, it does indicate that the system is operating in accordance with other existing energy balance testing systems.

For Table 5.2, the energy input or LHV for biodiesel and diesel fuel were 16073.7 and 18331.6 BTU/lb. The brake specific fuel consumption (BSFC) as defined by Canakci and Hosoz (2006) is "the ratio of the fuel mass flow rate to the engine power output". The BSFC for the biodiesel used in this thesis was $12.2 \%$ higher than that of diesel. This means that it took $12.2 \%$ more biodiesel than diesel to make the same amount of power. 
That value makes sense because the LHV of the biodiesel was $12.3 \%$ lower than the LHV of diesel fuel. Despite the uncertainty in the LHV of both fuels, this helps validate the claim that BSFC "is inversely proportional with the lower heating value of the fuel” (Canakci and Hosoz 2006).

\section{3) Conclusions Suggesting Improvements to the Test Procedure and Apparatus}

The ambient air temperature conclusions suggest future improvements to the laboratory and/or the test plan. To keep the temperatures more consistent throughout a single trial, a better source of outside air should be supplied. To keep the average temperatures of all the trials closer together they should be tested when the outside air temperature is not changing. One other consideration would be placing an in-line air heater with a feedback controller on the engine's air intake to keep those temperatures constant. Finally, if the air ventilation or heater addition can not be achieved, running tests with outside air temperatures below $55^{\circ} \mathrm{F}$ and lowering the energy inputs by reducing the engine speed or changing throttle positions should help. $55^{\circ} \mathrm{F}$ is about the temperature outside the lab by the end of the tests for this thesis when steady-state readings were shown to be achievable.

Figure 5.7 shows the steady decrease in torque as a function of time analyzed for the energy balance comparison. The average torque values for diesel and biodiesel decreased 2-3\% over this time period. If all other variables were kept constant during the test, one would expect the torque values to be consistent. Since the other variables did 
not stay constant during testing, a change in torque is not surprising. However, this percentage decrease in torque is on the order of about 5 times as large as the increases seen in the ambient air and its other dependent temperatures (shown in Figure 5.1). The torque output is the result of forces acting on the pistons producing crankshaft rotation which is measured by the dynamometer. These forces are caused by the combustion of fuel and intake air in each engine cylinder’s combustion chamber.

It seems possible that the torque output would decrease as intake air temperatures increased because warmer air is less dense and therefore contains less oxygen necessary for complete combustion of the fuel. Since diesel engines rely on compressing air to high pressures and temperatures to ignite injected fuel, higher intake air temperatures could also change the ignition delay times. Ignition delay is the amount of time between the injection of fuel and the start of combustion. Changes in ignition delay will affect the time at which the fuel starts to burn and the rate that heat is released. This could change the efficiency of the combustion process causing changes in the torque output. The optimum injection timing is determined and set by the manufacturer to account for combustion characteristics, such as ignition delay, based on the fuels and operating conditions (temperatures, air densities, etc.) they predict the engine will be used in. It can be concluded that the intake air temperatures were too high for peak efficiency to be reached due to the magnitude of our ambient air temperatures $\left(140^{\circ} \mathrm{F}\right)$. 
Looking at the large (9-10\%) increase in fuel supply temperatures as well as the 5\% increase in fuel return temperatures from Figure 5.8, it can be concluded that, like air, the fuel density (energy density) is lower at increased temperatures. Temperature also affects fuel viscosity which can impact combustion processes due to injection characteristics like spray tip penetration and fuel atomization. It was determined that the refueling procedure partially affected the fuel temperatures because the amount of fuel remaining in each tank differed from trial to trial. Adding additional (cool) fuel to each (warm) tank instead of completely replacing the fuel from our main supplies did not produce consistent temperatures at the start of each trial. Additionally, the surface the fuel tanks were placed on between tests transferred different amounts of heat. Placing the tanks on the cool concrete floor removed more heat from the tanks than the wooden bench top. It is recommended to modify the refueling procedure for future testing based on these findings.

Looking at the correlation between the fuel and air properties on the torque output, it suggests trying to control and monitor the sensitivity these products have on the torque output in the future. There is much more room for improvement with the fuel based on the consistency issues as well as larger temperature changes during the trials as mentioned earlier. Estimations of the air to fuel ratio indicate values of about 20:1 for biodiesel and 23:1 for diesel fuel. This shows that the air is the dominant presence in the combustion process but the fuel contains much more energy so its variation may have the largest impact on the torque output. The air to fuel ratios had to be estimated by the mass 
air flow rate given by the engine manufacturer because the mass air flow sensor on the engine did not work properly during testing.

In the future, these mass air flow values need to be measured for the trials of each fuel source to be able to make stronger conclusions about the sensitivity of air properties on torque output. Also, the procedure for monitoring the fuel flow rate needs to be improved because the flow rate was based on the weight change of fuel in the tank over the 20 minute trial. The weight values were only recorded at the beginning and end of the trial which give a very accurate average fuel flow rate for the trial, but it does not show any variations in the flow rate throughout the trial which could have changed based on density and viscosity changes from the increasing fuel temperatures. Multiple scale readings recorded in the future will produce precise fuel consumption results at any point during a trial. This will aid in drawing more accurate conclusions about fuel injection and combustion characteristic that may vary between diesel and biodiesel fuels. The scale does have an RS-232 port may be able to be linked to a computer for data logging.

\section{4) Achievement of Goals and Objectives}

The purpose of this section is to show how well the goals and objectives that were outlined in chapter 1 met the expectations.

The purpose of performing an energy balance or energy appropriation study on a compression ignition or "diesel” engine was partially achieved by accomplishing the 
main deliverable tasks of: preparing the available lab space, acquiring an appropriate diesel engine power unit, securely mounting the engine to the laboratory floor, developing a suitable coupling system from the engine to the dynamometer, and making a safe exhaust system to exit the building. The details of these deliverables have been described throughout this thesis and in general they were all implemented successfully.

The only issue with this base testing system is a vibration issue when the engine is running at speeds below 1200 RPM. It was determined that this is the result of a natural resonance frequency of the system and was something anticipated but the speed range affected was not known until it was run on the dyno. For this reason, future testing must be performed at speeds above 1200 RPM.

Building the test apparatus described in chapter 3, in accordance with the benchmarked systems, was an achieved goal towards understanding energy transfer through the diesel engine. The calculations performed in EngineCalc verified equipment selections were suitable for the desired measurement accuracies. The final step in understanding how energy got transferred through the engine was performing the research defined by the developed test plan in chapter 4 and analyzing the results. Both of these goals were successfully achieved.

This testing apparatus was developed as a platform for future testing of algal based biodiesel fuels. In order to determine the functionality of the system the energy balance 
need to be performed. The results and conclusions discussed earlier in this chapter indicate that the system is functional for performing energy balance studies to the level of the reported uncertainty values for each area of energy appropriation. It was also concluded from the energy balance study, that the engine is distributing input energy from the fuel into other areas of the engine in appropriate quantities verified by other benchmarked studies.

Although the energy balance did aid in validation of the diagnostic system's functionality, it did not achieve the objective of showing the difference between energy appropriation characteristics of biodiesel and diesel fuels. The system was very close to meeting the targeted uncertainty values for the different areas of energy appropriation and factors for reducing these uncertainties to values under those targeted were clearly identified. However, the primary reason that distinguishable differences in energy appropriation between fuel sources were not achieved was that the calculated results showed much smaller differences than the benchmarked values the system was designed for. It has been concluded that future tests with the suggested improvements to the test plan and test apparatus might yield discernable differences in energy appropriation between biodiesel and diesel fuel without any major redesign of the system. Until discernable differences in energy appropriation are made between biodiesel and diesel fuels at a high confidence interval, the theories on combustion and soot radiative heat transfer differences, identified by section 2.3, can not be adequately supported. Despite our inability to support some of the more complex combustion theories, the work in this 
thesis certainly adds validity to the belief that biodiesel fuel offers similar energetic performance to that of petroleum diesel fuel.

Finally, I feel the objective of learning how to develop a controlled and instrumented energy measurement system was achieved as evidenced by performing the literature review, designing the test plans and apparatus, and completing the research with it. It has been an enlightening and humbling experience. 


\section{Chapter 7: Future Work}

The work involved with this thesis is intended to be a starting point for future algal biodiesel research. The results and conclusions that have been made for the soy-based biodiesel used in this research are intended to be a starting point for algal-based biodiesel. Due to the limited availability, it would not be possible to perform the research done in this thesis with algal biodiesel. The necessary system improvements found as the result

of the work done in this thesis have all been identified in Chapter 6. These improvements should be implemented and validated before algal biodiesel is tested. This will insure that valuable algal biodiesel is not wasted.

An inverse relationship of the exhaust and ambient air temperature changes during the trials was noticed. It wasn't clear if this inverse relationship was a related directly to the ambient air or if it was partially dependent on the decreasing torque values. Due to this uncertainty, monitoring the exhaust temperature trends would be valuable in the future. In addition to this, some emission testing equipment is scheduled to be added to the diagnostic testing system. Monitoring exhaust gas constituents might aid in understanding both the exhaust temperature trends as well as energy losses through the exhaust. Looking at differences in emissions also helps draw conclusions on combustion characteristics for different fuel sources that can not be monitored based on appearance, pressure, or temperature distributions. Sampling the exhaust gas for NOx, CO, and unburned hydrocarbons would add value to the systems ability to link emissions 
characteristics of different fuels to theories about combustion developed from the energy balance results.

The energy balance diagnostic testing system was outfitted with a thermocouple for recording crankcase oil temperatures. These temperatures were recorded during testing but no analysis was done with the data. The losses to the lubricating oil were accounted within the engine coolant because of an external oil cooler using engine coolant as the cooling media. However, future testing of lubricating oil temperatures or analysis of the data already recorded could be done to determine if there is any indication of frictional differences between fuel sources used. Further analyses could be done using different types of lubricating oils to get indications of lubricating abilities of oils.

Finally, running an energy balance test in the future (with all improvements to the system implemented) on diesel fuel only could give a good indication of the system's functionality. The reason for this is that Cummins has energy balance measurements listed at its peak power and torque values for diesel fuel only. Running tests with the modification to the current test plan of a single fuel (diesel) and throttle position set at wide open should give good comparable values. The testing conditions from Cummins are given so that would also give an indication of possible differences in obtained results. 


\section{References}

Abdelghaffar, Waleed A., Mohamed N. Saeed, Mohsen M. Osman, and Abdelfattah I. Abdelfattah. "Effects of coolant temperature on the performance and emissions of a diesel engine." American Society of Mechanical Engineers, Internal Combustion Engine Division (Publication) ICE. vol. 38, 2002: 187-197.

Ajav, E. A., Bachchan Singh, and T. K. Bhattacharya. "Thermal balance of a single cylinder diesel engine operating on alternative fuels." Energy Conversion and Management, 2000: 1533-1541.

Annual Book of ASTM Standards. West Conshohocken: ASTM International, 2004 Vol. $5(4)$.

BQ-9000 The National Biodiesel Accreditation Commission. 2007. http://www.bq9000.org/ (accessed May 2007).

Canakci, Mustafa, and Murat Hosoz. "Energy and Exergy Analyses of a Diesel Engine Fuelled with Various Biodiesels." Energy Sources, Part B: Economics, Planning, and Policy, 2006: 379-394.

Cheng, A. S., A. Upanieks, and C.J. Mueller. "Investigation of the impact of biodiesel fuelling on NOx emissions using an optical direct injection diesel engine." Int. J. Engine Res. Vol. 7, 2006: 297-317.

Cummins, “6.7-Liter Turbo Diesel” Cummins, Inc. 2008. http://www.everytime.cummins.com/every/applications/ram67.jsp (accessed May 2008)

Engine Manufacturers Association. 2002. http://www.enginemanufacturers.org/ (accessed May 2007).

"Experiment 3: Performance of an Internal Combustion (I.C.) Engine." The University of Calgary - Faculty of Engineering, 2004.

Info Tree Ohio University libraries . 2003. http://infotree.library.ohiou.edu/singlerecords/90.html (accessed May 16, 2007).

Jaichandar, S., and P. Tamilporai. "Low Heat Rejection Engines - An Overview." Detroit,Michigan: SAE International, March 3, 2003.

Jha, M. K., Hem Kant Sharma, and Bindu Marwaha. "Processes for production of biodiesel from vegetables oils." Chemical Business, 2004: 61-73. 
Kopac, Mehmet, and Lutfi Koturk. "Determination of optimum speed of an internal combustion engine by exergy analysis." International Journal of Exergy - Vol. 2, No.1, 2005: 40-54.

Kumar, P. Ravi, P. N. Srinivas, Dr. J. E. B. Nelson, and Dr. S. S. Rao. "Experimental Studies on Energy Appropriation in a Single Cylinder Diesel Engine." IE(I) Journal-MC, Vol 85, July 2004: 45-49.

Leduc, Martin. "The diesel engine and it's development: A historical timeline." MartinCorp. 2007. http://www.dieselduck.ca/library/other/prime_movers.htm (accessed May 2007).

Memmolo, Sam. “Cummins Turbo Diesel Engine (2003 Ratings)” SRM Marketing Services, 2008.

http://www.shadetreemechanic.com/cummins_turbo_diesel_2003.htm (accessed May 2008)

Monyem, A., J. H. Van Gerpen, and M. Canakci. "The Effect of Timing and Oxidation on Emissioins from Biodiesel-Fueled Engines." Transactions of the ASAE Vol. 44(1), 2001: 35-42.

NMRI, “Structure and Principles of Engines” National Maritime Research Institute, 2008. http://www.nmri.go.jp/eng/khirata/stirling/engines/general_e.html\#gasoline (accessed May 2008)

Rakopoulos, C. D., and E. G. Giakoumis. "Comparative first- and second-law parametric study of transient diesel engine operation." Energy, 2006: 1591-1606.

Reed, Mary. "Outlook." Ohio University. 2007. http://www.ohio.edu/outlook/0607/September/27f-067.cfm (accessed May 2007).

Sayin, C., M. Hosoz, M. Canakci, and I. Kilicaslan. "Energy and Exergy analyses of a gasolne engine." International Journal of Science Research, 2006: 259-273.

Sharma, J. K., and A. K. Jindal. "Diesel cycle calculations with low heat rejection for fuel economy." Journal of the Institution of Engineers (India), Part JE: Mechanical Engineering Division. Vol. 70, 1989: 21-26.

Sheehan, J., T. Dunahay, J. Benemann, and P. Roessler. A Look Back at the U. S. Department of Energy's Aquatic Species Program: Biodiesel From Algae. CloseOut Report, Golden, CO: National Renewable Energy Laboratory, 1998.

Spliethoff, H., U. Greul, H. Rudiger, and K. R. G. Hein. "Basic effects on NOx emissions in air staging and reburning at a bench-scale test facility." Fuel Vol. 75(5), 1996: 560-564. 
Taymaz, Imdat. "An experimental study of energy balance in low heat rejection diesel engine." Science Direct, 2006: 364-371.

Winther, J. B. Dynamometer handbook of basic theory and applications. Cleveland, Ohio: Eaton Corporation, 1975.

Yuan, W., A. C. Hansen, M. E. Tat, J. H. Van Gerpen, and Z. Tan. "Spray, Ignition, and Combustion Modeling of Biodiesel Fuels for Investigating Nox Emissions." Transactions of the ASAE Vol. 48 (3), 2005: 933-939.

Yuksel, F., and M. A. Ceviz. "Thermal Balance of a four stroke SI engine operating on hydrogen as a supplementary fuel." Science Direct, 2003: 1069-1080. 


\section{Appendix A: Dynamometer Information}

\section{Doigalog}

\section{AE Series}

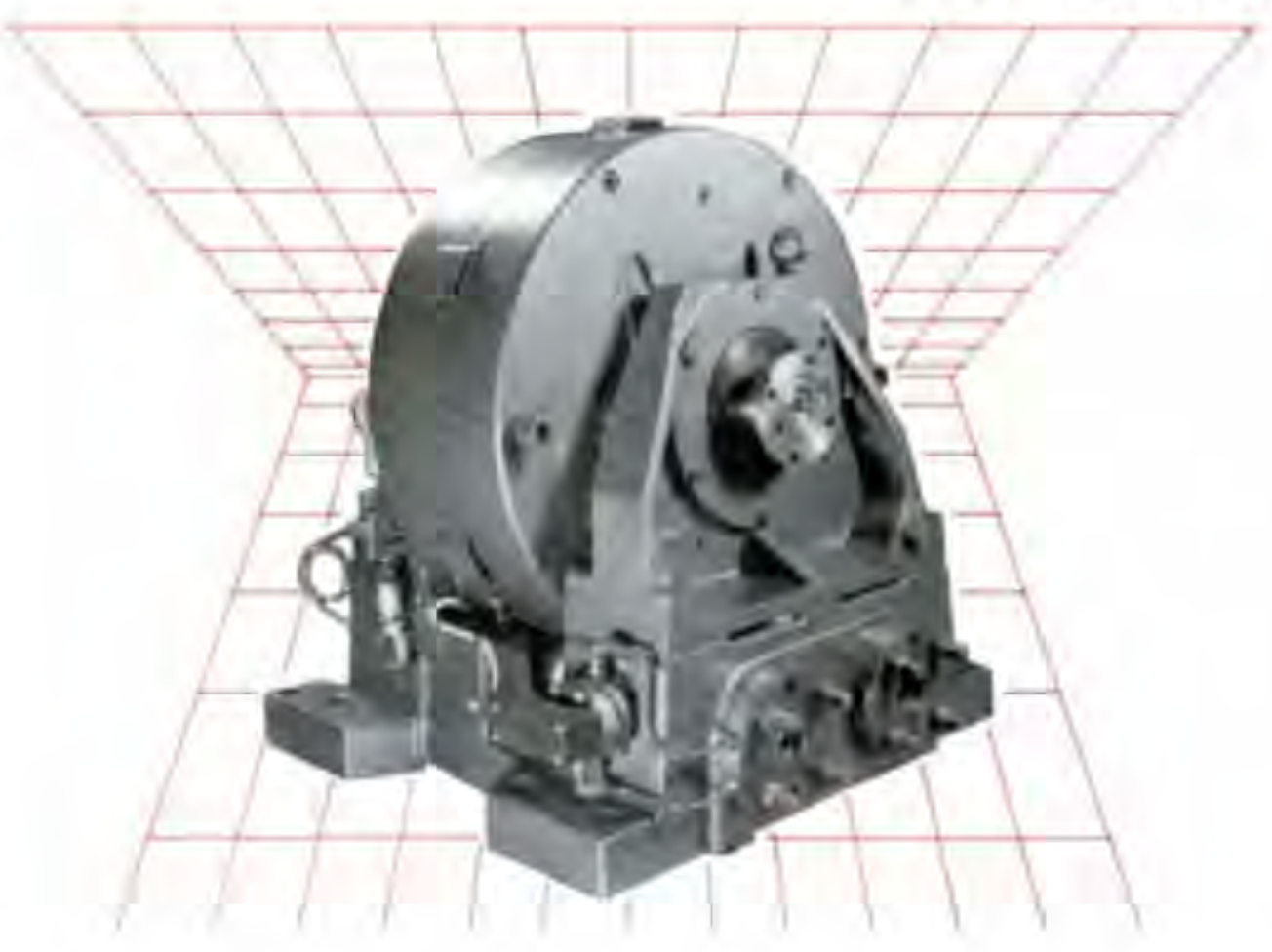

\section{Air Gap Eddy-Current Dynamometers}

The AE Series of Dynamometers provide a range of Air Gap Eddy-Current machines designed for testing engines from $20 \mathrm{~kW}$ to $400 \mathrm{~kW}$ capacity.

A high accuracy strain gauge load cell provides torque measurement for exacting test and development applications. A pulse pickup provides speed measurement with digital precision and reliability. The rugged design ensures a long operating life, even in the most demanding production and endurance testing environments. Electroless nickel plating of critical components in contact with the cooling water further enhances long life. 
Doigalog

STANDARD FEATURES

- I wo field coils encapsulated in silicon rubber, with central ventilation for reliability in extreme conditions.

- Carcass mounted in deep groove low friction trunnion ball bearings.

- High accuracy strain gauge load cell for torque measurement.

- 60 tooth wheel and pulse pickup for speed measurement.

- Electroless nickel plating of cooling passages for corrosion free operation.

- ' $O$ ' Ring articulated pipe connections for minimum torque calibration effects from cooling water supply pressure variations.

- 'Fail Safe' flow sensor cooling water safety.

- Loss plate thermocouples for additional cooling water safety monitoring and/or coolant flow control.

- Balanced high rigidity shaft assembly on precision rotor bearings for smooth operation.

- Low inertia spoke rotor design.

- Precise control, even at low loads.

- Fast response field coil designed for field forcing.

- Bi-directional operation.

\section{OPTIONS}

- IIigh speed version.

- Rotor bearing thermocouples

- Calibration arms and weights (SI or Imperial).

- Water Inlet Filter

- Water Inlet Control and Shutoff Valves

In addition, $\mathrm{AE}$ machines are available as part of a range of integrated engine test stands including:

- Engine mounting stands and carts. These include manual and automatic docking systems for production line applications.

- Drive shafis, couplings and guards

- Dynamometer base plates

- Engine starting systems (DC. AC or Pneumatic)

- Stall brakes for electric motor or transmission testing

- Inertia flywheel systems

- Lngine jacket water and oil cooling systems

- Dynamometer, engine and complete test cell control and instrumentation systems.

- Turn-key integration, installation, and commissioning services

PO Box 3315• Ventura, CA 93006 • 805/644-5000 • 805/650-0838 Fax 


\section{DoIGAlog SPECIFICATIONS}

\begin{tabular}{|c|c|c|c|c|c|}
\hline \multirow[t]{2}{*}{ Model } & \multirow{2}{*}{$\begin{array}{c}\text { Maximum } \\
\text { Power } \\
\text { kW @ RPM }\end{array}$} & \multirow{2}{*}{$\begin{array}{l}\text { Maximum } \\
\text { Torque } \\
\text { Nm @ RPM }\end{array}$} & \multicolumn{2}{|c|}{ Maximum Speed } & \multirow{2}{*}{$\begin{array}{l}\text { Inertia } \\
\mathrm{Kg} \cdot \mathrm{m}^{2}\end{array}$} \\
\hline & & & Standard & High Speed & \\
\hline AE20 & $20 @ 2400$ & $80 @ 1500$ & 6500 & 10000 & 0.0165 \\
\hline AE 30 & $3 J @ 3000$ & $95 @ 2000$ & 12000 & 14000 & 0.011 \\
\hline $\begin{array}{l}\text { AE80 } \\
\text { AE150 }\end{array}$ & $\begin{array}{c}80 @ 4800 \\
150 @ 2850\end{array}$ & $\begin{array}{l}160 @ 2000 \\
500 @ 1 B 00\end{array}$ & $\begin{array}{l}9000 \\
8000\end{array}$ & $\begin{array}{l}14000 \\
12000\end{array}$ & $\begin{array}{l}0.028 \\
0.093\end{array}$ \\
\hline AE250 & $250 @ 2000$ & $1200 @ 950$ & 6000 & 8000 & 0.464 \\
\hline AE400 & $400 @ 1900$ & $2000 @ 700$ & 4500 & 8000 & 1.107 \\
\hline
\end{tabular}

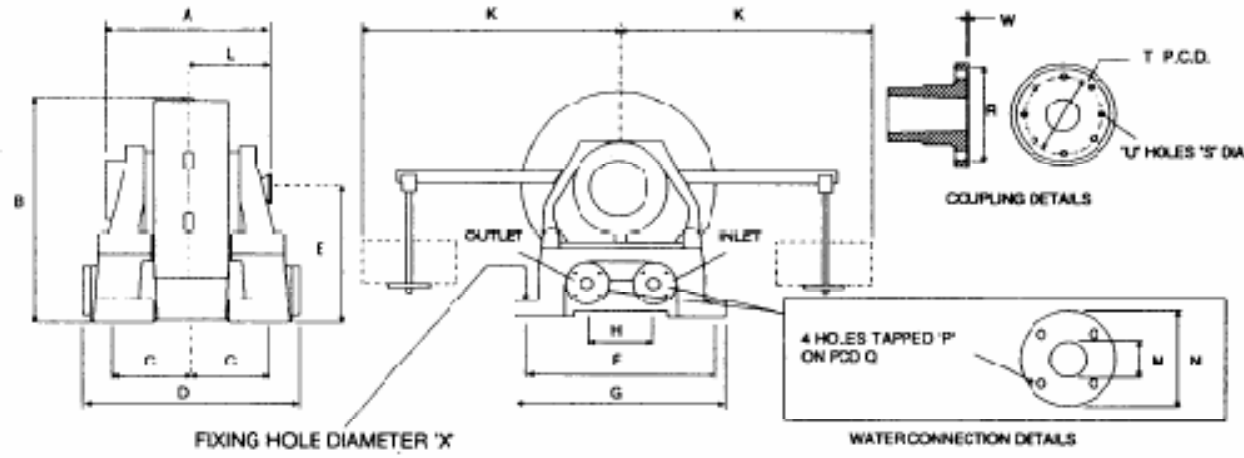

\begin{tabular}{|c|c|c|c|c|c|c|c|c|c|c|c|c|c|c|c|c|c|c|c|c|}
\hline \multirow[t]{2}{*}{ Model } & \multicolumn{10}{|c|}{ Overall Dimensions (mm) } & \multicolumn{4}{|c|}{$\begin{array}{c}\text { Water } \\
\text { Conncctions }\end{array}$} & \multicolumn{6}{|c|}{ Coupling } \\
\hline & A & $\mathrm{B}$ & $\mathrm{C}$ & $\mathrm{D}$ & $E$ & $F$ & $\mathrm{G}$ & $\mathrm{H}$ & $\mathrm{K}$ & $\mathrm{L}$ & $\mathrm{M}$ & $\mathrm{N}$ & $\mathrm{P}$ & $Q$ & $\mathrm{R}$ & $\mathrm{S}$ & $T$ & $\mathrm{U}$ & $W$ & $\mathrm{X}$ \\
\hline $\mathrm{EE} 20$ & 325 & 116 & $1 \in 2$ & 175 & 260 & 310 & 376 & 151 & 510 & 188 & 10 & & & & 88 & 0 & 80.0 & 1 & 2.6 & 11 \\
\hline $\mathrm{AE} 30 / 80$ & 424 & 540 & $2 \mathrm{C5}$ & 485 & 330 & 450 & 492 & 160 & 618 & 212 & 25 & 105 & M10 & 75 & 69.85 & 112 & 85.25 & $\angle$ & 3 & 18 \\
\hline $\mathrm{AE} 15 \mathrm{C}$ & 470 & 689 & 236 & 632 & 400 & 530 & 620 & 192 & 672 & 235 & 40 & 150 & M16 & 110 & 69.85 & 112 & 85.25 & 4 & 3 & 18 \\
\hline $\mathrm{AE} 25 \mathrm{C}$ & 560 & 835 & $2 \varepsilon 5$ & 662 & 485 & 680 & 740 & 384 & 1022 & 275 & 40 & 150 & M16 & 110 & 196.8 & 10.1 & 184.2 & 8 & 3 & 22 \\
\hline AE4OC & 600 & 970 & 310 & 712 & 540 & 770 & 830 & 470 & \begin{tabular}{|l|}
1025 \\
\end{tabular} & 300 & 50 & 165 & M16 & 125 & 196.8 & 10.1 & 184.2 & 8 & 3 & 22 \\
\hline
\end{tabular}




\section{Doisalog \\ TECHNICAL DATA}

\begin{tabular}{|c|c|c|c|c|c|c|c|c|}
\hline & Units & AE20 & \multicolumn{2}{|c|}{$\mathrm{AE} 30$} & AE80 & $\mathrm{AE} 150$ & $\mathrm{AE} 250$ & $\mathrm{AE} 400$ \\
\hline \multicolumn{9}{|l|}{ Accuracies } \\
\hline Torque Calibration Accuracy & $\mathrm{Nm}+1-$ & 0.2 & \multicolumn{2}{|c|}{0.29} & 0.4 & 1.25 & 3.0 & 5.0 \\
\hline Speed & RPM & \multicolumn{7}{|c|}{$+/-1$} \\
\hline \multicolumn{9}{|l|}{ Water Supply } \\
\hline Maximum Outlet Temp & Deg. C. & \multicolumn{7}{|c|}{60} \\
\hline Acidity & $\mathrm{PH}$ & \multicolumn{7}{|c|}{7.4 to 8.4} \\
\hline Filtration & Micron & \multicolumn{7}{|c|}{400 Maximum (Filter Available) } \\
\hline Suspended Particles & PPM & \multicolumn{7}{|c|}{1000 Maximum } \\
\hline Minimum Flow Required & $\mathrm{L} / \mathrm{min}$ & 14 & & & 57 & 107 & 178 & 280 \\
\hline Minimum Main Supply Pressure & $\mathrm{Kg} / \mathrm{cm}^{2}$ & 1.5 & & 8 & 1 & 1 & 1.6 & 2.4 \\
\hline \multicolumn{9}{|l|}{ Electrical Connections } \\
\hline Energizing Field Coil Voltage & VDC & 75 & & & 75 & 90 & 110 & 125 \\
\hline Maximum Current & ADC & \multicolumn{7}{|c|}{5} \\
\hline Low Water Flow Safety & & \multicolumn{7}{|c|}{$\begin{array}{l}\text { Fail Safe pulse output turbine or vortex shedding flow } \\
\text { meter with minimum frequency relay set to Open at } \\
\text { Minimum Water Flow }\end{array}$} \\
\hline Low Water Flow Safety Switch & & \multicolumn{7}{|c|}{$\begin{array}{c}\text { SPDT Normally connected in series with the control } \\
\text { system safety shutdown }\end{array}$} \\
\hline Maximum Voltage & VAC & \multicolumn{7}{|c|}{250} \\
\hline Maximum Current & AAC & \multicolumn{7}{|c|}{5} \\
\hline Pulse Pickup & & \multicolumn{7}{|c|}{$\begin{array}{c}60 \text { pulse per rev. Hall Effect zero velocity direction } \\
\text { sensing active pickup }\end{array}$} \\
\hline Load Cell & & \multicolumn{7}{|c|}{ Strain Gauge - Full Bridge } \\
\hline Resistance & Ohms & \multicolumn{7}{|c|}{350 Nominal } \\
\hline Sensitivity & $\mathrm{M} \vee / \mathrm{V}$ & \multicolumn{7}{|c|}{2.7 Nominal } \\
\hline Excitation & VDC & \multicolumn{7}{|c|}{10 Max. } \\
\hline \multicolumn{9}{|l|}{ Environmental Conditions } \\
\hline Operating Range & Deg. C. & \multicolumn{2}{|c|}{-10 to 60} & \multirow{2}{*}{\multicolumn{5}{|c|}{$\begin{array}{l}\text { Note: At or below } 0 \text { deg. C. Operating } \\
\text { procedures to prevent water freezing in } \\
\text { the machine must be instituted. }\end{array}$}} \\
\hline Load Cell Compensated Range & Deg. C. & 0 to & & & & & & \\
\hline $\begin{array}{l}\text { Recommended Operating Range } \\
\text { to Achieve Optimum Accuracy }\end{array}$ & Deg. C. & \multicolumn{7}{|c|}{20 to 30} \\
\hline Maximum Humidity & $\% \mathrm{RH}$ & \multicolumn{7}{|c|}{90 Non-Condensing } \\
\hline Machine Weight Approx. & $\mathrm{Kg}$ & 220 & & 30 & 330 & 560 & 1180 & 1620 \\
\hline
\end{tabular}




\section{Doigalog}

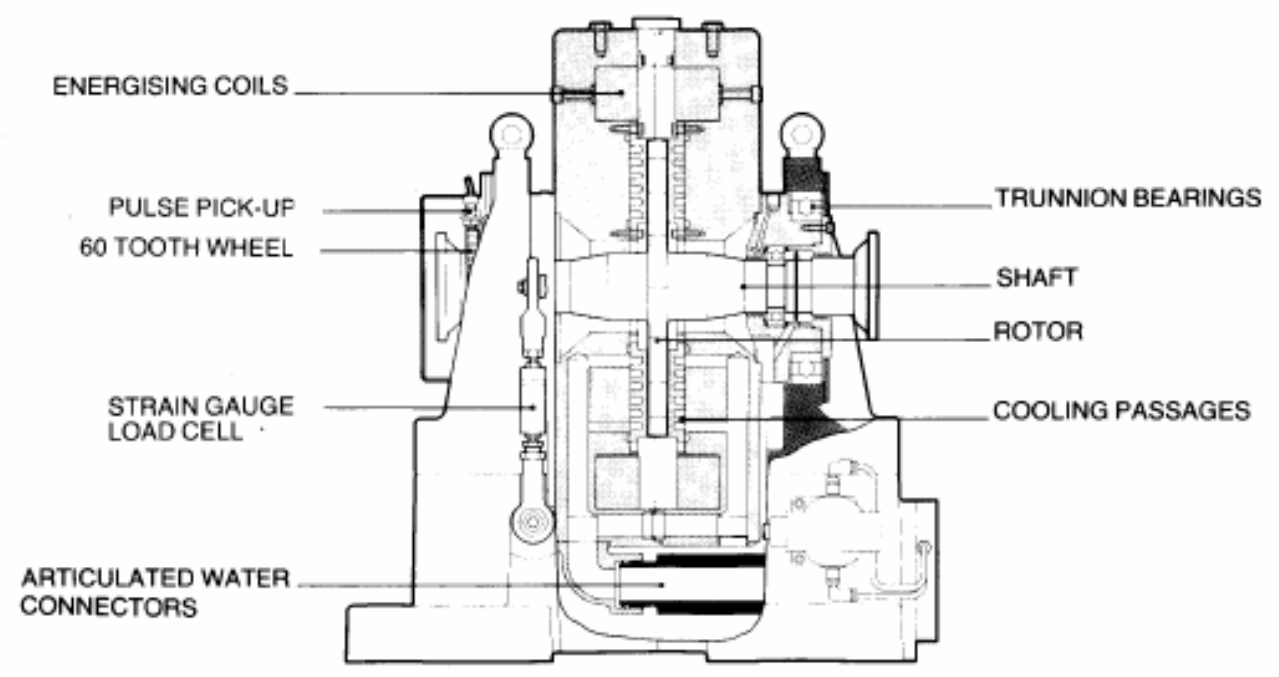

\section{DESCRIPTION OF STANDARD FEATURES}

\section{Energizing Field Coils}

These are fully encapsulated two piece coils, used in place of the more common and less expensive single coil arrangement. This configuration ensures optimum distribution of flux throughout the working area for maximum low speed torque, and at the same time allows the free flow of air from the center of the machine, through the critical air gap between rotor and stator, and out of radial ventilation slots. These features ensure both rapid response, and reliability under the severest loading conditions, which can be the cause of local overheating in single coil machines.

\section{Trunnion Bearings}

Deep groove ball bearings provide the most precise method of carcass mounting and are virtually free from friction. They are also extremely rigid and free from resonance problems, which can occur on flexure type carcass mounting systems. The bearing selection ensures extended life.

\section{Shaft and Rotor}

The rotor is manufactured from a high magnetic permeability material for maximum performance, and is a spoke design for minimum inertia. Precision grade bearings are used to ensure accurate shaft location and high safe operating speeds.

\section{Cooling Passages}

The cooling passages and "loss plate" are critical areas in any Eddy-current dynamometer, as thermal loading is high, and cyclic loading can cause corresponding temperature changes. Associated loss plate distortion may cause catastrophic contact between plate and rotor, or loss of coolant. Extensive design and development has therefore been carried out to arrive at the $\mathrm{AE}$

PO Box $3315 \bullet$ Ventura, CA 93006 • 805/644-5000 • 805/650-0838 Fax 


\section{Doigalog}

system of loss plate mounting, which allows controlled radial expansion without water leakage and prevents loss plate distortion. The water passages have been optimized to ensure consistent cooling, and they are electroless nickel plated to ensure that corrosion does not detract from performance over time. Thermocouples imbedded in the loss plates allow monitoring this critical area for additional assurance that adequate cooling is taking place and allows feedback for cooling water flow control if desired.

\section{Cooling Water Connections}

Cooling water connection is by means of ' $\mathrm{O}$ ' ring sealed articulated pipes, leading to flanges suitable for connection to the customer's water supply. The design ensures that water connection and supply pressure variations have minimum effect on machine accuracy.

A 'fail safe' paddle wheel or vortex shedding flow sensor is included to provide visual verification and electrical monitoring of flow rate, and a safety contact signal if water flow should drop below safe levels or the sensor fails. The more common and less expensive moving vane or piston type flow sensors, supply pressure switches, or differential pressure switches across orifice plates are notorious for 'sticking on' due to debris or scale buildup at the sensor. This causes these types of sensors to indicate adequate flow when little or none is present. Digalog's unique 'fail safe' water flow safety thus prevents this most common cause of premature eddy current dynamometer failure.

\section{Control}

Varying the excitation current at the coil controls the level of power absorbed. When used in conjunction with feed back signals for speed from the pulse pick-up and toothed wheel, torque from the load cell or current from the field coil, closed loop control is provided. Digalog offers several manual and automated control and instrumentation systems to meet any requirement.

\section{Digalog/SAJ}

For over 20 years Digalog has been an industry leader in the engineering, manufacture and integration of test cell control and instrumentation systems. Digalog has now formed a strategic alliance for product distribution with SAJ Test Plant Pvt. Ltd., a leading dynamometer manufacturer for over 25 years. SAJ manufactures a complete range of high quality eddycurrent and waterbrake dynamometers. Digalog supplies all sensors used in these dynamometers for ease of maintenance. Digalog also provides a stock of spare and service parts as well as service, support, repair, control systems and dynamometer expertise for SAJ manufactured dynamometers. Digalog/SAJ policy is one of continuous improvement and we reserve the right to change specifications without notice.

Digalog is dedicated to expand its product line, services and support to provide our customers total testing solutions with a skilled team of professionals committed to excellence. With over 180 Million test hours logged ... the commitment hasn't changed.

PO Box 3315 • Ventura, CA 93006 • 805/644-5000 • 805/650-0838 Fax 


\section{Appendix B: Cummins Information}

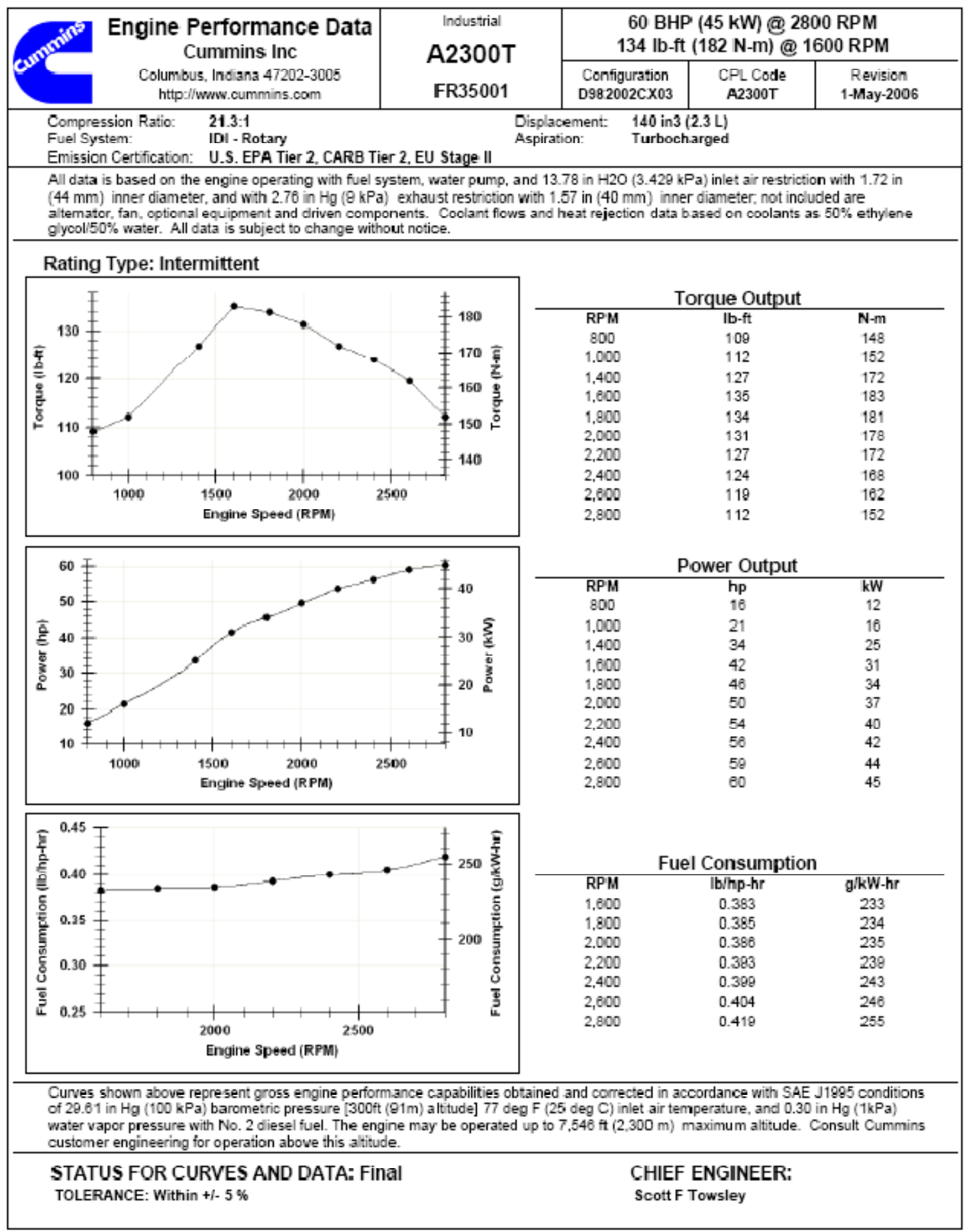


FR35001 (Continued) Page: 2

Intake Air System

Maximum allowable air temperature rise over ambient at Intake Manifold

(Naturally Aspirated Engines) or Turbo Compressor inlet (Turbo-charged

Engines): (This parameter impacts emissions, LAT and/or altitude capability)

18 delta deg $F$

10 delta deg $C$

Cooling System

Maximum coolant temperature for engine protection controls

235 deg F

230 deg F

$113 \operatorname{deg} \mathrm{C}$

Maximum coolant operating temperature at engine outlet ( $\max$. top tank temp):

2.98 in- $\mathrm{Hg}$

1.57 in

$14.2 \mathrm{psi}$

$50.8 \mathrm{psi}$

$7.1 \mathrm{psi}$
$0.11 \mathrm{~kW}$

$16 \mathrm{~kg} / \mathrm{hr}$

$52 \operatorname{deg} \mathrm{C}$

$28 \mathrm{~kg} / \mathrm{hr}$

$16 \mathrm{~kg} / \mathrm{hr}$

$4.9 \mathrm{~N}-\mathrm{m}$

$76 \mathrm{kPa}$

Engine fuel compatibility (consult Service Bulletin $\# 3379001$ for appropriate use of other fuels)

Maximum fuel inlet pressure:

11 psi

$10 \mathrm{kPa}$

$40 \mathrm{~mm}$

\section{Performance Data}

Engine low idle speed:

Maximum low idle speed

Minimum low idle speed:

Minimum engine speed for full load sustained operation:

Nominal governor droop:

Nominal governor regulation:

Engine high idle speed

Governor break speed:

Maximum torque avalable at closed throttle low idle speed:

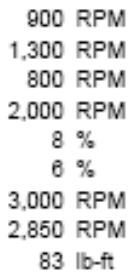

$113 \mathrm{~N}-\mathrm{m}$ 
FR35001 (Continued) Page: 3

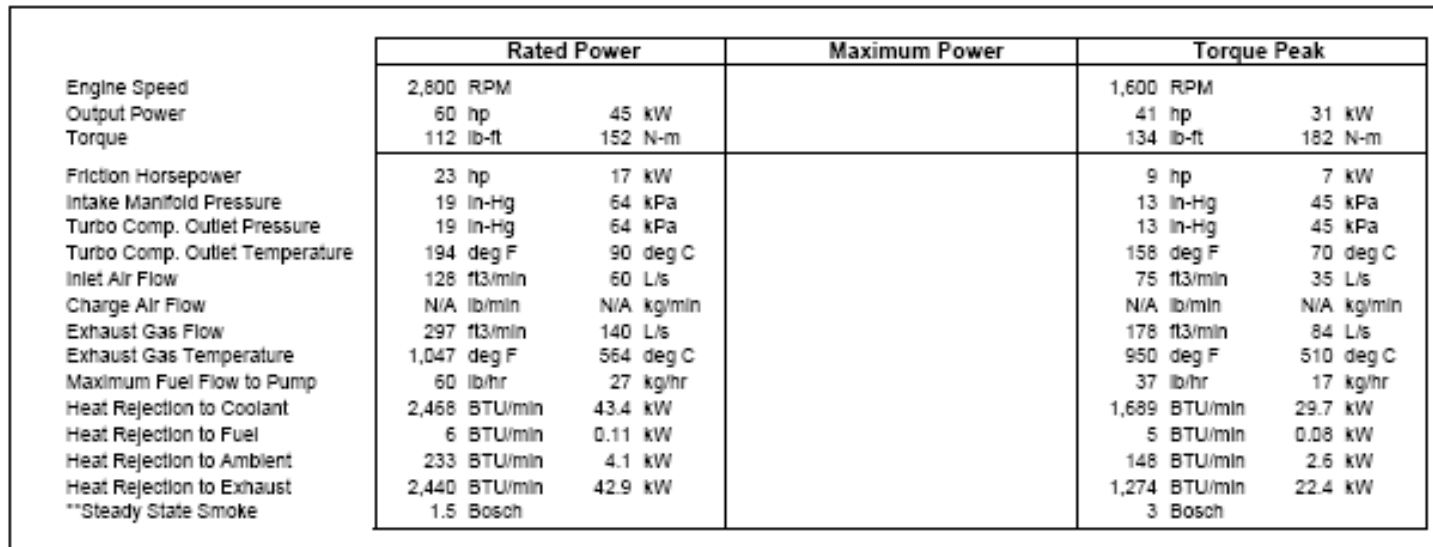

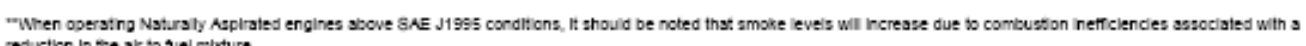
resuction in tre ar to vei minture.

\section{Cranking System (Cold Starting Capability)}

Unaided Cold Start:

Minimum cranking speed

Minimum ambient temperature for unaided cold start

Cranking torque at minimum unaided cold start temperature:

Aided Cold Start:

Minimum ambient temperature with Grid Heater only

Minimum ambient temperature with Ether only:

Minimum ambient temperature with coolant and lube heater only:

Cold starting aids avalable

$\begin{array}{rr}\begin{array}{l}180 \text { RPM } \\ -25.6 \text { deg F } \\ 8 \mathrm{lb}-\mathrm{ft}\end{array} & -32 \text { deg C } \\ & 12 \mathrm{~N}-\mathrm{m} \\ \text { N/A deg F } & \text { N/A deg C } \\ \text { N/A deg F } & \text { N/A deg C } \\ \text { N/A deg F } & \text { N/A deg C } \\ \text { Glow Plug } & \\ & \\ 90.5 \mathrm{dBa} & \\ 91 \mathrm{dBa} & \\ 91.6 \mathrm{dBa} & \\ 92.6 \mathrm{dBa} & \\ 100 \mathrm{dBa} & \end{array}$

Extimated Free Fleid Sound Presgure Level at $3.28 \mathrm{~s}$ ( $1 \mathrm{~m}$ ) and Ful-Losd Govemed Speed

(Exchudes Nolse from intake, Exhaust, Cooling System and Driven Components)

Top

Right Side

Left Side

Front 


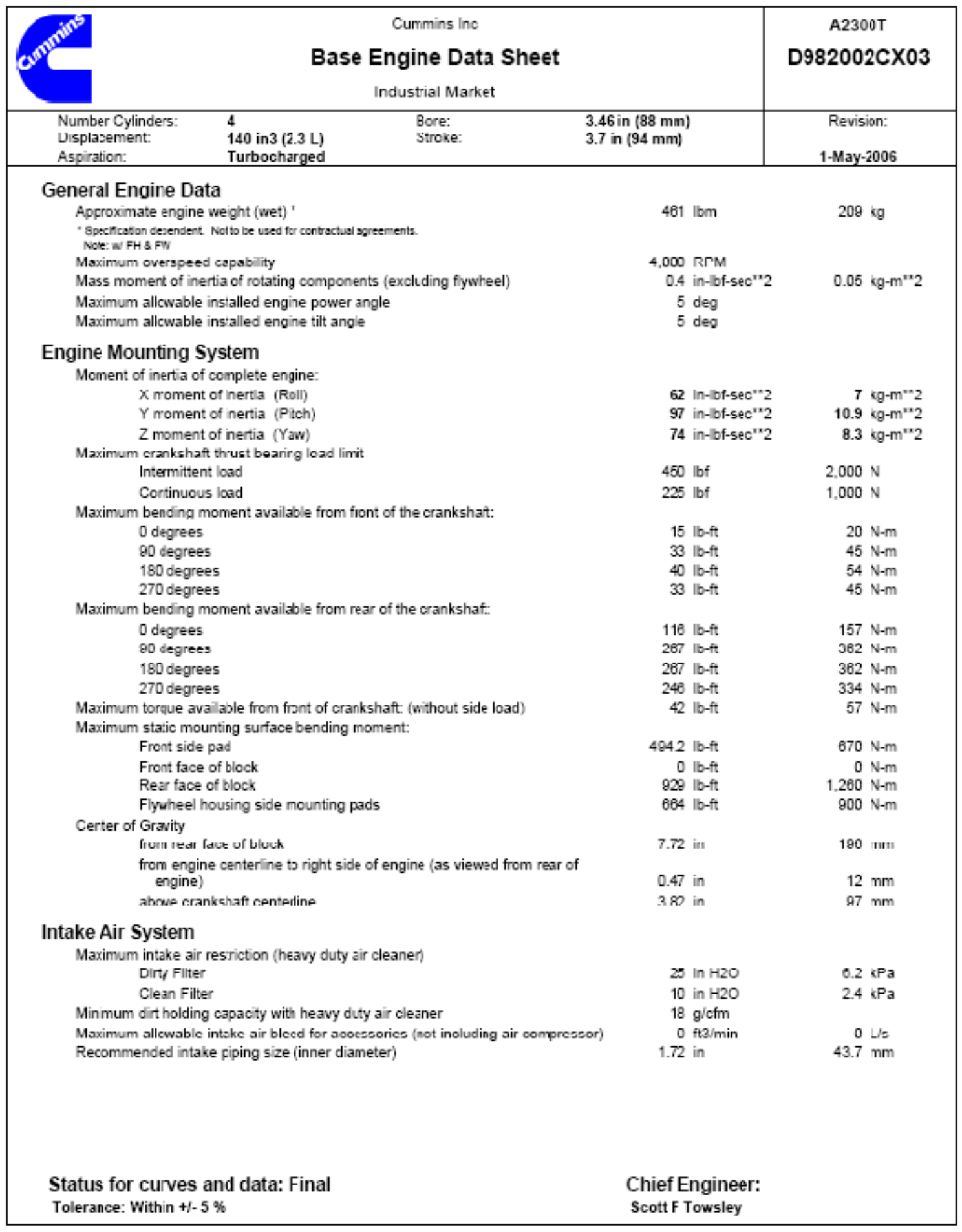


D982002CX03 (Continued) Page: 2

Exhaust System

Maximum allowable static bending momen: @ expaust outlet flange Exhaust manifold/turbocharger blanketing acceptable

\section{Cooling System}

Enzine cooling circuit

Coolant sfstem type

Ninimum operatng blosk coo ant temperature

Minimum fill rate

Maximum initial fill time

Minimum water pump inlet pressure with non-deasating or partially deaerating cooling systen

Minimum water pump inlet pressure with fully deaerating cooling system

Maximum static head ct coolant above cranksharl centerline

Minimum pressure cap rating at sea level

Maxinum pressure valy id ling al sed leve

Minimum coolant expansion space (\% of system capacity)

Moximum deacration tine

Acceptable types of deaeration systems

Mirimum drawdiown (\% total monling cysten caparity)

Ful ON Fan engine coolant outlet temperaure

Shutter opening tempe ature - coolant

Maximum allowable acsessory coolant flow

Coolant capacity - engine only

Maximum recormended external ccolant fow restriction in engine circuit:

Engine ccolant circuit thermostat opening temperature:

Engine ccolant circuit thermostat fully open temperature
$15 \mathrm{lb}-\mathrm{ft} \quad 2 \mathrm{C} \mathrm{N}-\mathrm{m}$

No

\begin{tabular}{|c|c|}
\hline \\
\hline \multicolumn{2}{|c|}{$\begin{array}{l}1 \text { Гump-1 Loop } \\
100 \text { feg F }\end{array}$} \\
\hline $1 \mathrm{opm}$ & 3. I /mir \\
\hline \multicolumn{2}{|l|}{$5 \mathrm{~min}$} \\
\hline $\mathrm{O}$ in $-\mathrm{Hg}$ & $0 \mathrm{kPa}$ \\
\hline $\mathrm{N} / \mathrm{A}$ in- $\mathrm{Hg}$ & $\mathrm{N} / \mathrm{A} \mathrm{kPa}$ \\
\hline $10 \mathrm{tt}$ & $\exists \mathrm{m}$ \\
\hline 7 psi & $48 \mathrm{kPa}$ \\
\hline 13 pai & $88 \mathrm{kPd}$ \\
\hline \multicolumn{2}{|l|}{$5 \%$} \\
\hline \multicolumn{2}{|l|}{$30 \mathrm{~min}$} \\
\hline \multicolumn{2}{|c|}{$\begin{array}{l}\text { Parial baffle, Coolant recovery } \\
7 \%\end{array}$} \\
\hline N/A deg F & N/A deg C \\
\hline N/A deg F & $\begin{array}{l}\text { N/A deg C } \\
\text { g L/mir }\end{array}$ \\
\hline 3.2 quarts & $3 \mathrm{~L}$ \\
\hline 5 psi & $34 \mathrm{kPa}$ \\
\hline $160 \mathrm{deg} F$ & $71 \operatorname{deg} C$ \\
\hline $180 \mathrm{deg} t$ & 80 deg C \\
\hline
\end{tabular}

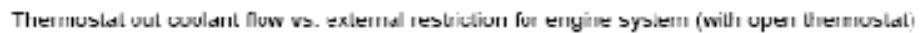

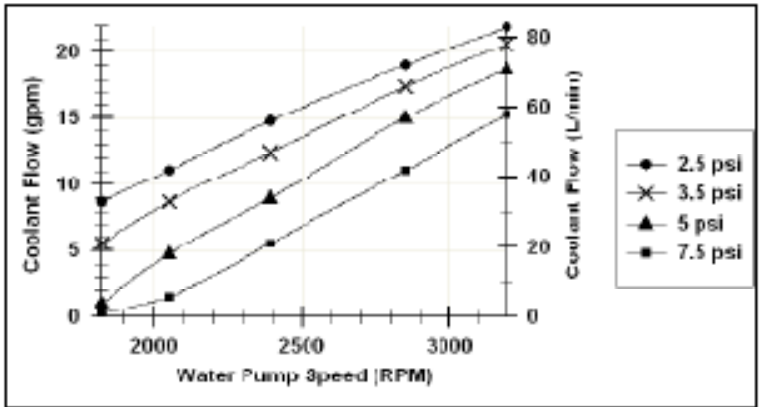

\begin{tabular}{|c|c|c|c|c|c|c|c|c|}
\hline \multirow{2}{*}{$\begin{array}{l}\text { Pump } \\
\text { speed } \\
\text { RPN }\end{array}$} & \multicolumn{2}{|c|}{$\begin{array}{c}2.5 \mathrm{pal} \\
(17 \mathrm{kPa})\end{array}$} & \multicolumn{2}{|c|}{$\begin{array}{l}3.5 \mathrm{psl} \\
\mathrm{R} 4 \mathrm{kPa}\end{array}$} & \multicolumn{2}{|c|}{$\begin{array}{c}5 \mathrm{pBl} \\
(34 \mathrm{kPa})\end{array}$} & \multicolumn{2}{|c|}{$\begin{array}{c}7.5 \mathrm{psl} \\
(52 \mathrm{kPa})\end{array}$} \\
\hline & gpn & L/min & gpn & L/rnin & $\mathrm{gpm}$ & Limin & gPm & Umin \\
\hline 1,824 & 9 & 33 & 5 & 21 & 1 & $\overline{4}$ & 0 & 7 \\
\hline 2.052 & 11 & 42 & 9 & 33 & 5 & 18 & 2 & 6 \\
\hline 2,394 & 15 & $5 E$ & 12 & 47 & 3 & 34 & 6 & 21 \\
\hline 2,855 & 19 & 72 & 17 & 66 & 15 & 57 & 11 & 42 \\
\hline$s, 1 y /$ & 22 & $6:$ & 21 & $/ \sigma$ & y & 1 & 10 & 58 \\
\hline
\end{tabular}

Minimum block coolant pressure at speed (open themostat without radiator cap)

$\begin{array}{ccc}\text { RPM } & \text { psi } & \text { kPa } \\ 1,000 & 4.3 & 28 \\ 1,800 & 4.6 & 32 \\ 2,100 & 5.1 & 35 \\ 2,500 & 6.8 & 47 \\ 2,800 & 7.8 & 54\end{array}$

\section{Lubrication System}

Maximum lube cil flow to all accessories

Maximum oil sump temperature

Maximum oil pressure spike cn cold engine

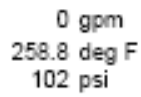

C L/min

$126 \operatorname{deg} \mathrm{C}$

$70 \mathrm{cPa}$ 
D982002CX03 (Continued) Page: 3

\section{Electrical System}

System voltage:

Minimum battery capacity-cold soak at - $18 \mathrm{deg}$ C ( 0 deg F) or above Engine only-cold cranking amperes: (CCA)

Engine only-reserve capacity: (ISO)

Maximum starting circuit resistance

$\begin{array}{cc}\underline{12} \underline{\mathrm{v}} & \underline{24} \underline{\mathrm{v}} \\ 500 \mathrm{CCA} & 250 \mathrm{CCA} \\ 135 \mathrm{~min} & 90 \mathrm{~min} \\ 0.004 \mathrm{Ohm} & 0.004 \mathrm{Ohm}\end{array}$

\section{Fuel System}

Typical clean fuel filter restriction

Maximum fuel supply restriction at fuel pump inlet with clean fuel filter element( 5 ) at maximum fuel flow with dirty fuel fiter element(s) at maximum fuel flow

Maximum fuel drain restriction (total head)

after (or with) check valve

before (or without) check valve

Maximum fuel inlet temperature

Minimum fuel tank venting rate

$\begin{array}{rc}2 \mathrm{in}-\mathrm{Hg} & 7 \mathrm{kPa} \\ 3 \mathrm{in}-\mathrm{Hg} & 10 \mathrm{kPa} \\ 8 \mathrm{in}-\mathrm{Hg} & 27 \mathrm{kPa} \\ \mathrm{N} / \mathrm{A} \mathrm{in}-\mathrm{Hg} & \mathrm{N} / \mathrm{A} \mathrm{kPa} \\ 15 \mathrm{in}-\mathrm{Hg} & 51 \mathrm{kPa} \\ 148 \mathrm{deg} \mathrm{F} & 65 \mathrm{deg} \mathrm{C} \\ 8.8 \mathrm{ft} / \mathrm{hr} & 0.07 \mathrm{~L} / \mathrm{s}\end{array}$

\section{RATING GUIDELINES}

\section{LOAD RATINGS}

1.1 Maximum Rating may be used for intermittent load applications (full throttle operation is cyclicaly interrupted) where the average load factor does not exceed the continuous rating. and where full throttle operation does not exceed 60 minutes without interruption.

1.2 "Continuous rating may be used for constant load applications requiring uninterrupted service at full throttle for extended periods of time and for Water Management applications.

2. SPEED RATINGS

2.1 If the application qualifies for the continuous load rating the governor cut-in point shall be set within the limits of the solid line portion of the continuous curve.

2.2 If the application qualifies for the maximum load rating the govemor cut-in point shall be set within the limits of the solid line portion of the maximum curve.

\section{DEFINITIONS}

3.1 Load (Speed) factor is defined as the arithmetic mean of the Load (Speed) profile of the normal duty cycle, not including prolonged periods of idle operation.

\section{INTERNATIONAL RATING GUIDELINES}

'These ratings represent gross engine performance capabilities obtained and corrected in accordance with SAE J1985 and the conditions as stated on the front of the curve. The ratings are in conformance with the requirements specified in ISO 3046 . BS 5514 and DIN 6271. Although these specific standards have a note excluding road construction, earth moving equipment, agricu/tural tractors and industrial trucks as applications not covered by the standard, these are included as acceptable applications of these ratings.

The Maximum Rating conforms to ISO 3046 overload power and fuel stop power. The Continuous Rating may be used for continuous service in commercial applications and it conforms to ISO 3046 continuous power.

Reference standards: BS 5514 and DIN 6271 standards are based on ISO 3046 . 


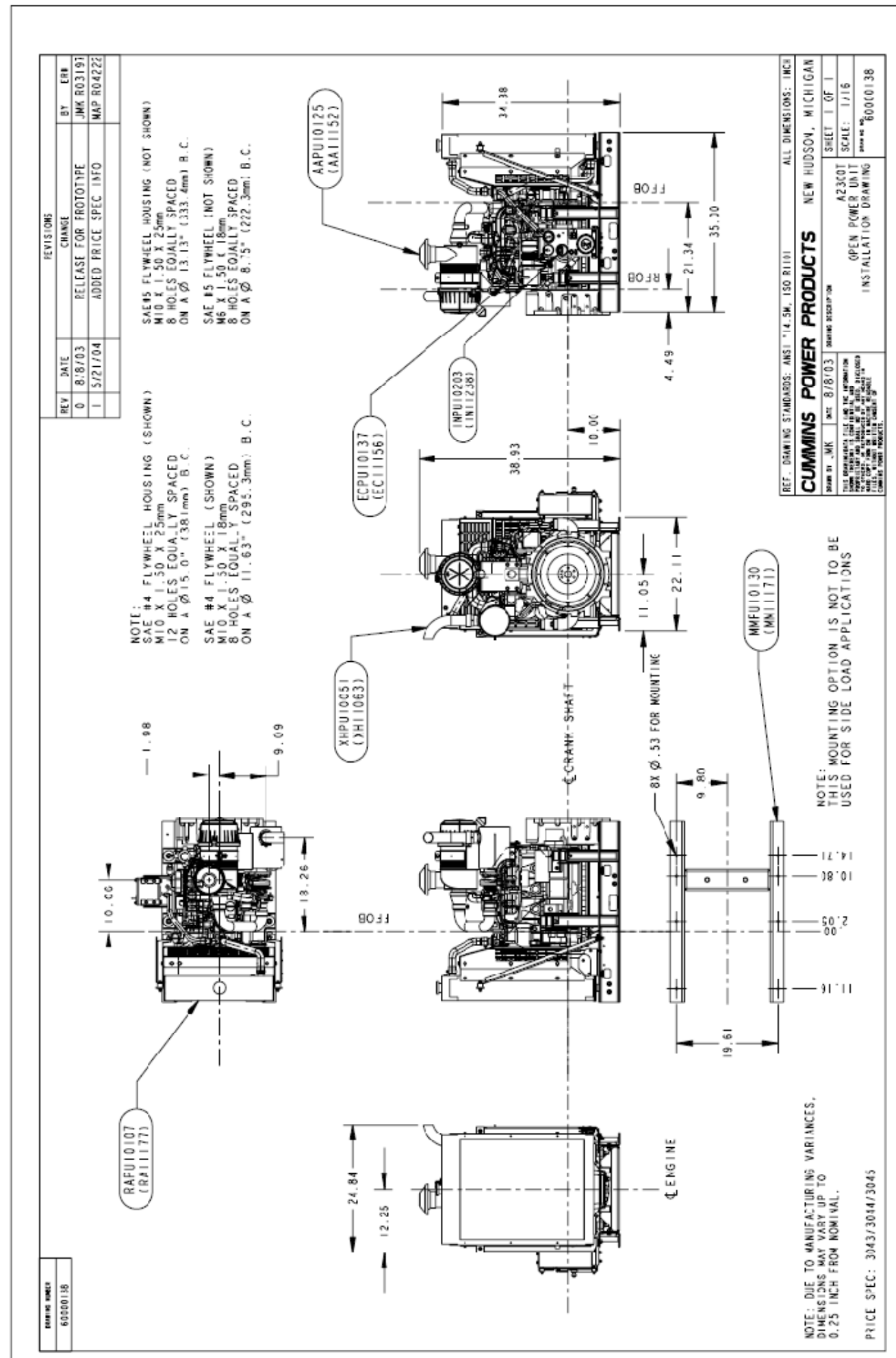




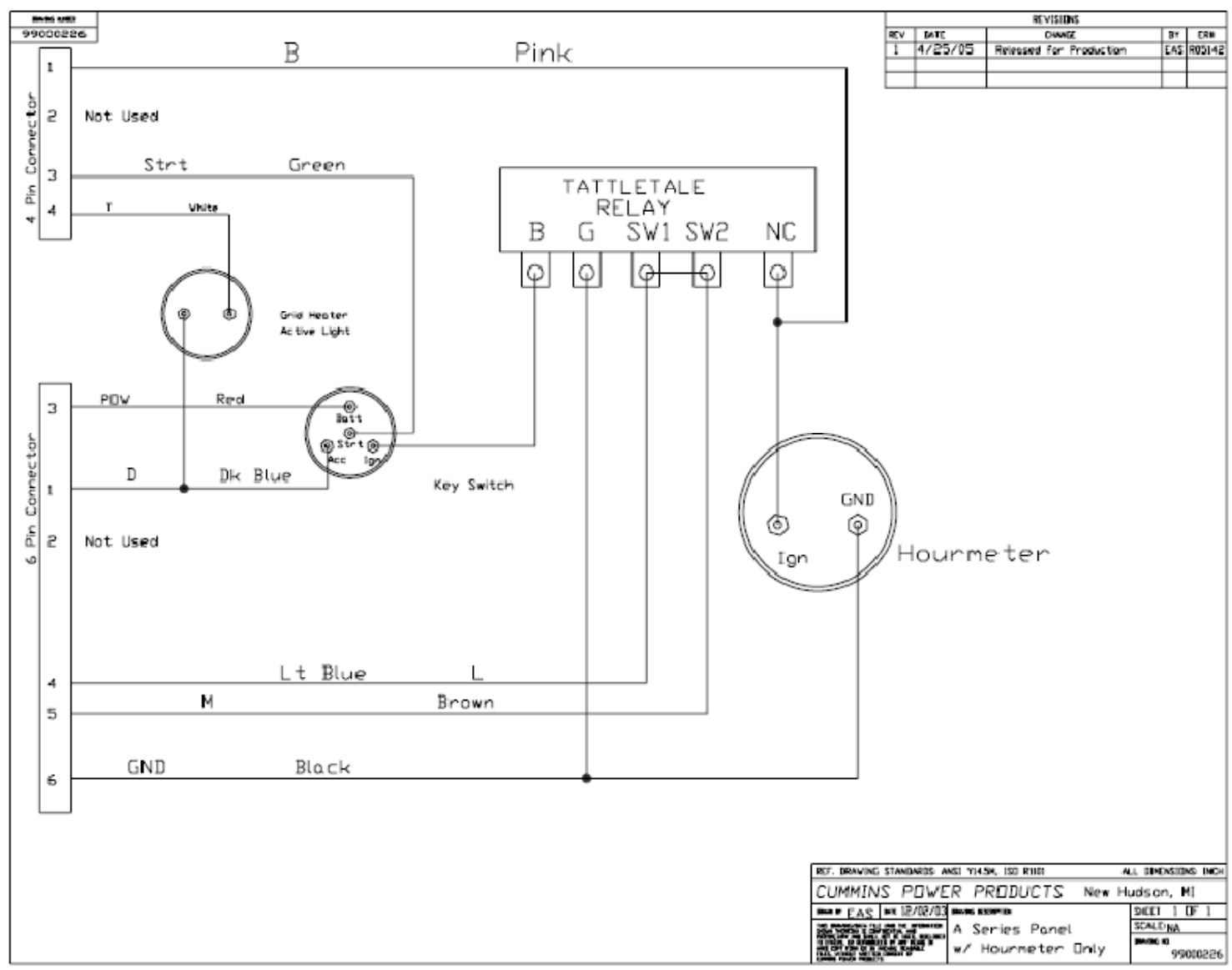




\section{Appendix C: Fuel Information}

Table 1

Some properties of No. 2 diesel fuel, SME, and YGME

(Canakci and Van Gerpen, 2003)

\begin{tabular}{|c|c|c|c|}
\hline Property & $\begin{array}{c}\text { No, } 2 \\
\text { diesel fuel }\end{array}$ & SME & YGME \\
\hline Typical formula & $\mathrm{C}_{14.09} \mathrm{H}_{24.78}$ & $\mathrm{C}_{18.74} \mathrm{H}_{34.43} \mathrm{O}_{2}$ & $\mathrm{C}_{18.06} \mathrm{H}_{34.72} \mathrm{O}_{2}$ \\
\hline $\begin{array}{l}\text { Average molecular weight } \\
\qquad\left(\mathrm{kg} \mathrm{kmol}^{-1}\right)\end{array}$ & 194.20 & 291.77 & 283.90 \\
\hline Higher heating value $\left(\mathrm{kJ} \mathrm{kg}^{-1}\right)$ & 45,339 & 39,871 & 39,817 \\
\hline Lower heating value $\left(\mathrm{kJ} \mathrm{kg}^{-1}\right)$ & 42,640 & 37,388 & 37,144 \\
\hline $\begin{array}{l}\left.\text { Specific exergy ( } \mathrm{kJ} \mathrm{kg}^{-1}\right) \\
\text { (calculated from Eq. (II)) }\end{array}$ & 45,427 & 40,105 & 39,902 \\
\hline
\end{tabular}

Converting units for the lower heating value:

\begin{tabular}{|l|r|r|}
\hline & No. 2 Diesel Fuel & SME \\
\hline & & \\
\hline Lower Heating Value $(\mathrm{kJ} / \mathrm{kg})$ & 42640 & 37388 \\
\hline & & \\
\hline Lower Heating Value $(\mathrm{BTU} / \mathrm{b})$ & 18331.6 & 16073.7 \\
\hline
\end{tabular}




\section{Appendix D: Hand Calculations}

\section{Uncertainty Analysis for measurement equipment resolution, $w_{\text {res }}$} assuming: Proper calibration of measuring equipment prior to tests, $\omega_{c a l}=0$. Repeatability uncertainty, $\omega_{\text {rep }}=0$ due to kirge tolerimus, single operatar

$$
\begin{aligned}
& R=R\left(x_{1}, x_{2}, x_{3}, \ldots, x_{n}\right) \quad w_{R}=\text { uncertainty in } R \\
& w_{R}=\left[\left(\frac{\partial R}{\partial x_{1}} w_{1}\right)^{2}+\left(\frac{\partial R}{\partial x_{2}} w_{2}\right)^{2}+\ldots+\left(\frac{\partial R}{\partial x_{n}} w_{n}\right)^{2}\right]^{1 / 2}
\end{aligned}
$$

Engine operating conditions: Full throttle/load

$$
2800 \mathrm{rpm}
$$

$$
0.5 \mathrm{hrs} \text {. }
$$

Energy in: $\begin{aligned} \dot{Q}_{i n} & =\dot{m}_{f} \cdot L H V \\ & =\frac{w_{i}-w_{f}}{\Delta t} \cdot L H V\end{aligned}$

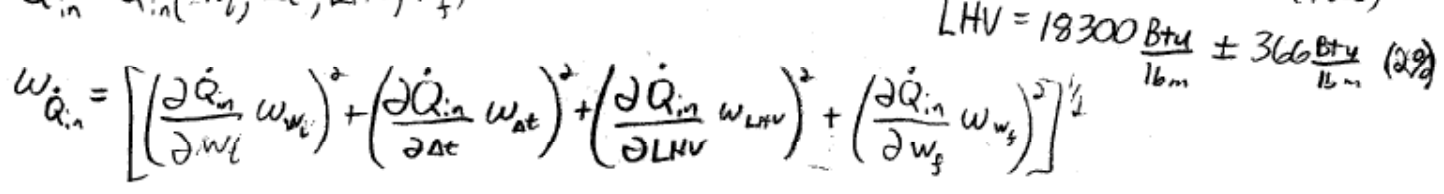

$\frac{\partial \dot{Q}_{i n}}{\partial w_{i}}=\frac{L H V}{\Delta t} \quad \frac{\partial \dot{Q}_{i n}}{\partial \Delta t}=-\frac{L H V\left(w_{i}-w_{f}\right)}{\Delta t^{2}} \frac{\partial \dot{Q}_{i n}}{\partial L H V}=\frac{w_{i}+w_{f}}{\Delta t} \quad \frac{\partial \dot{Q}_{i c}}{\partial w_{f}}=-\frac{L H V}{\Delta t}$

$\omega_{\dot{Q}_{\text {in }}}=\left[\left(\frac{18300}{.5} \cdot 0.005\right)^{2}+\left(\frac{-18300 \cdot 12,6}{.5^{2}} \cdot 0.00027\right)^{2}+\left(\frac{12.6}{.5} \cdot 366\right)^{2}+\left(-\frac{18300}{.5} \cdot 0.005\right)^{2}\right]^{1 / 2}$

$=9230.4 \frac{\mathrm{Btu}}{\mathrm{hr}}$

$\frac{\omega_{\dot{Q} \text { in }}}{\dot{Q}_{\text {in }}}=10 \gamma=2 \%$ 
121

Energy transferee to power output

$$
\begin{aligned}
& P_{b}=\tau_{b} w c=112 \mathrm{lb}-\mathrm{ft}\left(2800 \frac{\mathrm{rev}}{\mathrm{min}}\right)\left(\frac{2 \pi \mathrm{rad}}{\mathrm{irev}}\right)\left(\frac{6 \mathrm{amin}}{\mathrm{ibr}}\right)\left(\frac{1 \mathrm{Btu}}{778.2 \mathrm{lb} \cdot \mathrm{ft}}\right)=151920.3 \frac{\mathrm{btu}}{\mathrm{hr}} \\
& P_{b}=P_{b}\left(\tau_{b}, w\right) \\
& \tau_{b}=112.0 \mathrm{lb} \cdot \mathrm{ft} \pm 0.5 \mathrm{lb} \cdot \mathrm{ft} \\
& \omega=2800.0 \frac{\mathrm{rev}}{\mathrm{min}} \pm 0.5 \frac{\mathrm{rev}}{\mathrm{min}} \\
& C=\frac{120 \pi}{778.2} \frac{\mathrm{min} \cdot \mathrm{BH}}{\mathrm{rev} \cdot \mathrm{hr} \cdot \mathrm{Br} \cdot \mathrm{ft}} \\
& \omega_{P_{b}}=\left[\left(\frac{\partial P_{b}}{\partial \tau_{b}} \omega_{\tau_{b}}\right)^{2}+\left(\frac{\partial P_{b}}{\partial w} \omega_{w}\right)^{2}\right]^{1 / 2} \\
& \frac{\partial P_{b}}{\partial \tau_{b}}=\omega c \quad \frac{\partial P_{b}}{\partial \omega}=\tau_{b} c \quad \omega_{P_{b}}=\left[\left(2800 \cdot \frac{120 \pi}{72,2} \cdot 0.5\right)^{2}+\left(112 \cdot \frac{120 \pi}{778,2} \cdot 0,5\right)^{2}\right]^{1 / 2} \\
& =678.76 \frac{\mathrm{B}+\mathrm{u}}{\mathrm{hr}} \\
& \frac{\omega_{P_{b}}}{P_{b}}=.0045=0.45 \%
\end{aligned}
$$


122

Energy transferred to the engine coolant:

$$
\begin{aligned}
& \dot{Q}_{c}=\dot{m}_{c} C_{p_{c}}\left(T_{c, 0}-T_{c, i}\right)=\dot{V}_{c} \rho_{c} C_{p_{c}}\left(T_{c, 0}-T_{c, i}\right)
\end{aligned}
$$

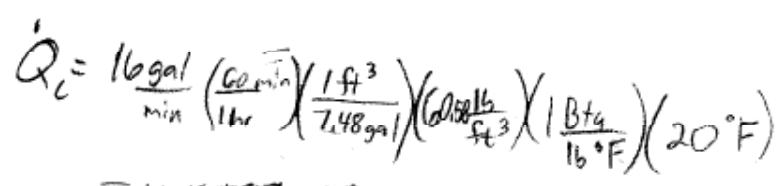

$$
\begin{aligned}
& =155499.5 \frac{\mathrm{Bty}}{\mathrm{hr}} \text { (nominal) }
\end{aligned}
$$

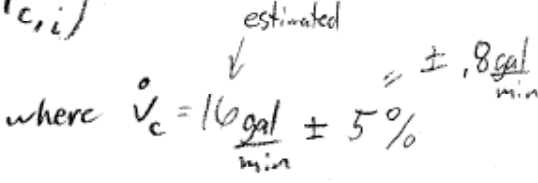

$$
\begin{aligned}
& \dot{Q}_{c}=\dot{Q}_{c}\left(\dot{\theta}_{c}, T_{c, 0}, T_{c, i}\right) \\
& P_{c}=60,5 \frac{16}{\mathrm{ft}^{3}}=C_{1} \quad \text { water } 010^{\circ} 0^{\circ} \mathrm{F} \\
& C_{P_{C}}=1,00 \frac{B+4}{16{ }^{\circ} \mathrm{F}}=C_{2}{ }^{\text {neater }} \text { (B) } 100^{\circ} \mathrm{F} \\
& \text { conversion factor: } 7.48 \text { gat } 1=1.4^{3} \\
& \omega_{\dot{Q}_{c}}=\left[\left(\frac{\partial \dot{Q}_{c}}{\partial \dot{V}_{c}} \omega_{\dot{v}_{c}}\right)^{2}+\left(\frac{\partial \dot{Q}_{c}}{\partial T_{c, 0}} \omega_{T_{c, 0}}\right)^{2}+\left(\frac{\partial \dot{Q}_{c}}{\partial T_{c, i}} \omega_{T_{c, i}}\right)^{2}\right] \\
& 7 \mathrm{~h} r=60 \mathrm{~min} \\
& T_{c, 0}=190^{\circ} \mathrm{F} \pm 3.6^{\circ} \mathrm{F} \\
& T_{c_{1}:}=170^{\circ} \mathrm{F} \pm 3.6^{\circ} \mathrm{F} \\
& \frac{\partial \dot{Q}_{c}}{\partial \dot{V}_{c}}=\left(T_{c, 0}-T_{c, i}\right) \cdot c_{1} \cdot c_{1} \cdot c_{3} \quad \frac{\partial \dot{Q}_{c}}{\partial T_{c, 0}}=\dot{V}_{c} \cdot c_{1} \cdot c_{2} c_{3} \frac{\partial \dot{Q}_{c}}{\partial T_{c, i}}=-\dot{V}_{c} \cdot c_{1} \cdot c_{2} \cdot c_{3} \\
& \omega_{\dot{Q}_{c}}=\left[\left(20 \cdot 60,58 \cdot 1 \cdot \frac{60}{7.48} \cdot .8\right)^{2}+\left(16 \cdot 60.58 \cdot 1 \cdot \frac{60}{7.48} \cdot 3.6\right)^{2}+\left(-16 \cdot 60.58 \cdot \cdot \cdot \cdot \frac{62}{7.48} \cdot 3.6\right)^{2}\right]^{1 / \alpha} \\
& =40340 \frac{\mathrm{Btv}}{\mathrm{hr}} \text {. } \\
& \frac{w_{\dot{Q}_{L}}}{\dot{Q}_{c}}=25.9 \%
\end{aligned}
$$


123

Energy transfer to the exhaust: see next sheet based mainly on airffuel ratio

A/F ratio measurements: Mass air flow rate and fund flow rate

Air flow rate: $\dot{M}_{4}$

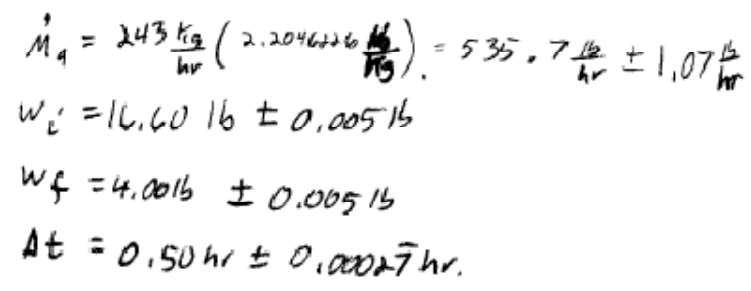

fuel flow rate $=\frac{w_{i}-w_{f}}{\Delta t}$

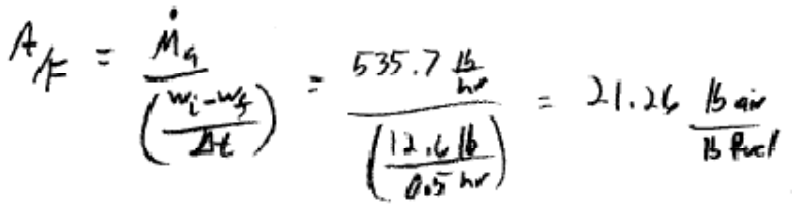

$$
\begin{aligned}
& \omega_{A_{/ F}}=\left[\left(\frac{\partial A_{/ F}}{\partial \dot{\mu}_{a}} \omega \dot{\mu}_{a}\right)^{2}+\left(\frac{\partial \mu_{B}}{\partial w_{i}} \omega_{w_{i}}\right)^{2}+\left(\frac{\partial A / F}{\partial w_{f}} w_{w_{t}}\right)^{2}+\left(\frac{\partial A / F}{\partial \Delta t} \omega_{\Delta t}\right)^{2}\right]^{1 / 2}
\end{aligned}
$$

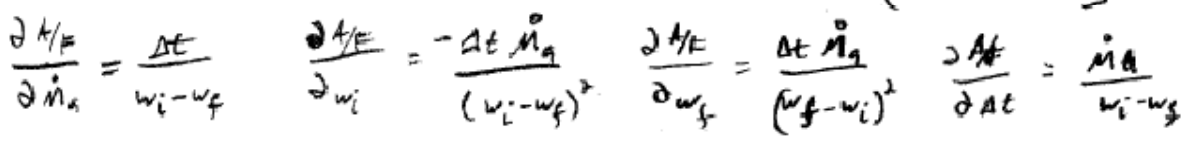

$$
\begin{aligned}
& v_{A_{j /}}=\left[\left(\frac{.5}{12.6} 1.07\right)^{2}+\left(\frac{-.5(535.7)}{12.6^{2}} \cdot 005^{-2}+\left(\frac{.5(535.7)}{(-12.6)^{2}} \cdot 005\right)^{2}+\left(\frac{535.7}{12.6}, 0.00027\right)^{2} 7^{\prime} / 2\right.\right. \\
& =0,045657 \frac{16 \text { air }}{16 \text { fuel }} \\
& \frac{W_{A / F}}{A / F}=.00215=0.215 \%
\end{aligned}
$$




$$
\begin{aligned}
& \text { inlet air }=128 \frac{\mathrm{ft}^{3}}{\mathrm{~min}} \quad p_{\text {air }} \text { ot } 77 \mathrm{~F} \text { and } 650 \text { metars above sealevel }: 1.118 \frac{\mathrm{kg}}{\mathrm{m}^{3}} \\
& \text { air flow rate }=128 \frac{\mathrm{ft}^{3}}{\mathrm{~min}}\left(0.06979 \frac{\mathrm{kb}}{\mathrm{ft}^{3}}\right)\left(\frac{60 \mathrm{~min}}{\mathrm{thr}}\right)=535.99 \frac{\mathrm{lb}}{\mathrm{hr}}=0.06979 \frac{\mathrm{bb}}{\mathrm{ft}^{3}} \\
& \text { fuel flow rate }=\frac{12.6 \mathrm{lb}}{.5 \mathrm{hr}}(2)=25.2 \frac{\mathrm{lb}}{\mathrm{hr}} \\
& \frac{A}{F}=21.27 \frac{15 \mathrm{air}}{16 \mathrm{fuel}} \text { (mass based) }
\end{aligned}
$$

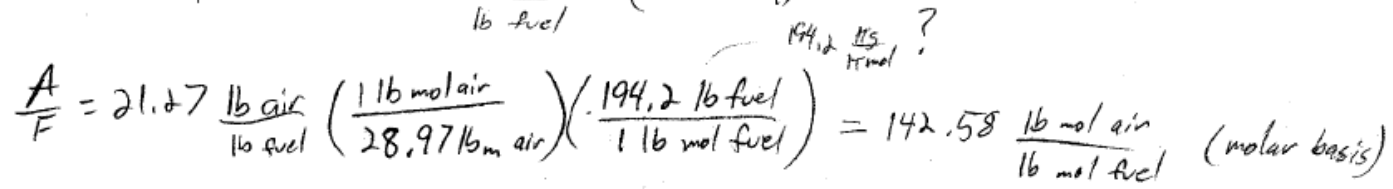

$$
\begin{aligned}
& C_{14.09} H_{24.78}+142.58\left[0.21 O_{2}+0.79 N_{2}\right] \Rightarrow \theta_{1} C_{2}+\theta_{2} H_{2} O+\theta_{3} N_{2}+\theta_{4} O_{2} \\
& \text { carbon balance: } 14.09=\theta_{1} \\
& \text { hydrogen balance: } 24.78=2 \theta_{2}: \theta_{2}=12.39 \\
& \text { Nitrogen balance: } 142.58(.79)_{2}=2 \theta_{3} \therefore \theta_{3}=112.6382 \\
& \text { Oxygen balance: } 142.58(.21)_{2}=14.09(2)+(12.39)(1)+2 \theta_{4} \therefore \theta_{4}=9.6568
\end{aligned}
$$

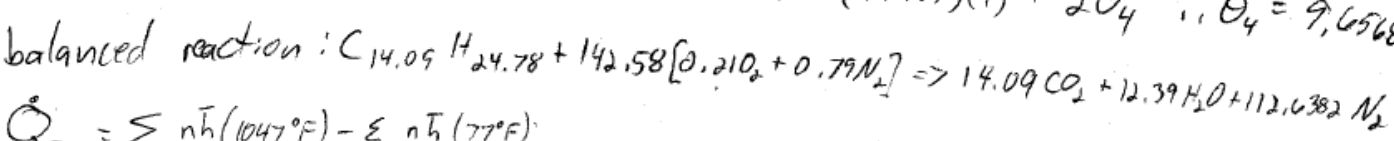

$$
\begin{aligned}
& Q_{E x}=\sum_{\text {prodicts }} n \bar{h}\left(1047^{\circ} \mathrm{F}\right)-\sum_{\text {prowuchs }} n T\left(77^{\circ} \mathrm{F}\right) \quad+9165680_{2}
\end{aligned}
$$

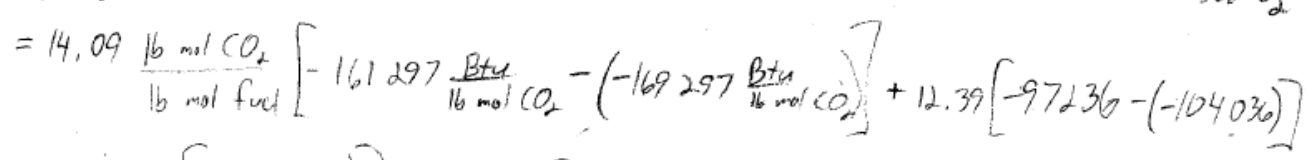

$$
\begin{aligned}
& +112.6382[6000-(0)]+9.6568[6000-0]=330742 \frac{\mathrm{B}+\mathrm{u}}{\mathrm{bm} \text { mol fuel }}
\end{aligned}
$$

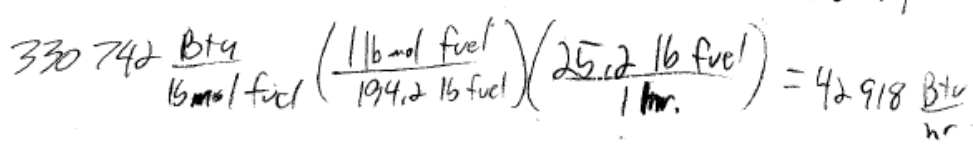


125

heat rejected to fuel: $6 \frac{\mathrm{BTT}}{\mathrm{min}}=360 \frac{\mathrm{BTV}}{\mathrm{hr}}$ from Commons

$$
\begin{aligned}
& \dot{Q}_{f \text { vel }}=\dot{m}_{f} C_{p_{\text {fuel }}} \Delta T \\
& =\frac{w_{i}-w_{f}}{\Delta t} \cdot C_{\text {fuel }} \cdot\left(T_{f, p}-T_{f, i}\right) \\
& w_{i}=16.6016=0.005 / 5 \\
& w_{Y}=4.001 \mathrm{~B} \pm 0.0051 \mathrm{~s} \\
& \Delta T=0.50 \mathrm{hr} \pm 0.0002 \mathrm{Fhr}
\end{aligned}
$$

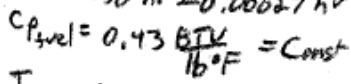

$$
\begin{aligned}
& T_{f, 0}=103,20 \mathrm{~F} \pm 3.6 \% \mathrm{~F} \\
& T_{f, i}=70.00^{\circ} \mathrm{F} \pm 3.6 \% \mathrm{~F} \\
& =\frac{12.6 \mathrm{Bb}}{.5 \mathrm{hr}}\left(.43 \frac{\mathrm{BTV}}{16^{\circ} \mathrm{F}}\right)\left(103.2^{\circ} \mathrm{F}-70^{\circ} \mathrm{F}\right)=360 \frac{\mathrm{BTV}}{\mathrm{hr}} \\
& \hat{Q}_{\text {fuel }}=\dot{Q}_{\text {feel }}\left(w_{i, w_{f}, \Delta t}, T_{f, 0}, T_{f, i}\right)
\end{aligned}
$$

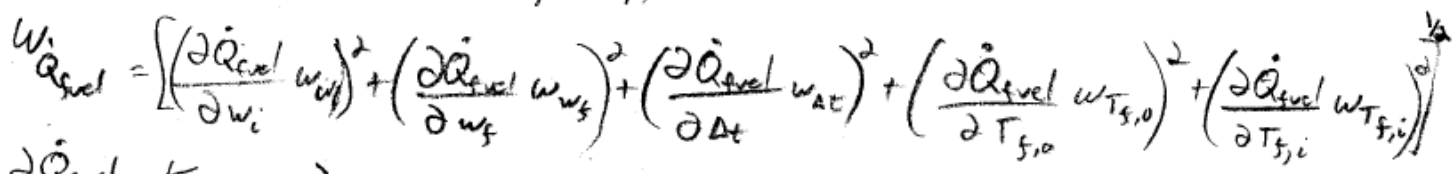

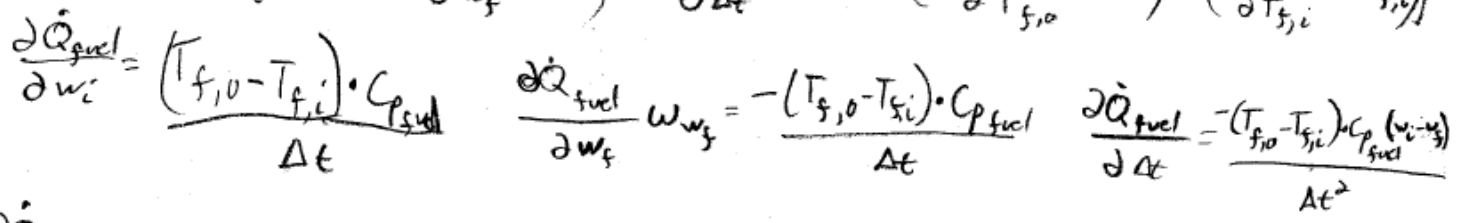

$$
\begin{aligned}
& \frac{\partial \dot{Q}_{\text {fuel }}}{\partial T_{f, 0}}=\frac{C_{p_{\text {fuel }}}\left(w_{i}-w_{f}\right)}{\Delta t} \quad \frac{\partial \dot{Q}_{\text {fuel }}}{\partial T_{f, i}}=-\frac{C_{p_{\text {fuel }}}\left(w_{i-w_{f}}\right)}{\Delta t} \\
& \omega_{\dot{Q}_{\text {fuel }}}=\left[\left(\frac{33,2 \cdot 0.43}{.5} \cdot 0.005\right)^{2}+\left(\frac{-33,2 \cdot 0.43}{.5} \cdot 0.005\right)^{2}+\left(\frac{-33,2 \cdot 0.43 \cdot 12.6}{.5^{2}} \cdot 0.0005 \overline{7}\right)^{2}\right. \\
& \left.+\left(\frac{0.43 \cdot 12.6}{5} \cdot 3.6\right)^{2}+\left(-\frac{0.43(12.6)}{.5} \cdot 3.6\right)^{2}\right]^{\prime / 2}=55.2 \frac{\mathrm{BTV}}{\mathrm{hr}} \\
& \frac{L \dot{Q}_{\text {fuel }}}{Q_{\text {fuel }}}=15,3 \%
\end{aligned}
$$


126

heat brought in by ambient air:

$$
\begin{aligned}
& \dot{Q}_{\text {air }}=\dot{m}_{\text {air }} C_{p_{a i r}} \Delta T=\dot{m}_{\text {air }} c_{p_{\text {air }}}\left(T_{a, a m b}-T_{a, 7 \geqslant \% F}\right) \\
& =882.6 \frac{\mathrm{H}}{\mathrm{hr}}\left(.24 \frac{\mathrm{BTV}}{16^{\circ} \mathrm{R}}\right)\left(130-77^{\circ} \mathrm{F}\right)=11226.7 \frac{\mathrm{BTV}}{\mathrm{hr}} \\
& \dot{m}_{\text {ir }}=882.60 \frac{\mathrm{db}}{\mathrm{hr}} \pm 1.765 \frac{\mathrm{lb}}{\mathrm{hr}} \\
& T_{a, a m b}=90.0^{\circ} \mathrm{F} \pm 3.6 \% \mathrm{~F} \\
& \dot{Q}_{\text {air }}=\dot{Q}_{\text {air }}\left(\dot{m}_{a,}, T_{a, \text { ans }}\right) \\
& c_{P_{\text {air }}}=24 \frac{B T U}{B_{b}{ }^{\circ}}=4 \\
& \omega_{\dot{Q}_{\text {air }}}=\left[\left(\frac{\partial \dot{Q}_{\text {air }}}{\partial \dot{m}_{a}} \omega_{\dot{m}_{a}}\right)^{2}+\left(\frac{\partial \dot{Q}_{\text {air }}}{\partial T_{a, m b}} \omega_{T_{a, m b}}\right)^{2}\right]^{1 / 2} \\
& T_{a,>P_{F}}=>>P_{F}=c_{p} \\
& \frac{\partial \dot{Q}_{a i r}}{\partial \dot{m}_{a}}=-\left(T_{a, 77 \cdot F}-T_{a, a m b}\right) \cdot C_{p_{\text {air }}} \quad \frac{\partial \dot{Q}_{a i r}}{\partial T_{a, a m b}}={ }^{+} \dot{m}_{a i r} c_{p_{\text {air }}}
\end{aligned}
$$

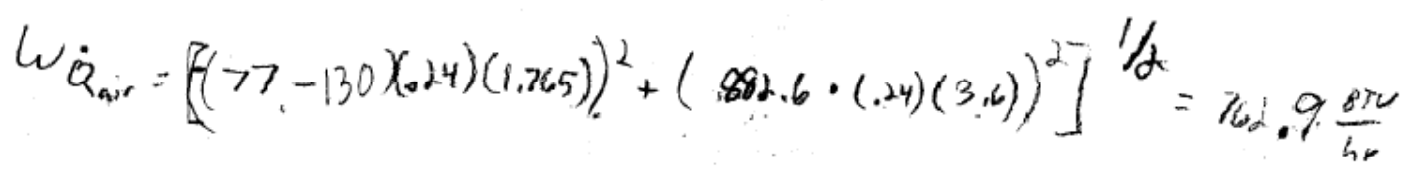

$$
\begin{aligned}
& \frac{w_{\dot{Q}_{\text {air }}}}{Q_{\text {air }}^{\prime}}=.0680=6,80 \%
\end{aligned}
$$


Appendix E: SOP/SER

\title{
Ohio Coal Research Center (OCRC)
}

\author{
Standard Operating Procedure
}

for

"Biofuels Engine Test Stand"

Document Number:
SOP_Biofuels_Engine_Test_Stand_080403.DOC

Authors:

Dhruv Kohli

Scott Wallace 


\section{Test System Description}

The Engine test stand is designed to facilitate emission and energy balance testing. The test bed is fully equipped with thermocouples to give readings for coolant (in \& out) temperatures, exhaust temperature, engine oil temperature, ambient air temperature and inlet air temperature. The diesel engine can run on pure biodiesel and/or any blends of biodiesel with regular diesel fuel. The dynamometer system is connected to a Dyne systems control box which contimuously monitors RPM, Torque and Power generated by the engine. An emission testing stand comprising of a NOx analyzer capable of monitoring up to $2000 \mathrm{ppm}$ of NOx is connected to the exhaust port. The complete system including the dynamometer's control box, Agilent data acquisition and the analyzer will gather complete information for the energy balance and emission's study.

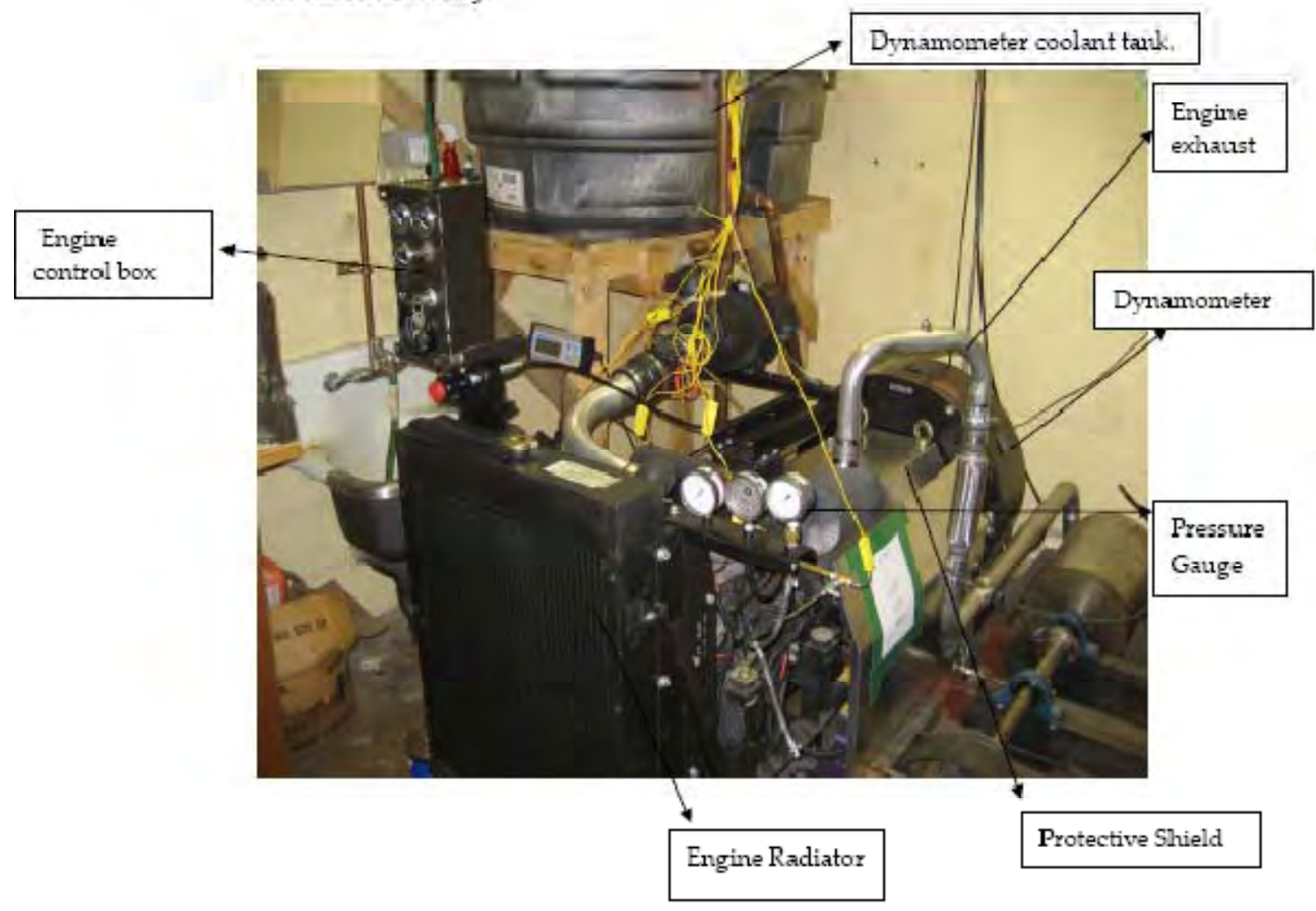

FIGURE 1 ENGINE TEST STAND 


\section{Personnel Preparations}

\section{A. Required Personnel Training}

\begin{tabular}{|l|l|l|}
\hline No. & \multicolumn{1}{|c|}{ Training for Operators } & \multicolumn{1}{c|}{ Offered By } \\
\hline 1. & $\begin{array}{l}\text { Occupational Safety and Health Administration } \\
\text { (OSHA) laboratory chemical hygiene training }\end{array}$ & $\begin{array}{l}\text { Environmental Health \& Safety } \\
\text { (EHS) at Ohio University }\end{array}$ \\
\hline 2. & Analytical Instruments Safety and Usage Guidelines & OCRC \\
\hline 3. & Lab Tools Usage Guidelines & OCRC \\
\hline
\end{tabular}

1. All operators are required to complete the "Laboratory Tool Training CheckList" and to follow the "Laboratory Tool Usage Guidelines" for OCRC.

2. All operators are required to complete the applicable portions of "Analytical Instruments Training Check-List" and follow the "Analytical Instruments Usage Guidelines" for OCRC.

\section{B. Required Safety Equipment}

\begin{tabular}{|l|l|l|l|}
\hline No. & \multicolumn{1}{|c|}{ Safety Equipment } & \multicolumn{1}{|c|}{ Purpose/Condition } & \multicolumn{1}{c|}{ Location } \\
\hline 1. & Safety Glasses & For General Safety & Stocker 012 \\
\hline 2. & $\begin{array}{l}\text { M40 Multi-Gas } \\
\text { Monitors }\end{array}$ & For monitoring CO level in the lab & Stocker 012 \\
\hline 3. & CO Detector & For monitoring CO level in the lab & Stocker 012 \\
\hline
\end{tabular}

\section{Required Tools/Analytical Equipment}

\begin{tabular}{|l|l|l|l|}
\hline No. & \multicolumn{1}{|c|}{ Tools/Equipment } & \multicolumn{1}{|c|}{ Purpose } & \multicolumn{1}{|c|}{ Location } \\
\hline 1. & Dyne Controller & $\begin{array}{l}\text { To monitor RPM, torque and } \\
\text { Power }\end{array}$ & Stocker 012 \\
\hline 2. & Agilent Data Acquisition & $\begin{array}{l}\text { To monitor Coolant (in \& out) } \\
\text { temperature, Exhaust } \\
\text { Temperature, engine oil } \\
\text { temperature, inlet air temperature. }\end{array}$ & Stocker 012 \\
\hline 3. & NOx Analyzer & $\begin{array}{l}\text { To monitor NOx in the engine } \\
\text { exhaust }\end{array}$ & Stocker 012 \\
\hline 4. & Digital Scale/Readout & To Weigh fuel & Stocker 012 \\
\hline 5. & 12 V Power Supply & To power mass air flow sensors & Stocker 012 \\
\hline 6. & K Type Thermocouples & For temperature measurement & Stocker 012 \\
\hline 7. & Mass air flow sensor & To measure Intake air flow & Stocker 012 \\
\hline 8. & Temperature Monitor & To monitor room temperature & Stocker 012 \\
\hline
\end{tabular}




\begin{tabular}{|l|l|l|l|}
\hline 9. & Phill:ps Screw Driver & $\begin{array}{l}\text { To pump the fuel from the fuel } \\
\text { pump }\end{array}$ & Stocker 012 \\
\hline
\end{tabular}

\section{Required Procedures}

No required procedures exist for operating the engine test stand.

\section{Project/Site Preparations}

\section{A. Required Services}

\begin{tabular}{|l|l|l|l|}
\hline No. & \multicolumn{1}{|c|}{ Service } & \multicolumn{1}{c|}{ Purpose } & \multicolumn{1}{c|}{ Location } \\
\hline 1. & 110 V electrical & General power requirements & Stocker 012 \\
\hline 2. & 220 V Electrical & To power Dynamometer system & Stocker 012 \\
\hline 3. & Regular Diesel fuel & Diesel fuel testing & Stocker 012 \\
\hline 4. & Water Supply & Dynamometer Cooling System & Stocker 012 \\
\hline
\end{tabular}

\section{B. Required Equipment/Supplies}

\begin{tabular}{|l|l|l|l|}
\hline No. & \multicolumn{1}{|c|}{ Equipment } & \multicolumn{1}{c|}{ Purpose } & \multicolumn{1}{c|}{ Locaticn } \\
\hline 1. & Air circulation fan & For blowing hot air of the lab & Stocker 012 \\
\hline 2. & Water pump & For coolant water circulaton & Stocker 012 \\
\hline 3. & 55 Gallon biodiesel drum & Biodiesel testing & Stocker 012 \\
\hline 4. & 5 gallon transfer cans & $\begin{array}{l}\text { For transferring fuel into the } \\
\text { engines fuel supply }\end{array}$ & Stocker 012 \\
\hline
\end{tabular}

\section{Required Number of Operators}

A minimum of one operator and one observer is required all the time when testing is conducted.

\section{Date of Final Safety Review Board Evaluation and Certification of Project/Stite}

Safety Certification Completed: 


\section{Operation}

\section{A. Calibration of the Dynamometer}

1. The dyno needs to be calibrated before the first time use. To calibrate the dyno refer to the calibration procedure mentioned in Appendix A.

\section{B. Preparation of the Lab}

1. Make sure that the coolant water tank is filled up at least $3 / 4$ of its maximum capacity.

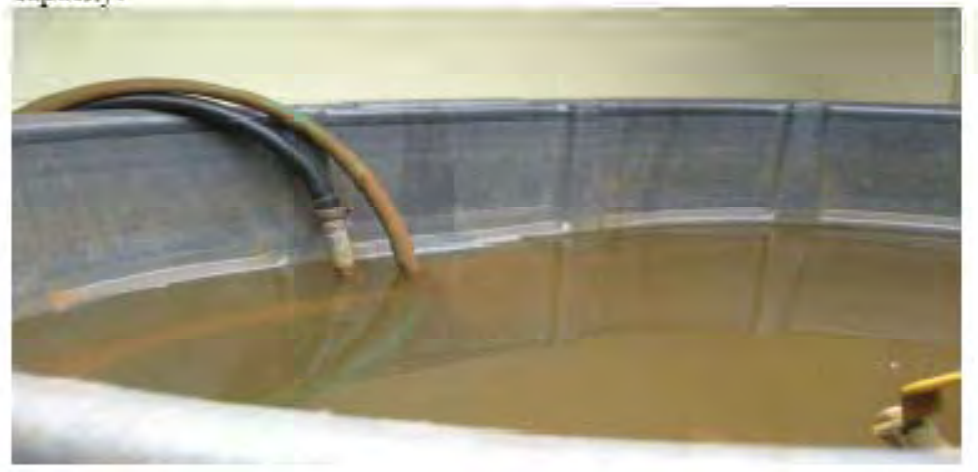

FIGURE 2 COOLANT WATER TANK FILLED $3 / 4$ OF ITS CAPACITY.

2. Make sure clear retum tube is attached is attached to the coolant retum pipe that has the flow control valve on it. Also make sure the water supply is tumed on.

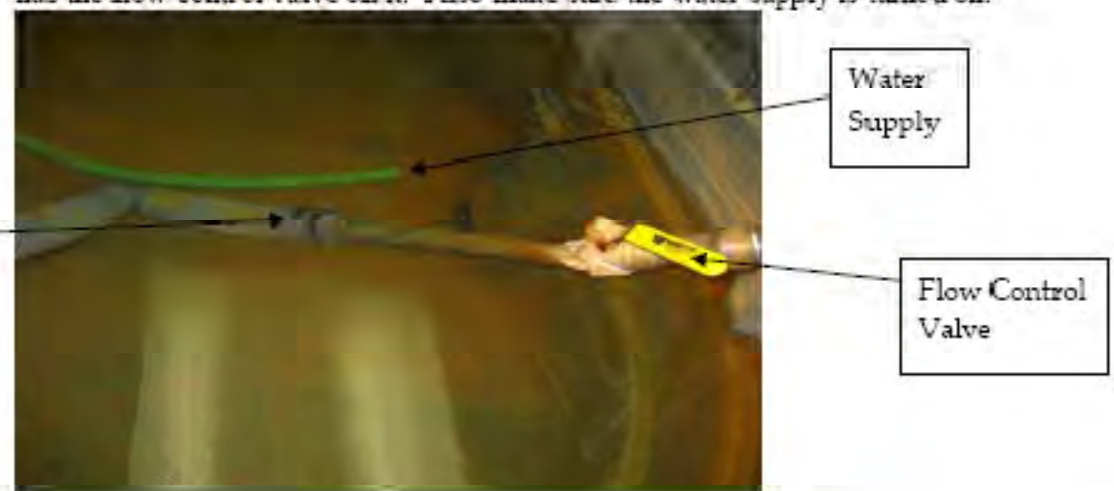

FIGUDE 5. RETURN TUBE FLOW CONTHOL VALVE AND WATER SUFFLY 
3. Plug in the water pump into the electric supply for just a fraction of a second vo get the water to flow through the coolaur retum mo the sink.

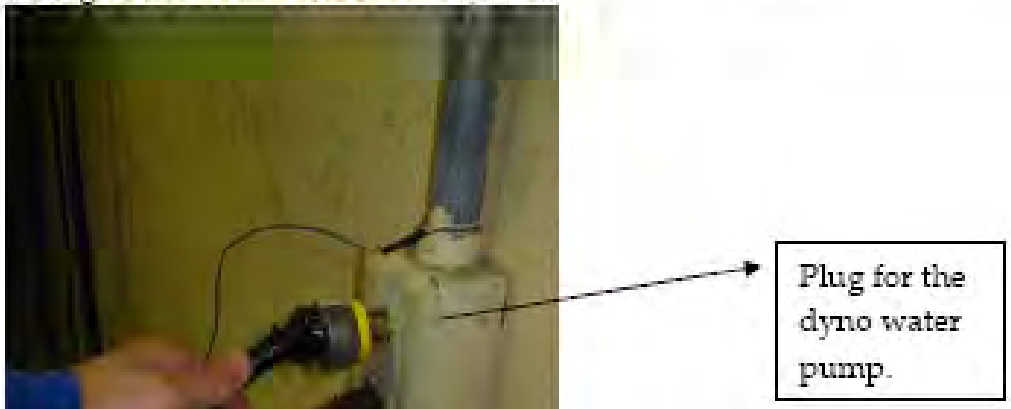

FIGURE 4. COOLING TANK WATER PUMP PLUGGED INTO THE ELECTRIC SUPPLY.

4. Make sure that the flow from the cold water supply is the about the same as the coolant renurn by adjusting the flow connol valve in Figure 3 matil the level in the tank stays coustait. Also check to make sure that the presaue gauge on the pump reads at least 13 psi. This pump is located on the ground below the coolant tank:

Coolant

Retum to

Sink

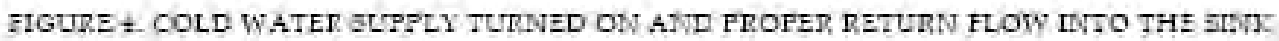


5. Place the ventilation fan abou: 6 to 8 inches from the frout of the engmes radiator and tum the far to the "High" position.

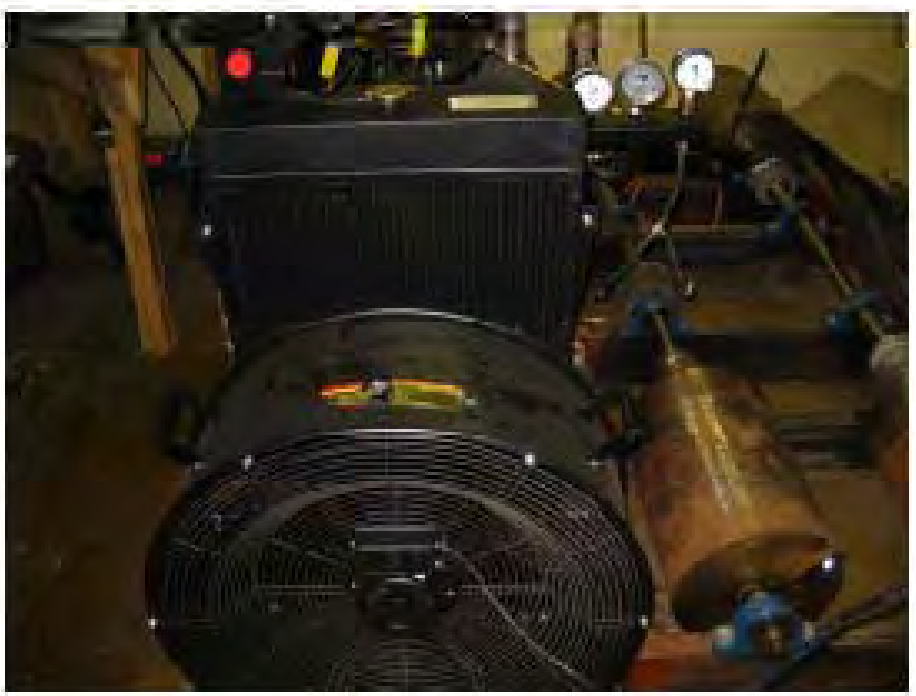

FIGURE 4. VEMTILATION FAB;

6. The exhaust oulet shonid run dirough the open lab coors past the filst cracti in the ride wall as shown in the picture belcw.

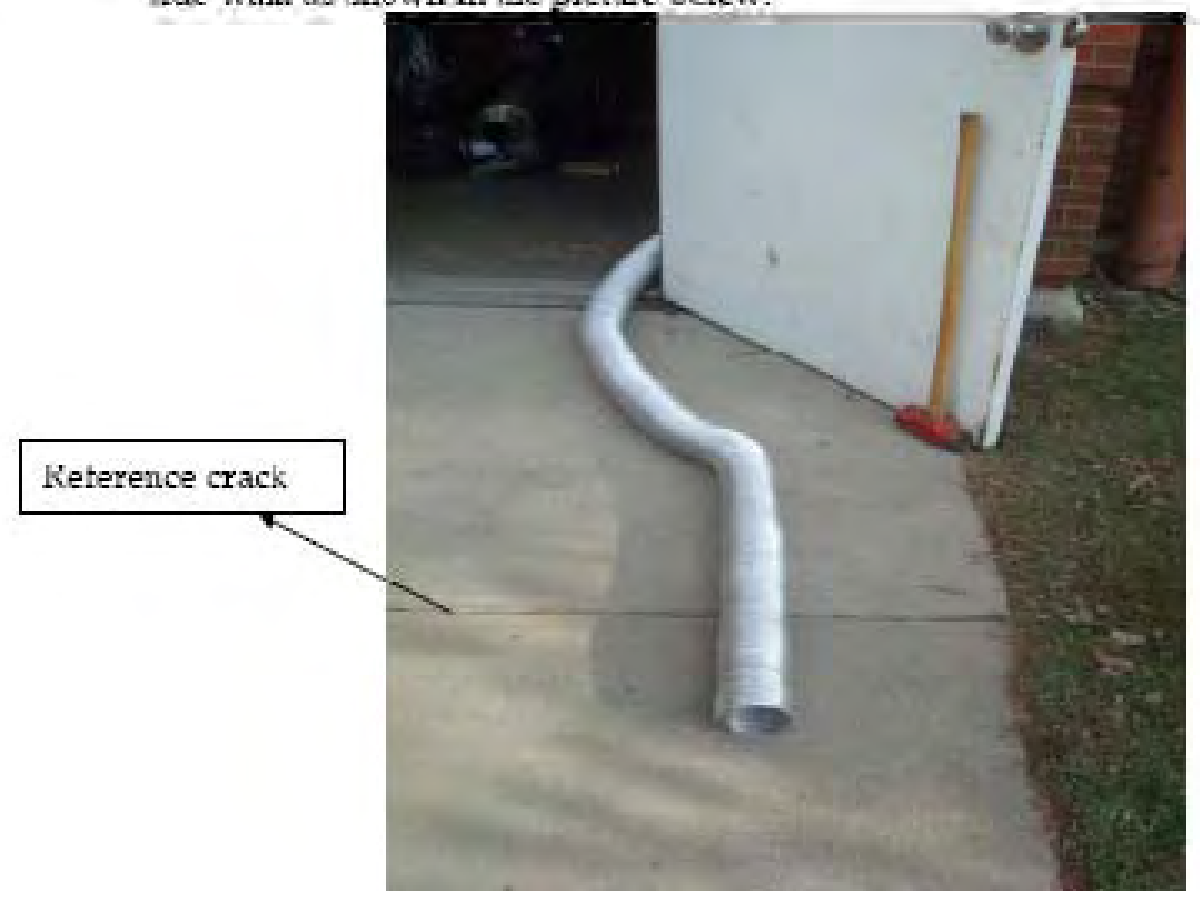

FIGURE 5. EXHAUST LIN RUNNING OUT OF THE LABS MAIN DOOR. 
7. Make sue that you. press the dyme ofl button on the dyne contuollen and set the initial RPM values according to test plan.

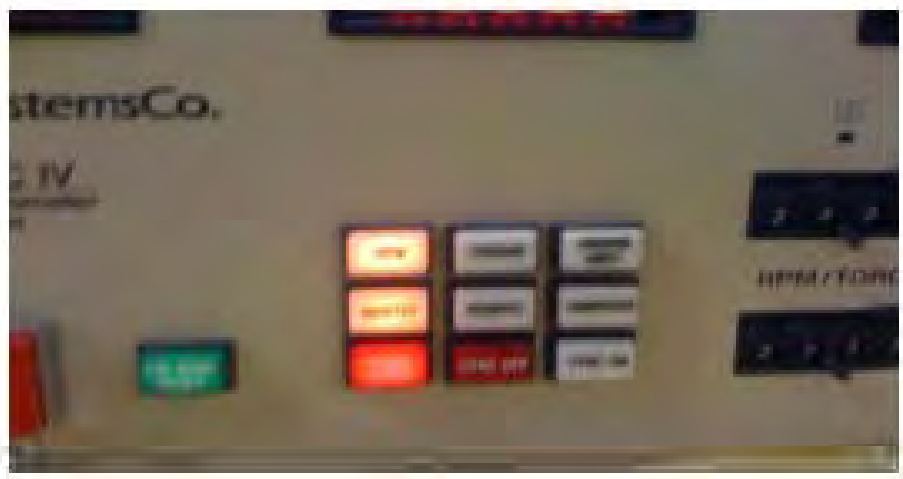

FICURE 6. DYNAMOMBTER CONTROL UNIT

8. Fun on the M40 ges monitor. Wait for monitor reading to stabilize ( 20 to $25 \mathrm{sec}$ )

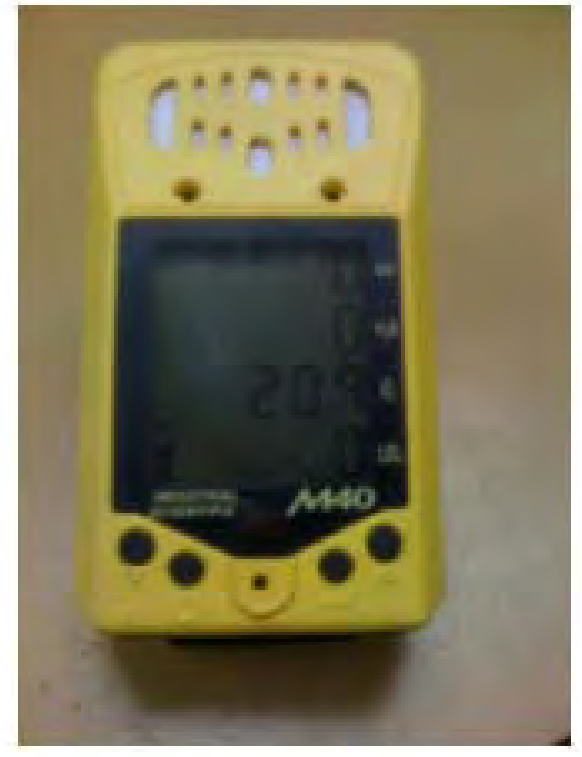

FIGURE 7. M40 GAS MONITOR. 
9. The operator or observer should wear the $\mathrm{CO}$ detector on his her belt.

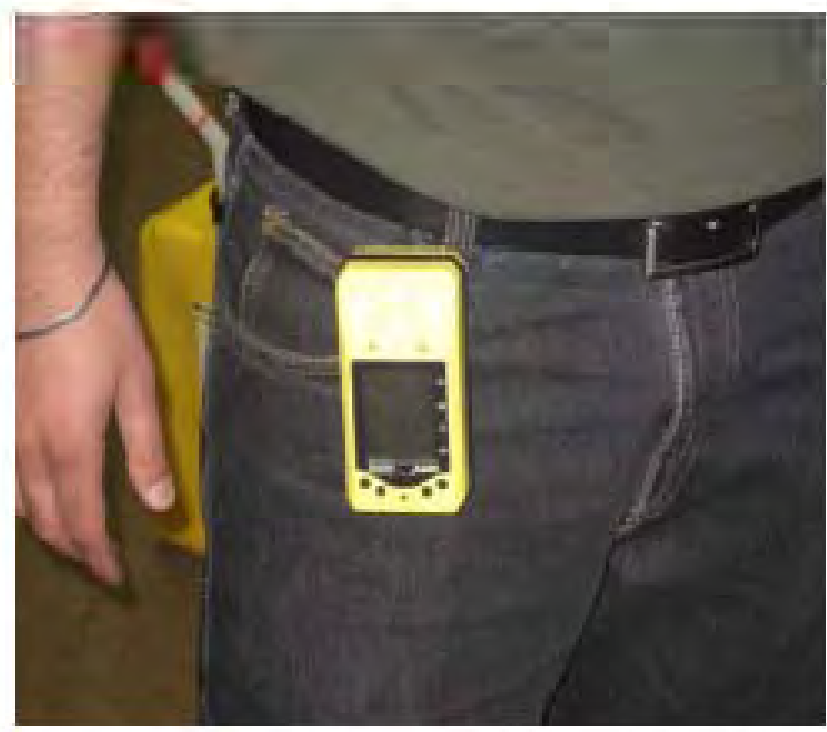

FIGURE 3. OPERATOR WITH THE M40 GAS MONITOR ON HIS BELT

10. Verify that there is power to the CO room monitor. The monitor should read as shown in the picture below.

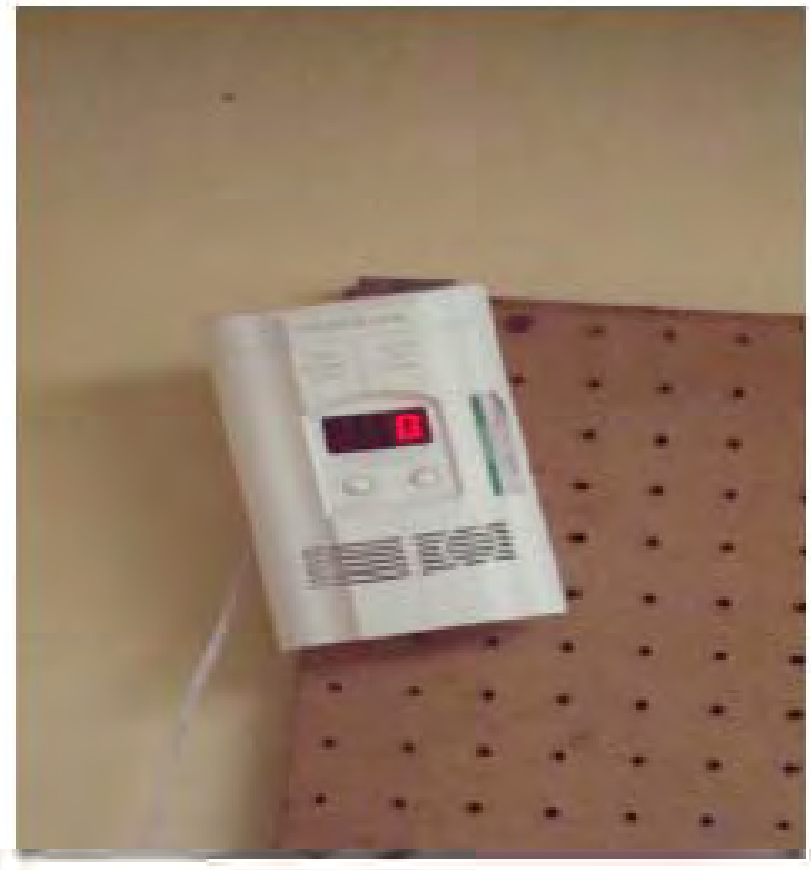

FIGURE 9. WALL HANGING CO DETBCTOR. 
11. Check that the coupling shield is securely bolted in place. Also conduct a visual inspection of all the engine mounting bolts. The engine mounting bolts should be checked for proper torque specifications every 30 hours of operation or 6 months (whichever comes first)

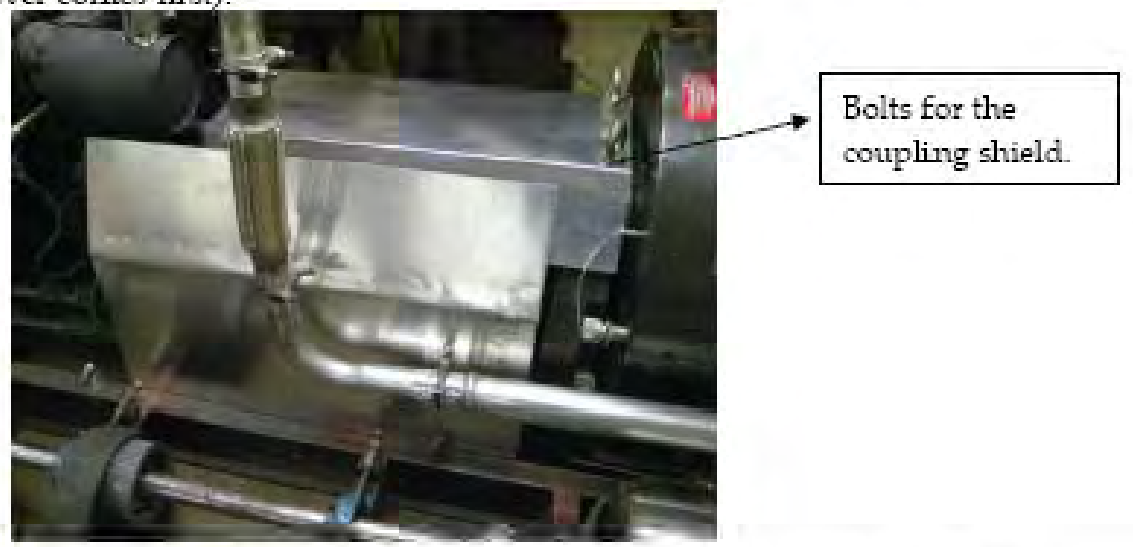

FIGUSE 10. SHIELD ON THE COUPLMYG TO PREVENT INIURY FROM ANY ROTATMVG COMPONENTS

\section{Starting the Engine}

1. The operator or observer should wear safety glasses and the M40 multigas detector on his/her belt.

2. No one should be standing between the sink and the engine when operating the engine.

3. Turn the engine key to on position, press the "Murphy Tattletale" switch simultaneously.

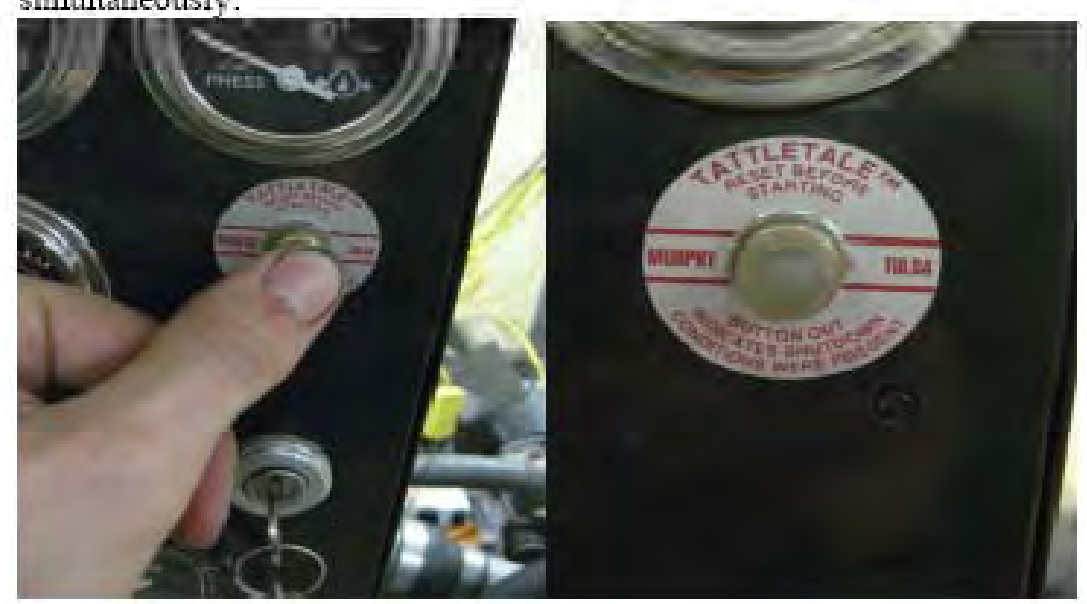

FIGURE 11. OPERATOR PRESSING THE MURPHY TATTLETALE SWITCH SHORTLY BEFORE CRANKING THE ENGINE. 
4. Crank the engine and hold the "Murphy Tattletale" switch tuntil the low pressure inght goes oft.

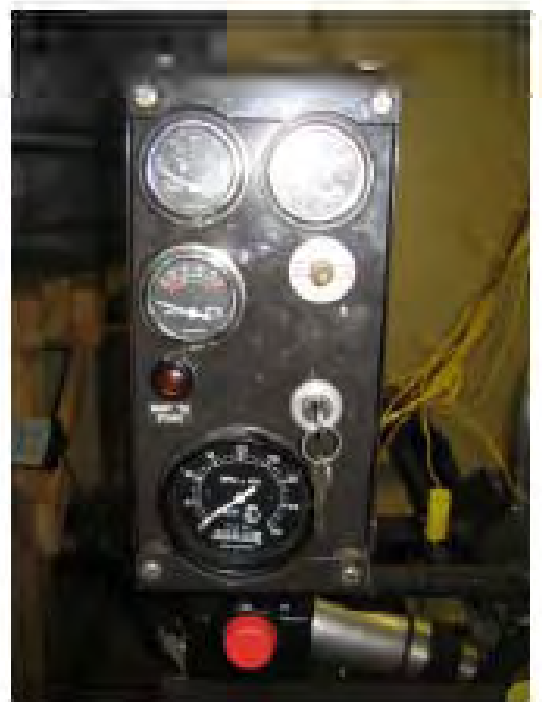

IIGURE 12. ENGINE CONTROL UNIT

\section{Fuel Transfer}

1. The transfer of fuel takes place either from the diesel can to the diesel fuel tank or from the biodiesel drun to the biodiesel can to the bicdiesel fuel tank. For this reason the biodiesel fuel transfer steps will be outlined since they are the same as the diesel fuel with the extra complexity of transferring the fuel from the drum to the biodiesel can.

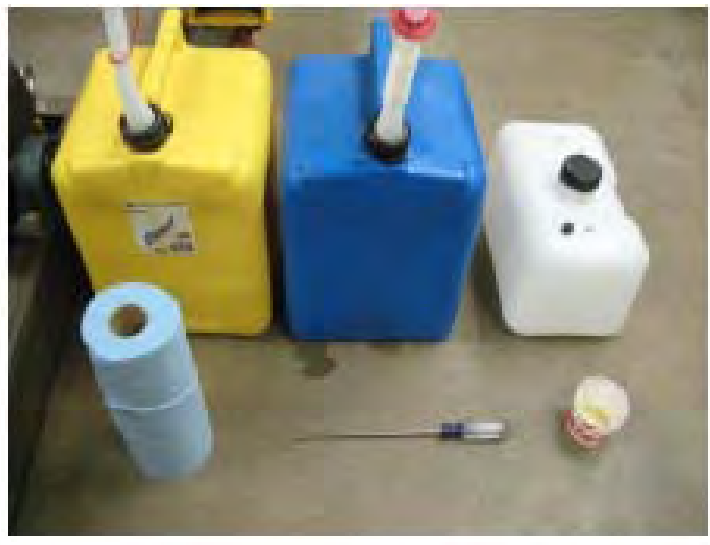

FIGURE 13. DIESEL TRANSFER CAN (YELLOW), BIODIESEL TRANSFER CAN (BLUE) AND FUEL TANK (WHITE) WHICH INCLUDES THE DIESEL (YELLOW) AND BIODIESEL (BLUE) CANS, THE FUEL TANK (WHITE), SHOP RAGS, A PHILLIPS SCREWDRIVER, AND A SMALL CATCH CUP. 


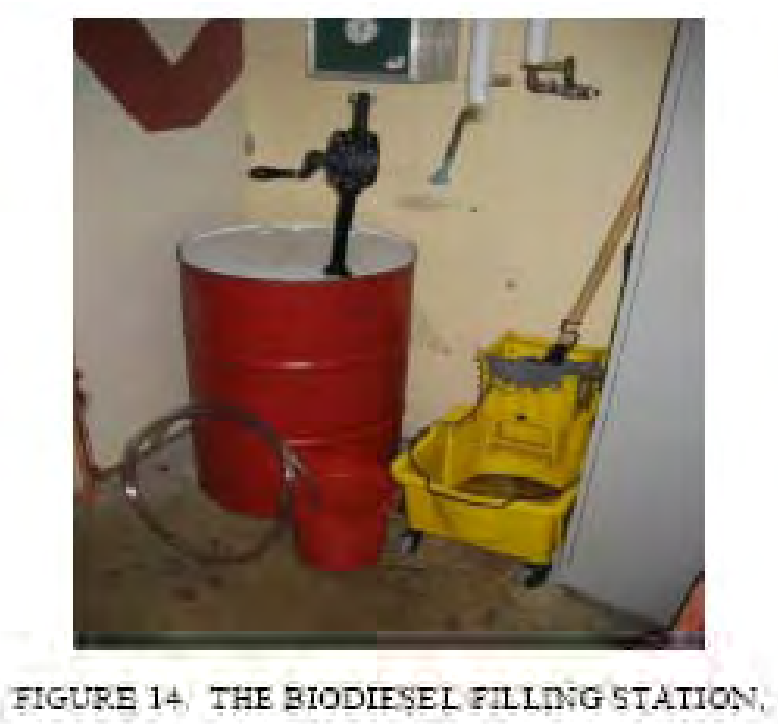

2. It is important to keep the floor clean to prevent anyone from slipping filling. For this reason. all suills should be cleaned up immediately with the mop. The drip bucket should remain under the pump spout in case of excess fuel drainage. The setup for fuel transfer is shown below.

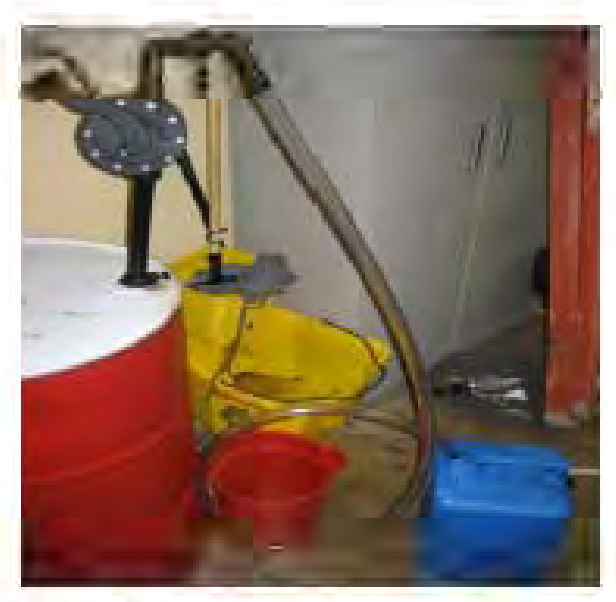

FIGURE 15. BIODIESEL DRUM, ROTARY HAND PUMP. IRANSFER HOSE, DRIP CONAINER. AND MOP BUCEET.

3. The transfer hose should be hooked up to the pump and the other end inserted into the biodiesel can. Always make sure that the transfer hose is inserted at least 3 inches into the biodiesel can to insure it doesn't fall out during filling. Once the hose is connected, rotate the pump handle clockwise. This will fill the can at a rate of 1.3 gallons per 20 hand cranks. The biodiesel can holds 5 gallons and the biodiesel fuel tank only holds two gallons. Therefore, it is only necessary to fill the can up about halfway which is recommended for ease of handling and pouring. After the biodiesel can has the appropriate amount of fuel in it, the end of the 
transfer hose comected to the rotary hand pump outlat should be removed and the excess furel in the transier hose should be allowed to drain into the biodiesel can (Figure 15).

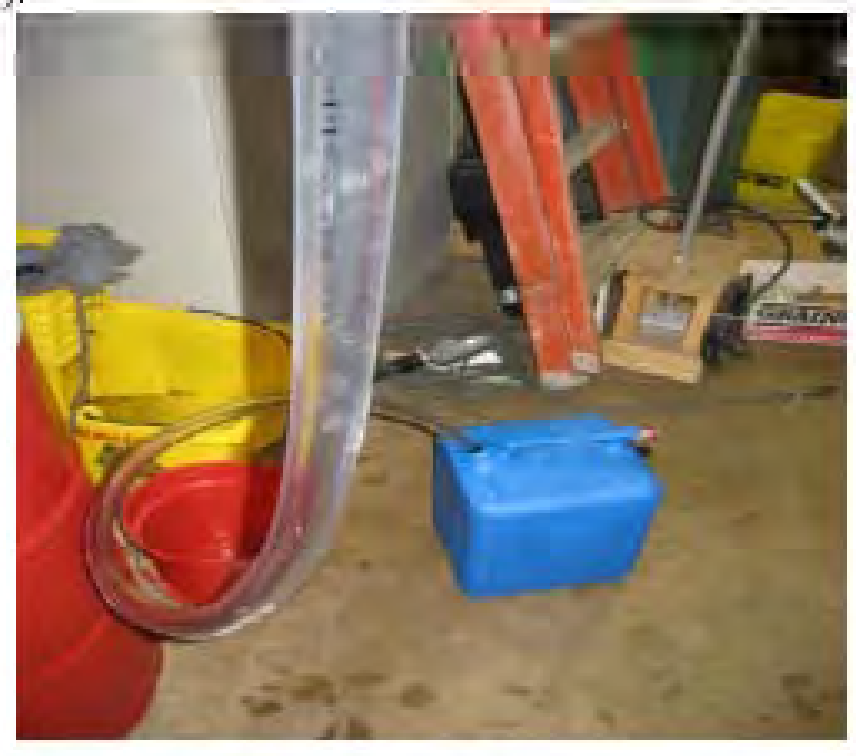

FIGURE 16. TRANSFER HOSE AND BIODIZSEL CAN.

4. Unce the fiuel has dramed, the hose can be removed from the biodiesel can and set down with the ends placed into the drip can incase of additional fual drainage. At all times shop rags shonld be slose by for wiping wo small fuel drips throughout these sters.

5. Place the pour spout onto the biodiesel can and place the biodiesel fuel tank on an elevated surface with the lid removed so that it can easily be filled. Bend the pour epout on the biodiesel can down so that it fite into the biodiecel fuel tank opening and slowly pour in the desired amount of fuel.

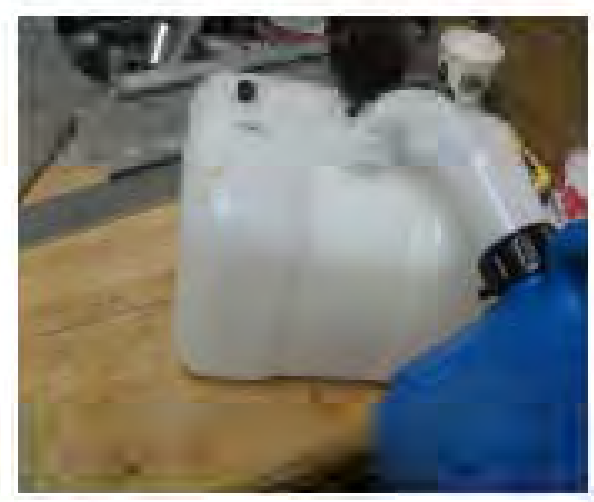

FIGUFE 12. FUEL TRANSFER TO THE FUEL TANK FFOM BIODIESEL TRANSFER CAN 
6. Once the biodiesel fuel tank is filled to the desired capacity it should be placed on the scale behind the engine. The fuel supply line will already be attached to the fuel tank and the other end should be comected to the fuel filter inlet and secured with a hose clamp. Also, the thermocouple with rubber stopper attached should be placed into the hole next to the fuel supply line and the fuel return line which is already attached to the engme should be inserted into the hole on the opposite end of the tank as the supply line. Make sure that the hoses and themocouple reach to the bottom of the tank to insure they will always remain under the fuel. An image of the setup is shown below.

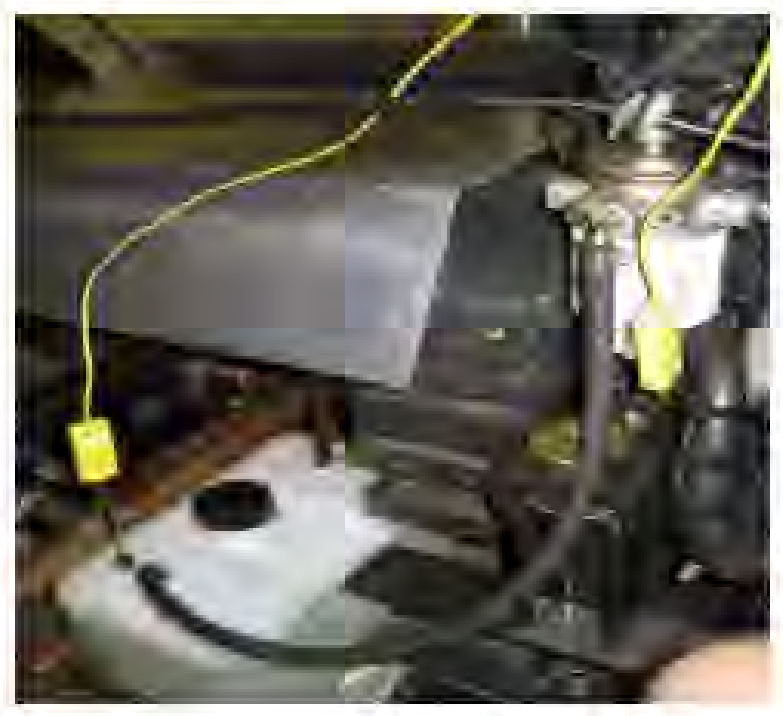

FIGURE 17 SETUP SHOWING FUEL TANK, FUEL FIL TER, THERMOCOUPLE WITH RUBBER. STOPPER, FUEL SUPPLY LINE AND FUEL RETURN LINE.

\section{E. Changing between fuel sources}

1. When changing from one fuel source to another, such as regular diesel fuel to biodiesel fuel it is important to change fuel tanks to insure that the different fuels are not mixed together. In order to change from one tank to another, the fuel supply line should be removed from the fuel filter inlet by loosening the hose clamp with a Phillips screwdriver and pulling the line towards the floor while holdmg the small catch cup under the fuel filter inlet. Before doing this make sure to keep shop rags around to clean up small fuel drips that are not contained. This holds true for the remainder of this procedure. Also, remove the fuel return line and the fuel tank thermocouple and place them both on a rag on top of the driveshaft guard. 


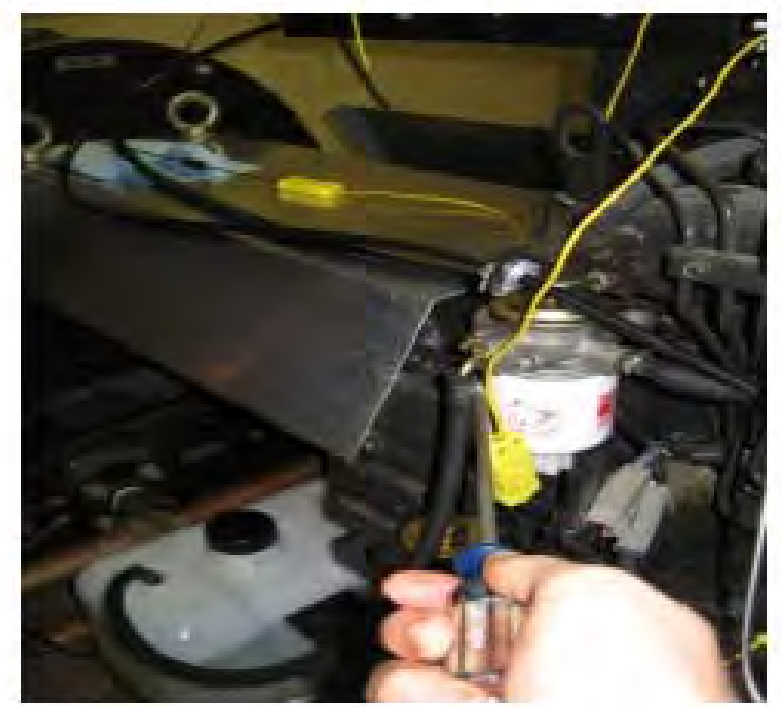

FIGURE 18. FUEL FILTER, RETURN LINE AND THERMOCOUPLE.

2. Now the fuel tank can be lifted off of the scale and the other fuel tank (with a different type of fuel) can be placed onto the scale and hooked up in accordance with the procedure outlined in the "Fuel Transfer" section.

\section{F. Priming the fuel system}

1. Once the new fuel source as been hooked up to the engine, it is important to purge the system of any remaining fuel from previous testing. The majority of this fuel will be in the engine's fuel filter. To purge this old fuel, place the small catch cup under the fuel filter as shown below and loosen up the air bleeding screw to the left of the fuel inlet.

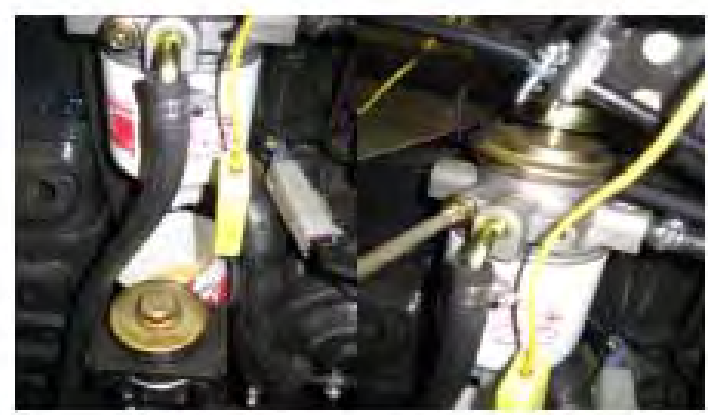

FIGURE 19. CATCH CUP AND THE FUEL FILTER FOR DRAINING THE LEFT OVER FUEL FROM THE SYSTEM. 
2. Next unscrew the drain on the bottom of the filter and allow the fuel drain down into the small catch cup.
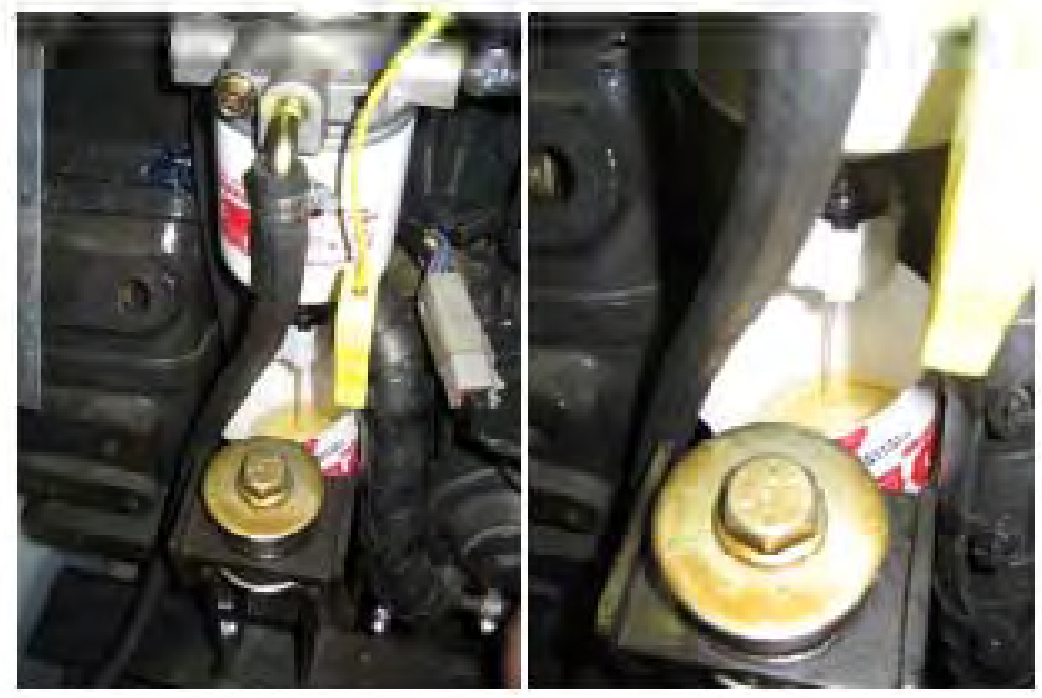

FIGURE 20. FUEL DR.AINING OUI OF THE FUEL FILIER.

3. Once all the fuel from the filter has drained, screw the drain back in and remove the catch cup. Take the fiuel from the small catch cup and pour the fiel back into its respective can making sure not to allow large dirt particles to escape. Clean the remainder of the dirt and fuel out of the small catch cup with a rag.

4. Next place the small catch cup back under the filter and with the air bleeding screw loose (about 4 full turns) pump the hand primer located at he top of the fuel filter housing. Continue pumping until no more air come out of the bleeding sxrew and only fuel flows out. This should only take about 15 or 20 seconds of moderate pumping.
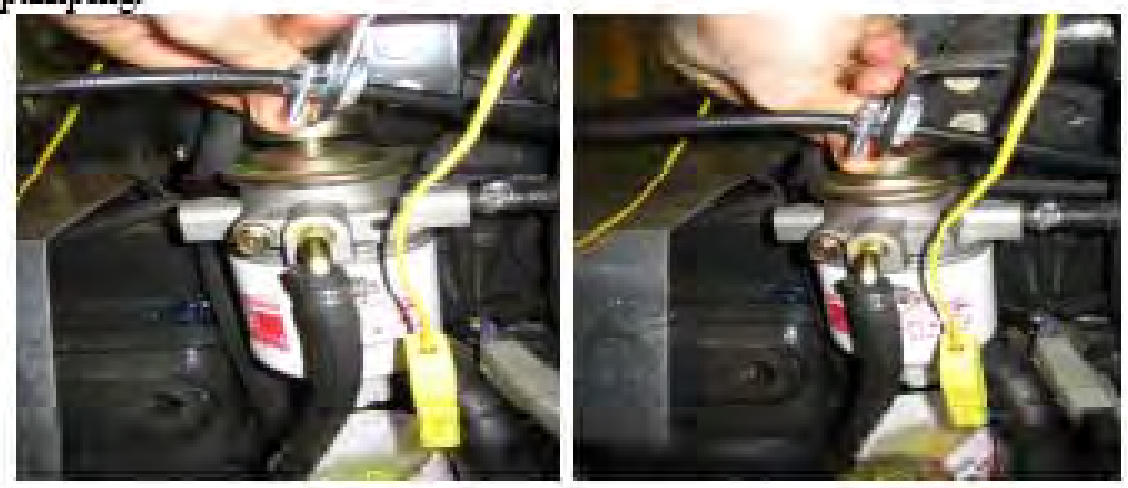

FIGURE 21. OPERATOR PUMPING THE FUEL FILTER 
5. Once fuel is flowing ont of the bleeding screw, tighten it up as you are applying moderate pressure to the pump. Once the bleeding screw is tightened the priming pump should be hard to pump and at this point the fuel system on the engine should be primed with very few remnants of the previous fuel source used for testing. As always be sure to wipe up any fuel residue off of engine components and from the surrounding area.

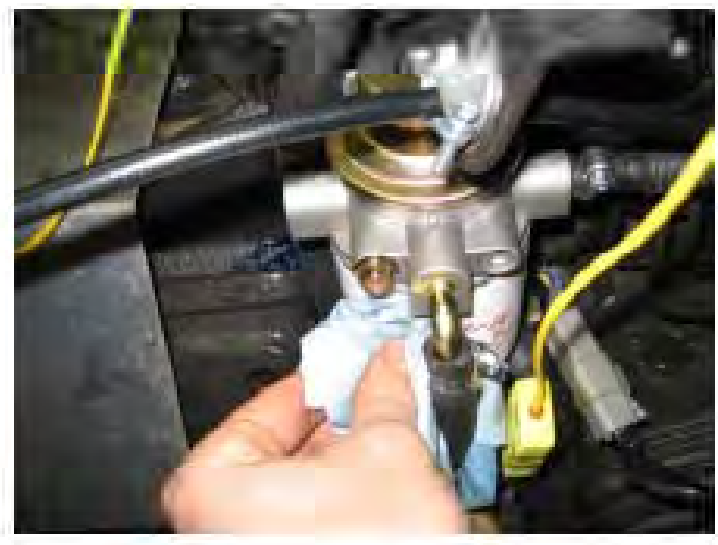

FICURE 22. OPERATOR CLEANING THE FIL TER AND ENGINE COMPONENTS TO MAKE SURE THERE IS NO FUEL SPILLAGE.

\section{G. Safoty moasures while the engine is in operation}

1. Once the engine has reached normal operating temperature the operator should check to make sure that there is not excessive smoke coming out of the exhaust exit. If this condition exists, shut down engine and consult engine manufacturer.

2. In case of any emergency or any mishap with the engine the operator should either hit the red button on the throttle to bring the engine down to idle and turn of the engine key or just hit the emergency stop buton on the dynamometer's control unit.

3. If something goes wrong with the drive shaft or the ccupling system, the operator is required to hit the red button on the throttle as quickly as he can and turn off the engine key.

\section{H. Engine shut down procedure}

1. Bring the engine back to idle and turn off the engine.

2. Put the dynamometer in the dyne off mode.

3. Let the cooling fan and the water pump run for at least $5 \mathrm{~min}$ and shut it down.

4. After attaining a constant room temperature shut down the cooling fans and the water pump. 


\section{Project/Site Cleanup}

1. Sweep the floor if required.

2. In the event of a large fuel spill (1 gallon or mcre), the available cleanup equipment consist of: a mop and bucket, oil-dry, shop rags and all-pupose cleaner with degreaser. These cleamp materia.s should be used in that order to insure the floor will be dry with no slippery residue. These materials are all located by the biodiesel storage drum. If there is any question of how to clean up a spill, EHS should be contacted at 740-593-1662. 

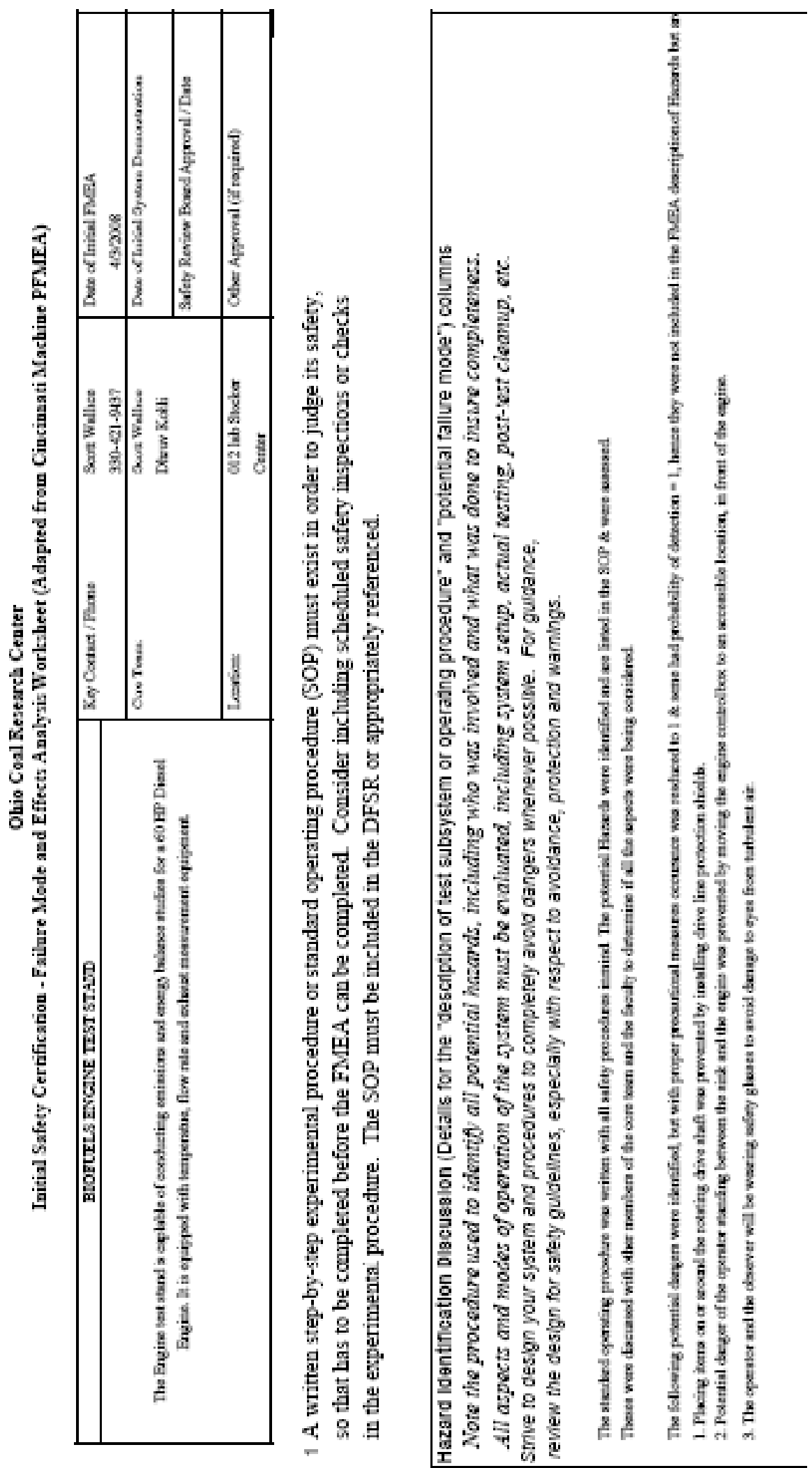


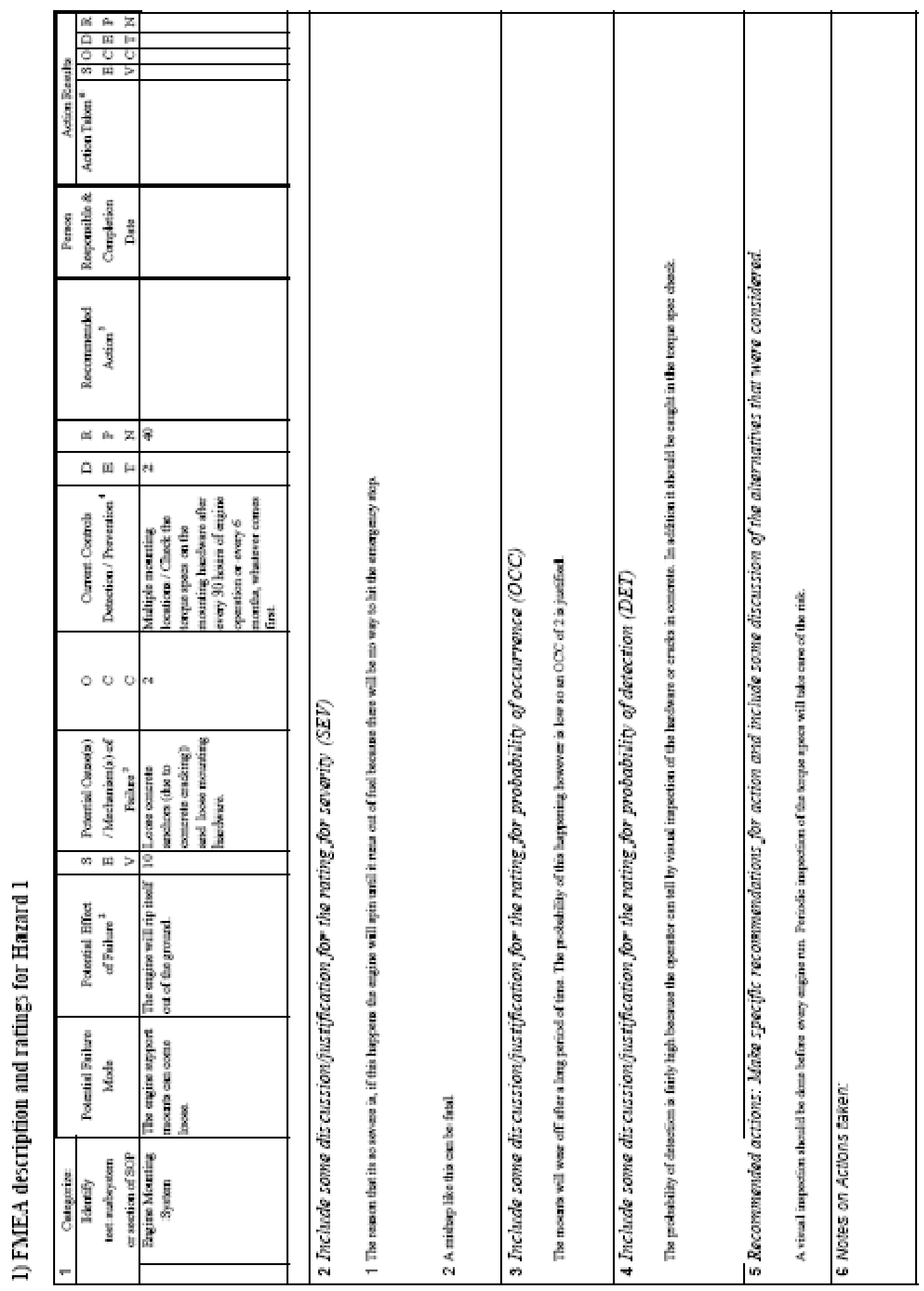




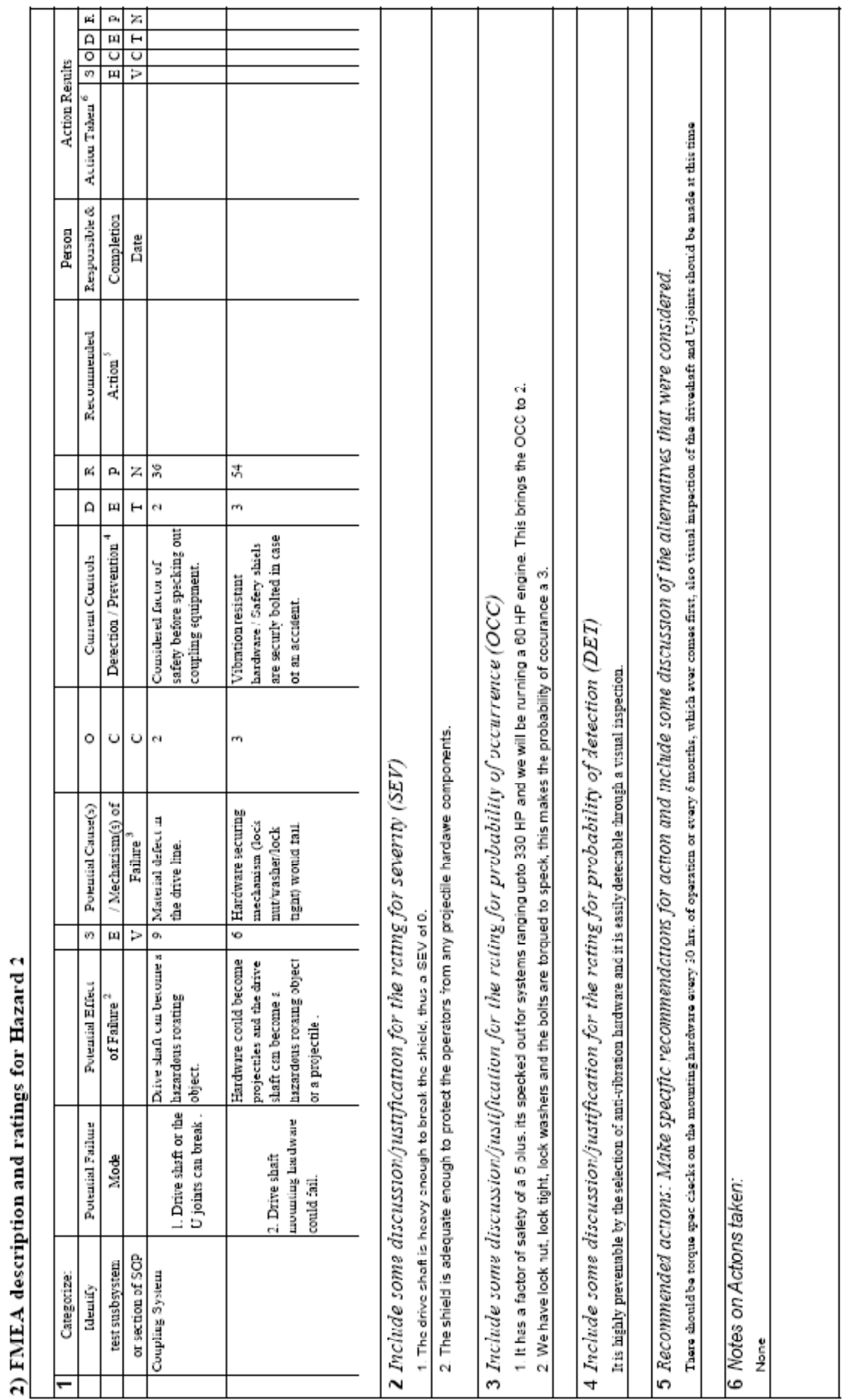




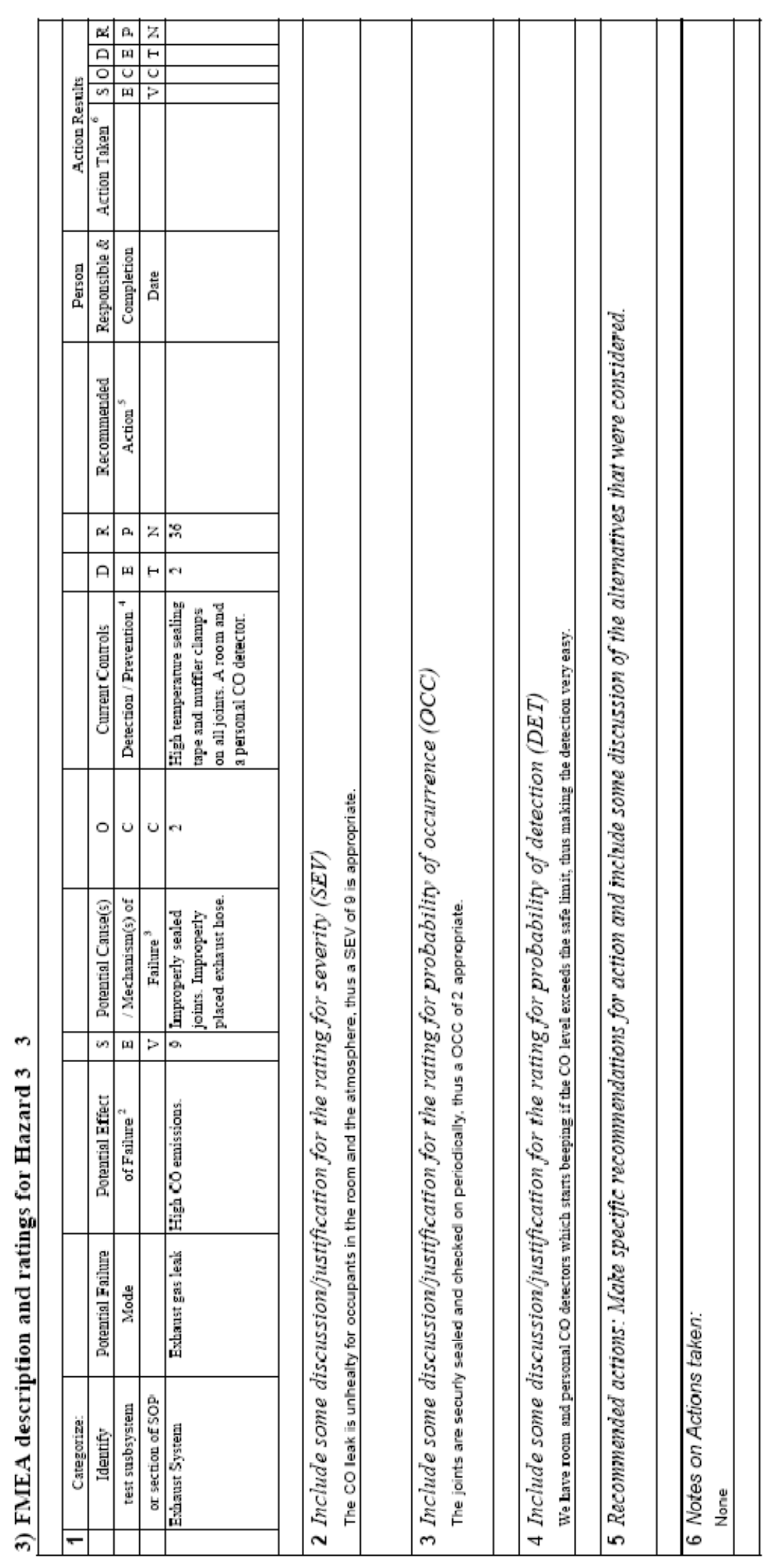




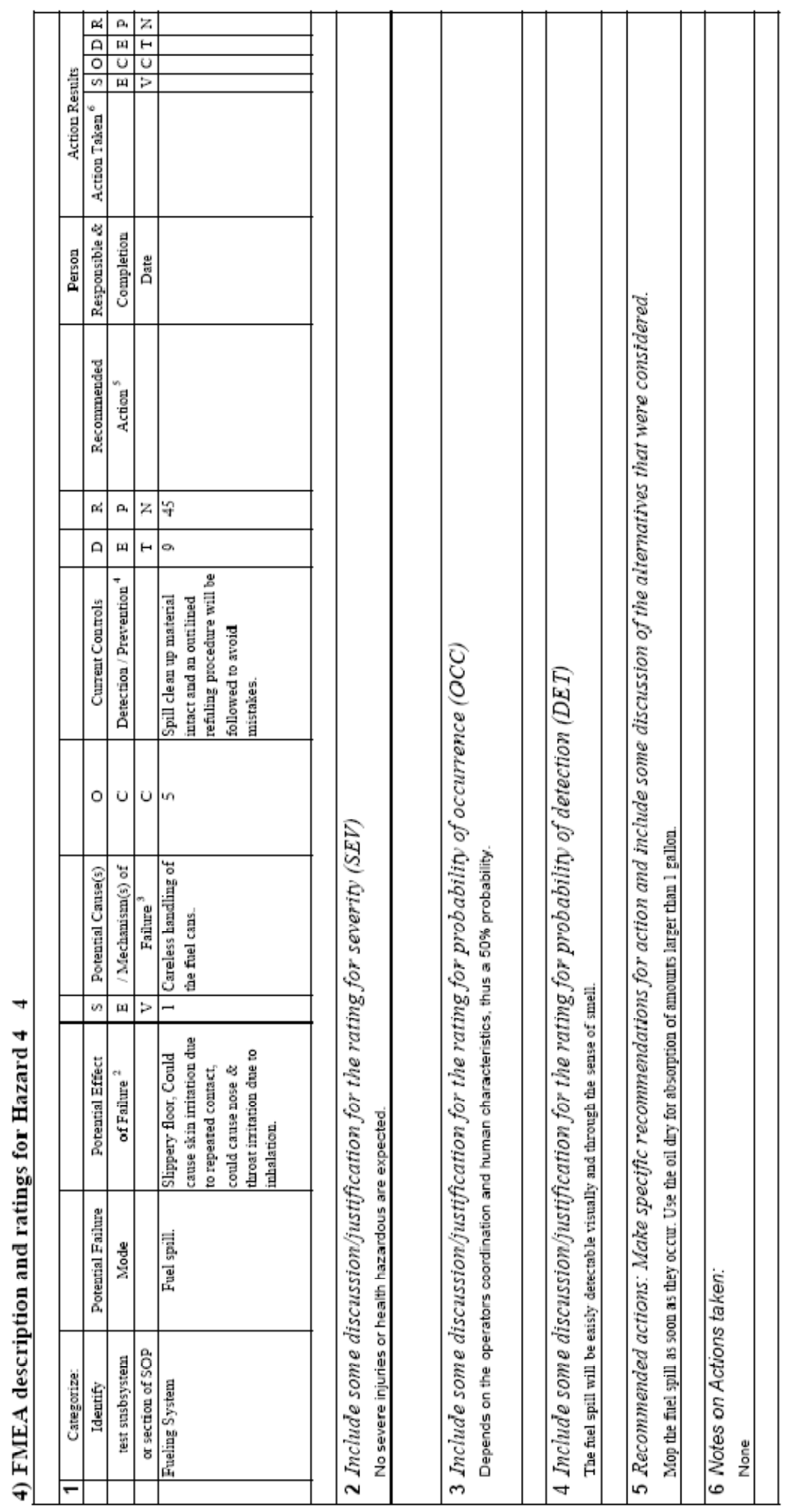

